\title{
Land readjustment and metropolitan growth: an examination of suburban land development and urban sprawl in the Tokyo metropolitan area
}

\author{
André Sorensen \\ Department of Urban Engineering, University of Tokyo, Tokyo, Japan
}

\begin{abstract}
Land Readjustment (LR) is a land development technique used in many countries around the world including Germany, Sweden, Japan, Taiwan and Korea. In essence it is a method whereby an irregular pattern of agricultural land holdings is re-arranged into regular building plots and equipped with basic urban infrastructure such as roads and drains. A percentage of each landowner's holding is contributed to provide land for roads and parks, and for some plots to sell to pay the costs of the project. Its use has been particularly widespread in Japan where it is responsible for some $30 \%$ of the existing urban area, and is commonly referred to as 'The Mother of City Planning' (Toshi Keikaku no Haha). LR has for 20 years also been the focus of an international effort to introduce the technique to the developing countries of South East Asia. Although there is now a large literature on Japanese LR as a result of that project, however, virtually all of that literature focusses on practical aspects of how to implement projects, and on case studies of individual projects. Little attention has been paid to the role of LR in Japanese urban growth and urban planning at a city or regional scale, although such an examination is necessary to understanding LR in Japan, and Japanese urbanisation and urban planning more generally. The present research examines the role of LR in shaping patterns of urban development in the rapidly growing northern suburbs of Tokyo in Saitama prefecture. In particular, the claim commonly made by Japanese writers that LR prevents urban sprawl is examined. Sprawl and its prevention have long been a preoccupation of both Western and Japanese urban planners for aesthetic and efficiency reasons. However, it has recently
\end{abstract}

E-mail address: andre@up.t.u-tokyo.ac.jp (A. Sorensen) 
gained importance as the critical interconnections between urban form and urban travel patterns, and greenhouse gas emissions and global warming have become more widely recognised. The case studies examine the role of LR in land development and urban growth at the regional scale (Saitama prefecture) and at the local scale (Urawa, Omiya and Ageo cities). GIS mapping and analysis of the case study areas, and interviews with planners and participants are used to examine the role and impacts of LR projects in suburban land development in Japan. The research suggests that while there are various impacts of LR projects because they are so widely used, in a range of different contexts, it is fair to say that LR projects contribute to increased sprawl at the regional scale, while largely failing to prevent it at the local scale. (C) 2000 Elsevier Science Ltd. All rights reserved. 


\section{INTRODUCTION}

One thing that strikes many Western visitors to Japan as extraordinary is the extreme sense of disorder of many Japanese cities. The high degree of intermixture of seemingly incompatible land uses, streets which are irregularly laid out and often lack sidewalks, the fantastically dense wirescape overhead, and the jumble of different styles, shapes and orientations of buildings all make for a confusing urban environment. Many visitors and even long-term residents from the west find it hard to believe that there is such a thing as urban planning in Japan at all, and are incredulous when told that in fact there is a highly developed urban planning system, with vast resources being put into urban planning and infrastructure development. Nowhere are these contradictions more evident than on the urban fringe. It is here in the half urban, half agricultural districts, criss-crossed by high voltage transmission lines and scattered with high rise apartment blocks fronting on rice fields, scrap metal dealers, small clusters of single family houses, fields of vegetables and fruit trees, busy factories and truck depots, that the costs of rapid urbanisation and industrialisation are particularly evident. It is indeed hard to credit a sophisticated planning system with the patchwork road system which is here a maze of narrow winding lanes and there an orderly grid of broad streets, and where for no apparent reason a busy two lane arterial road broadens to a four or six lane boulevard for a few hundred meters and then narrows again.

It is in these same areas on the fringes of the great metropolitan areas that city planners have worked hardest to carry out Land Readjustment (LR) projects, and where indeed they have been most widely used. This study examines the role of LR in the urbanisation process in Japan. LR is a method whereby a group of landowners can join forces to develop or redevelop land. In essence, LR is a process whereby ownership of scattered and irregular plots of agricultural land is pooled, roads and main infrastructure are built, and the land is then subdivided into urban plots. Each landowner must contribute a portion of their previous land holding (usually about $30 \%$ of the total) to provide space for roads, parks and other public space, and for reserve land. The reserve land is sold at the end of the project to pay the costs of planning, administration and construction. The attractiveness of the method for landowners is based on the fact that substantial increases in the value of land can be achieved by the process, so that the value of the individual land holdings can be greatly increased, even though the remaining area is smaller. The attraction for planning authorities is that projects provide land for public facilities, and build needed urban infrastructure.

There are two main reasons for wishing to understand Land Readjustment as used in Japan. The first is that Japan is an important case for the study of urbanisation and urban planning, especially in Asia, which is currently one of the most rapidly urbanising regions in the world. Japan is a country which 
experienced rapid urbanisation and industrialisation during a relatively short period after WW2. It is both the first Asian country to complete an industrial revolution, and a much analysed economic success story. Japan is now the second largest economy in the world with $15 \%$ of world GNP, with similar levels of wealth and urbanisation as the developed western countries, yet with a vastly different tradition of land use, ownership and planning. Japan also shares a heritage of rice-ased agriculture and land tenure patterns with many other Asian countries. As Ginsberg (1991) has argued, the land ownership structure of rice agriculture areas can have profound effects on patterns of urbanisation. In this respect, Japan may be closer in its basic conditions to some of the rapidly urbanising countries of Asia, which also have rural land holding and settlement patterns structured by rice agriculture, than to western countries. Since Japan is also two or three decades ahead of most of the developing countries of Asia, a better understanding of the Japanese case may be of special interest to planners in those countries, and more generally to those interested in comparative urbanisation and urban planning study.

LR has long been a key part of the Japanese urban planning system, about $30 \%$ of the current urban area having been developed with LR projects. To understand urbanisation and urban planning in Japan, it is absolutely necessary to understand the role of LR. However, despite considerable interest in the Japanese urban planning system and techniques since the middle 1980s (e.g. Alden, 1986; Hebbert, 1986, 1989, 1994; OECD, 1986; Hebbert and Nakai, 1988a, 1988b; Shapira and Masser, 1994; Golany and Hanaki, 1998), there has been no detailed examination of the effects of the widespread use of LR for land development in Japan. Therefore, it is hoped that the current study will prove a useful contribution to the study of Japanese urban planning.

The second factor that gives relevance to the current study is that LR has been the subject of substantial international interest as a possible land development technique for developing countries. In part because of Japan's extensive experience with LR and also because of the enthusiastic response of many Japanese to the opportunity to share their expertise, Japanese experts, with substantial government backing, have played a central role in the resulting technology transfer project designed to enable other countries to make use of the LR method. One visible outcome has been a series of nine international conferences designed to examine and aid the introduction of LR to developing countries, and a substantial literature in English has accumulated (Sorensen, 2000).

However, apparently as a result of the fact that the literature is focussed on the transfer of the LR technique, existing case studies have focussed on projects themselves. Apart from frequently cited statistics on the large areas of LR in Japan, and the ubiquitous assertion that "Land Readjustment is the mother of Japanese urban planning," there has been no detailed examination of the role of LR projects in Japanese urban development. Thus, while questions of how to design and carry out projects have been extensively examined, there has been little examination of the overall effects of the use of LR in Japan. More surprising, 
there has also been almost no research of this sort published in Japan. ${ }^{1}$ It appears that in Japan, LR projects are so common, and their direct public and private benefits are seen to be so self-evident, that they have ceased to attract very much academic attention, and the main focus of study is how to ensure that they are applied more widely.

It is a premise of the current research that while the existing literature on LR makes a valuable contribution to understanding the implementation of the technique, it is also necessary to examine its role in the development of larger urban areas if we are to understand the effectiveness of LR as a planning technique. That is, because LR projects have been used to develop a third of all urban areas in Japan it is reasonable to expect that to some extent the nature of Japanese urbanisation as a whole has been influenced by this reliance on LR for land development. It seems reasonable to suggest that while case studies for the technology transfer project are appropriately at the individual project scale, in order to study the role and outcomes of LR as an urban planning method the study area should be at the city or regional scale. Because urban planning interventions commonly result in a range of effects, both anticipated and unanticipated, it seems important to examine the overall impact of LR projects, instead of restricting analysis to the level of the individual project. It is, therefore, hoped that the study, by contributing to a more rounded understanding of LR will be useful to those interested in adopting or modifying the technique for use in other countries.

The organisation of the study is as follows. Chapter 1 introduces the context of the research. The first section introduces the LR technique as used in Japan. The second section describes the Japanese urban planning system, and discusses the role of LR in Japanese planning. The third section examines the relevance of a discussion of urban planning and urban sprawl in the Japanese case. The final section introduces the hypotheses and research questions addressed in the study. The key question the study asks is: what have been the effects of the widespread use of Land Readjustment for land development on the patterns of urban growth

\footnotetext{
${ }^{1}$ Within the city planning literature there is extensive analysis of individual projects, of means to ensure the greater use of LR (Hanayama, 1986; Higasa, 1993), of rates of land use change within projects (Kotoh, 1991; Murahashi, 1993), of ways of persuading landowners to join projects (Ukai, 1993), and of the history of LR projects (Matsubara, 1982; Ishida, 1986a, 1987; Kishii, 1993). Other work has examined how and where to promote more projects in the Tokyo Area (Sugiyama and Nakagawa, 1988; Shimoda, 1993), how LR can be used to prevent urban sprawl (Higasa, 1993, p. 9), (Nishi, 1993, p. 27), and explains why Japan should respond willingly to requests to contribute its expertise in LR to other countries (Nishiyama, 1988; Nakano, 1993, p. 52; Nishi, 1993, p. 28). However, there has been almost no research which attempts to analyse the impact of LR on larger patterns of urban development and growth. One research project, by Munemoto et al. (1994) made an interesting analysis of the role of LR in the development of Fukuoka City and compared the development of areas which had been developed with LR with those which had developed outside LR projects. However, the main focus of the research was a mathematical analysis of the resulting road network, which showed that LR areas had many fewer dead end roads, and far more curved streets than non LR areas. While interesting, this sheds little light on the questions addressed in this paper.
} 
and development of the suburban areas surrounding Tokyo? The hypothesis is that because of factors inherent to the method, LR may be expected to encourage urban sprawl in suburban areas, rather than prevent it.

In seeking to answer this question, two levels of empirical analysis are pursued. Chapter 2 examines the impact of LR projects on patterns of urban growth at the metropolitan scale through a case study of LR in Saitama Prefecture, one of the three prefectures bordering Tokyo that have seen the bulk of metropolitan population growth through suburban development in the post-war period. The section begins with an outline of the factors affecting urbanisation and the use of LR in Saitama, including the physical features of the prefecture, the transportation system, and national and prefectural planning policies. To analyse the role of LR projects on the patterns of urban land development at the metropolitan scale, all projects begun since 1960 were categorised based on their proximity to existing development and rail stations at the time they were begun. In this way the changing patterns of LR use are analysed.

Chapter 3 examines the role of LR projects in land development at a more detailed level. The planning strategies of three case study cities in Saitama are examined, with particular focus on the nature of the decision making processes that affect the location of new LR projects. The effects of LR on land development patterns, land use change, and infrastructure provision in the three case study areas are studied, and the nature of suburban development outlined.

Chapter 4 draws together the main findings of the research. The findings are divided into three main sections. The first section looks at the effects of Land Readjustment on patterns of urban growth and development of suburban Tokyo. The second section looks at the implications of the research for the understanding of Land Readjustment as used in Japan, and the third section summarises its role in Japanese urban planning. 


\section{CHAPTER 1}

\section{Land Readjustment, urbanisation and urban planning in Japan}

\subsection{Land Readjustment in Japan}

Land Readjustment is a method whereby the ownership of scattered and irregular plots of agricultural land is pooled, roads and main infrastructure are built, and the land is then subdivided into urban plots. Each landowner must contribute a portion of their previous land holding (commonly about $30 \%$ of the total) to provide space for roads, parks and other public space, and for reserve land. The reserve land is sold at the end of the project to pay the costs of planning, administration and construction. The attractiveness of the method for landowners is based on the fact that substantial increases in the value of land may be achieved by the process, so that the value of the individual land holdings can be greatly increased, even though the remaining area is smaller. The attraction for planning authorities is that projects provide land for public facilities, and build much needed urban infrastructure.

LR was imported to Japan at the turn of the century, and initially followed a German model (Ishida, 1986a; Ishida and Hatano, 1987). At first it was used primarily for agricultural land consolidation and irrigation improvement projects, although it was soon put to use for suburban expansion projects as well (Hayashi, 1982; Latz, 1989). In the early stages only individuals were legally authorised to start projects. However, after the Great Kanto Earthquake of 1923 a modified form of LR was used to rebuild large areas of downtown Tokyo and Yokohama. A special government agency was set up to carry out these works. During the 1930s LR was widely used by the central government to establish military facilities (Ishida, 1987, p. 57). Again in the aftermath of World War Two LR projects were extensively used in the post-war urban reconstruction projects.

In 1954, a comprehensive revision of the LR law was passed. Lease holders of land were given formal rights for the first time to participate in the project implementing body, local public corporations were allowed wider scope to implement LR projects and increased processes for review of Action and Replotting plans and participation by those affected by projects were included. This act remains in force to the present day as the basic LR law. The method has been widely used, and in an extraordinary variety of circumstances, for urban expansion into agricultural areas primarily, but also for downtown redevelopment, new town building, public housing projects, railway and mass transit development, and others (Nishiyama, 1986). One important feature of the new law was that it empowered the national government to subsidise local government initiated projects. The money was drawn from the Road Improvement Special Account which collected the revenues of the gasoline tax (Ishida, 1986a, p. 83). The reasoning was that where arterial roads are constructed by LR projects it is unfair that local landowners bear the burden, as the roads primarily benefit others outside the project area. Therefore, national subsidies are used to subsidise road 
construction at the same rate as though the land was purchased. This quickly became a major source of funds for local government led LR projects and allowed a significant expansion in the total area of new projects during the second half of the 1950s from less than 1000 ha/year of new projects nationally in 1955 to over 3000 ha/year by 1960 (Kishii, 1993, p. 13). A variety of other sources of subsidy are available in Japan, ranging from various grants for plan preparation and project organisation, to low interest bridge loans to finance projects in which the main expenses are invariably incurred up front and the main revenues from land sales come near the end, as explained by (Miyazawa, 1982, p. 98). Miyazawa also shows that the share of costs paid by the sale of reserve land varies greatly between different initiators, with private projects more dependant on land sales, and public projects receiving a higher proportion of their funding from public funds.

In the literature on Japanese LR a strong distinction is generally drawn between privately initiated projects and publicly initiated projects (e.g. Kishii, 1993, p. 13). In fact there are five types of project executor: Individuals, Associations, Local Governments (municipal and prefectural), Administrative Agencies (of the Ministry of Construction or prefectural governments), and Public Corporations (such as the Japan Housing and Urban Development Corporation) (Miyazawa, 1982, p. 92). The first two above are considered private executors, while the latter three are considered to be public executors. As of March 31, 1994, there were 207 $\mathrm{km}^{2}$ of projects completed or in progress executed by Individuals, $1072 \mathrm{~km}^{2}$ by Associations, $1205 \mathrm{~km}^{2}$ by Local Governments, and $548 \mathrm{~km}^{2}$ by administrative agencies and public corporations (City Planning Association, 1995, p. 114). Thus, private executors are responsible for some $42 \%$ of the project area, and public executors for $58 \%$.

Individuals may only execute projects when all land owners and lease holders within the project area are in agreement on the project. Because all those affected have agreed, this type of project has the least formal legal procedure that must be followed.

An Association is a corporation including all owners and lessees of land in the project area. Agreement of at least two thirds of all owners and lessees of land (with two thirds of the land) is necessary before the Association can be incorporated. The goal of organisers is $100 \%$ consent, although projects are commonly started after $80 \%$ agreement is achieved. Because it is possible legally to carry out an Association LR project over the objections of up to one third of the landowners in the project area, various legal safeguards are built into the process. To establish the Association seven or more individuals must prepare the project program and articles of association. The project program will generally include a plan of the project area indicating road layout, public facilities etc., and a rough schedule. Precise indication of land reduction for each land owner are not normally calculated at this stage. When consent of two thirds of the landowners in the project area is secured they can apply for the approval of the prefectural governor. The governor is responsible for exhibiting the program publicly for two weeks. People affected by the project can submit written complaints within two 
weeks of the public exhibition. After review the governor can either order changes to the program to satisfy the complaints or allow the program to proceed as is. In either case the complainants are informed. Approval is then given and the Association is legally established (Miyazawa, 1982, p. 94).

Associations have an executive of five or more directors and two or more auditors elected from the membership at a general meeting. The decision making body of the Association is the general meeting of all members, who must be landowners and lessees in the project area. According to Miyazawa (1982, p. 94) the general meeting can decide on "amendment of the articles, the project program, interim financing, budgeting, replotting plan, designation of tentative replotting, method of sale of cost-equivalent land, and so forth." Where the membership is over a hundred, representatives may be elected to carry out the business of the general meeting. Quorum is more than $50 \%$ of the total membership, and decisions are by simple majority, except for some major decisions such as the replotting plan (which indicates what new plots will be redistributed to each landowner upon project completion) which require two thirds majority and a two thirds quorum.

The three kinds of public initiators all follow a procedure that is rather different than that for Associations. The project program is passed in the form of an ordinance which in the case of municipalities must be approved by the prefectural governor, and with public corporations by the Minister of Construction. Public exhibition of plans are required, with provision for comment and complaint. In the case of municipalities, the governor refers complaints to the local city planning council which has power to recommend or deny action on a complaint. In the case of public corporations, the minister is responsible for complaints, after getting the advice of the city planning council. A critical feature not often explicitly pointed out in the literature is that agreement of landowners is not a legal requirement for initiation of public projects, although initiators try to gain landowner consent in order to enable a smoothly run project. In the case of projects by public sector initiators, a Land Readjustment Council of elected representatives of the landowners and land lessees is established to represent landowners. The council is invited to give its advice on the selection of evaluators and decisions on the disposal of land (Minerbi and Nakamura, 1986, p. 197). Municipalities can only execute projects on land within a designated LR area in the city plan, however, it is not difficult for local governments to designate such areas. Administrative agencies can execute projects under the same conditions as public bodies when the project has national importance and must be completed quickly (Miyazawa, 1982, p. 93).

There is broad agreement on the main advantages of LR for urban land development. First, LR has the potential to be a self-financing technique for urban land and infrastructure development, and is almost certain to be cheaper than to gather all project land into a single ownership, whether on the open market or by expropriation. This is because on project completion most land remains in the possession of the original land owners, who must contribute portions of their land holding for roads and for land to sell to pay the main costs 
of the project. Second, the pattern of property divisions (cadastral) is reformed and new infrastructure and public space, particularly for roads and parks, is acquired. This feature is particularly important in locations where rural property divisions were irregular and fragmented into many small parcels with little or no road space as is common in rice paddy areas. Third, because the original land owners retain title to the majority of their land there is less land owner opposition to LR projects than to large scale land expropriation and development, and LR projects are considered less disruptive of the existing community (see Doebele, 1982, p. 15; Miyazawa, 1982; Larsson, 1993, p. 142).

Japanese LR is often described as a consensual, bottom-up style of planning and city building, and emphasis on the co-operative and consensual aspect of LR projects is quite pervasive in Japan. For example, Nishiyama recently argued that "Neighbours initiate a process of consensus-building and work toward their common benefits, and the project cost is financed by portions of land from landowners and public funds. This is the foundation of land readjustment projects" (Nishiyama, 1995, p. 1). A similar perspective is put forward by Nagamine who suggests that "the essence of LR is to let people and government join hands in coping with the ordeals of rapid urbanisation" (Nagamine, 1986, p. 58). This conception of LR as a consensual, bottom-up, self-financing planning method is highly appealing, and formed a part of the argument that the method might be useful in other Asian developing countries. ${ }^{2}$

In Japan the main reason for the widespread use of LR is the fact that in urban fringe areas most farmland is extremely fragmented into small, irregularly shaped plots, and it is almost impossible for a prospective developer to assemble such farm plots into larger blocks for development (Miyazawa, 1982, p. 91). Equally, all levels of government are wary of land expropriation, which can be expensive, time consuming, and commonly provokes heated opposition, of which the Narita Airport debacle is only the most prominent example (see Apter and Sawa, 1984). This situation, combined with Japan's extremely high land prices, has meant that governments have found it difficult and expensive to build space intensive public goods such as roads and parks. Planned networks of expressways and arterial roads are far from complete, and in suburban areas sewers, parks and improved local roads are primarily found in LR areas. LR is thus widely and justifiably considered to have been an essential planning tool in Japan.

It should be noted that in Japan it is recognised that there are some inherent weaknesses of LR as a planning tool which may be particularly relevant to its use in developing countries. These are seen to be the fact that as most of the land remains private property, and most landowners have not made a cash investment in developing their land, there is often little incentive to sell or build on the newly serviced plots (Nagamine, 1986, p. 57). Thus, project areas often develop slowly, while owners wait for the value of their land to increase. The slow development of

\footnotetext{
${ }^{2}$ The English language literature on LR, and the project to transfer the LR technique to other developing countries in Asia are reviewed in Sorensen (2000).
} 
urban plots in LR areas has often resulted in two problems common in Japan. These are sometimes referred to as 'okure' (delay) and 'zure' (discrepancy) (Ishida, 1986b).

Okure refers to delays in reaching target populations for full use of infrastructure, ${ }^{3}$ and zure refers to discrepancies between plans for an area and its eventual development which result from the very long development times. Thus, in some cases in areas of small detached houses built soon after completion of a project, high rise buildings have been built later because of changes in economic conditions. Also while LR is very effective at providing infrastructure, it does not necessarily result in more land supply if owners choose not to sell (Honjo and Inoue, 1984, p. 11). For similar reasons it does not necessarily result in better access for the poor to urban land, as it does not change basic problems in land markets, is designed to increase land values, and the poor will often not be able to afford such improved land (Inoue, 1985, p. 21). The use of some of the public land created through LR projects for low income housing as in Korea may be a solution to this problem (Hwang, 1986; Archer, 1997), but as Nagamine points out, any increase in the amount of land landowners must contribute makes LR less attractive to them and can threaten the viability of the process (Nagamine, 1986, p. 57). Only where a politically very strong government agency is carrying out the process can very large land contributions be enforced, as in Seoul where up to $70 \%$ of land was taken as contributions. Honjo and Inoue also note that in Japan LR projects have often been opposed by anti-LR movements. They argue that this is because while larger landowners can often see the benefit of land development, tenants or a person who owns a small house on a small plot who is primarily interested in the use value of his land, not the investment value, may see no advantage to an LR project (Inoue, 1985, p. 17). Also the land contribution may make a small lot too small to be sold later, resulting in a net loss in both use value and exchange value (Honjo and Inoue, 1984, p. 11). Inoue (1985, p. 17), notes that as LR must be carried out in many small projects, it is not suitable as a method for planning the overall development of a city, but must be carried out in conjunction with an over all master plan. Finally, it is noted that as LR requires a large number of experienced staff to carry it out, including land appraisers, surveyors, planners and project administrators, precisely the sort of staff which are in short supply in developing countries (Inoue, 1985, pp. 17-18)

The practice of LR is discussed further in the case study chapters, the next section outlines the basic features of the Japanese urban planning system.

\subsection{The Japanese urban planning system}

Japan has a long tradition of urban planning, difficult though that may be for

\footnotetext{
${ }^{3}$ Apart from the obvious waste of leaving fully serviced land idle, other more serious problems can arise, such as in one LR project where the sewers had to be mechanically flushed at great expense because there was not enough flow to allow self-flushing of the system.
} 
western observers to believe. The Tokyo Urban Renewal Ordinance of 1888 is commonly cited at the first modern city planning law in Japan (Inoue, 1984, p. 38; Ishida, 1987 see chapter 3). That law provided the basis of future planning legislation and in 1918 it was applied to five other major cities: Osaka, Kyoto, Kobe, Yokohama and Nagoya. It also laid the foundations for two laws passed in 1919 which provided the structure of urban planning for the next 50 years, the City Planning Law and the Building Standards Law. The City Planning Law had only 26 articles and was based largely on the earlier Tokyo Urban Renewal Ordinance. The law defined the city planning area where its provisions would be applicable, set up a crude zoning system (with three zones, commercial, industrial and residential), and provided a legal framework for using Land Readjustment projects for urban planning. The Building Standards act was primarily a building code, although it also contained the detailed explanation of what buildings would be allowed in each of the three use zones, and rules governing building coverage ratios and building height limitations (Inoue, 1984, p. 38; Ishida, 1987). These two laws applied initially only to the six major cities mentioned above, and was only extended to cover all cities, towns and villages (shichoson) in 1933. Even though the laws were applied to all incorporated settlements, however, there was no compulsion to establish a zoning system, and indeed even as late as the 1960s there were many urban areas in Japan that had enacted no zoning at all.

After the war overriding priority was given by the Japanese state to achieving economic growth and development (Johnson, 1982). Because there was such clear necessity to recover from the destruction of war, the alliance of central government bureaucrats, the long ruling Liberal Democratic Party (LDP), and big business sometimes referred to as the 'Ruling Triad' (Broadbent, 1998) was given a very free hand to pursue their development strategy. Samuels (1983, p. 168), has called the period from the end of the war to the middle of the 1960s a 'conservative's paradise' in which there was an 'unassailable consensus' on economic reconstruction and rapid growth. Although the Local Autonomy Law imposed by the Occupation had resulted in independently elected prefectural and local governments, during the first two post-war decades the conservatives controlled the central government, virtually all prefectural governorships and most municipal governments, so it was relatively easy for them to set the agenda for all levels of government. The central government also provided incentives such as grants-in-aid and bond permits to local governments which co-operated by helping the expansion of new industries in their area through gifts of land, temporary property tax exemptions and local infrastructure (Steiner, 1980, p. 5; Broadbent, 1998). The perennially financially hard-pressed local governments were used to following central government guidance, and they were easily convinced that new industries would broaden the tax base in the future. Thus, local governments which might have been expected to be more responsive to the needs of their constituents than the distant central government were, during the period of rapid growth, effectively dominated by the growth oriented policies of the conservative central government.

The urban planning goals of the Japanese government before the comprehensive 
revision of the planning law in 1968 were limited. This stage of planning intervention Morimura (1994, p. 8), has characterised as the 'demand-response pattern of urban planning,' in which the main priority was 'primarily flow countermeasures focussing on the development of key facilities and industrial facilities.' The main goal of government planning intervention was the provision of key industrial infrastructure to aid economic growth, as argued by Yamamura (1992, p. 48), who notes that while $41 \%$ of the public works budget was allocated to roads, harbours and airports in 1960 , and $49.9 \%$ in 1970 , the percentage devoted to housing and sewer systems was $5.7 \%$ in 1960 and $11.2 \%$ in 1970 . Japanese planning was focussed on projects to provide basic infrastructure such as ports, water supply, hydroelectric power and serviced industrial land, while ignoring social infrastructure such as sewerage, local roads, and parks. ${ }^{4}$ In all the major areas of social overhead capital Japan even today shows levels much lower than other developed countries. The case study sections provide detailed documentation of this point, and what it has meant in suburban areas.

Urban planning during the period before 1968 was thus based on large-scale projects to supply needed infrastructure, whether for electricity supply, water supply, trunk roads, housing, or port development. In 1955, the Japan Housing Corporation (JHC) was created to develop large scale housing sites. In this regard mass housing should be seen as in aid of further industrialisation, as the metropolitan areas needed cheap housing for workers to ensure an adequate supply of labour to growing industries. There was little priority given to other considerations such as long-term patterns of growth, residential quality or environmental consequences, as is witnessed by the policy of the JHC of building high-rise housing estates on greenfield sites far from existing settlements. Although this caused serious hardships for the residents of the projects, and was a major contributor to sprawl (Ishida, 1987, p. 296), it was justified by the fact that such land was much cheaper, and so greater numbers of units could be built for the same budget.

One result of the emphasis on industrial growth was that there was little effort to plan, provide infrastructure for, or even regulate the development of residential areas. Rather than develop an urban planning system, in Japan the state provided infrastructure for industrial development, including some large-scale housing projects, and largely left other residential development activity to market forces, constrained only by a weak zoning system and the building standards act. There was no provision for land-use control or standards for urban infrastructure in the pre 1968 system, and there was also no subdivision control. Landowners could subdivide lots and build as-of-right if they were in conformance with the land's

\footnotetext{
${ }^{4}$ See Calder (1988, Chapter 9) and Witherick (1981). Also see the annual White Papers (Hakusho) of the Ministry of Construction (MOC), which document the low rates of achievement of social overhead capital compared to other developed countries, and compared to government targets. The MOC, which is responsible for urban planning and infrastructure, has the delicate task of annually documenting Japan's woefully inadequate infrastructure levels in order to argue for larger budgets in future.
} 
zoning and the building code (if the area was zoned at all). Since buildings could be built almost anywhere within commuting range of urban areas there was a strong tendency towards scattered development wherever land was available. These conditions remained fundamentally unchanged until the passage of the New City Planning Law of 1968, and proved disastrous during the period of rapid growth.

The consequences of rapid urban and economic growth, in conjunction with a laissez faire approach to urban planning and development control are familiar from the experience of the other developed countries during the industrial revolution. Rapid, unserviced and haphazard urban growth in suburban areas, particularly surrounding the great metropolitan areas of Tokyo, Osaka and Nagoya created large areas of substandard urban development characterised by the intermixture of agricultural, industrial, commercial and residential areas. The typical problems associated with unregulated urbanisation, including increasing congestion, the dumping of industrial and human wastes directly into rivers, streams and irrigation channels, the degradation and pollution of farmland near urban areas, the exposure of residential areas to air, water, and noise pollution, problems of subsidence due to overpumping of groundwater by industry, and the contamination of air, water and food sources by industrial discharges were all widespread in Japan (see Huddle and Reich, 1975; McKean, 1981; Reich, 1983; Barret and Therivel, 1991; Broadbent, 1998).

The first cases of all the major pollution-related diseases appeared in Japan, with hundreds of deaths recorded. Far greater numbers suffered chronic environment related illness, with official government recognition as pollution victims (entitling them to relief and medical aid) extended to over 73,000 people by 1979 (McKean, 1981, p. 20). Air pollution was caused directly by industrial expansion and increased car use, with total emissions of $\mathrm{SO}_{2}$ and $\mathrm{NO}_{2}$ tripling during the 1960s. Water pollution was caused by a combination of untreated industrial discharges directly into watercourses, increasing use of agricultural chemicals (BHC and DDT were introduced in 1945 and were widely used until they were banned in 1972) which eventually leached into both ground and surface water supplies, and significant increases in municipal sewage wastes with the increase in urban population. Before the 1960s most municipal sewage systems only transported wastewater without treating it, discharging it directly into rivers. Although construction of sewerage systems and treatment plants has been a major MOC priority since the 1960 s, by 1970 only $16 \%$ of the population were connected to sewage systems, and even as recently as 1988 the rate was still less than $40 \%$ (Barret and Therivel, 1991, p. 35).

The environmental crisis was not just a question of air and water pollution, however. It was also very much a question of deteriorating living conditions in expanding metropolitan areas. McKean (1981, p. 19), points out that complaints about noise, vibrations, blocking of sunlight, proximity to electrical transmission wires, and foul smells have consistently outranked air and water pollution in the numbers of formal complaints lodged. These kinds of problems are, of course, all directly related to the rapid and haphazard growth of urban areas, and the intense 
intermingling of different uses that the weak zoning system allowed. That is, these sorts of environmental problems were the direct result of poor land use planning, as much as they were the result of pollution itself. Unregulated urban industrialisation thus led directly to the environmental crisis of the 1960s.

Environmental crisis led eventually to a political crisis for the LDP. As shown by MacDougall, during the two and a half decades from 1952 to 1976, the LDP share of the popular vote in House of Representatives elections decreased unilinearly, while the total progressive vote (JSP and JCP) steadily increased. Significantly for questions of urban planning, while local government had been until the mid 1960s the almost exclusive territory of conservative politicians, by the late 1960s conservative dominance was clearly on the wane. While nationally the conservatives were still in control of $71 \%$ of city assembly seats as late as 1975 , their continued strength was largely in rural areas and smaller cities. In the largest cities they suffered dramatic decreases in their share of the popular vote after 1959, with the result that by the early 1970s the executive office of all of the largest cities in Japan was controlled by progressive candidates. In 1975 there were only seven 'designated cities' in Japan; Tokyo, Yokohama, Nagoya, Kyoto, Osaka, Kobe, and Kitakyushu. Of these only Kitakyushu was governed by a conservative mayor in 1975 (MacDougall, 1980, p. 84). According to Ishida (1987, p. 305), one of the key reasons for progressive electoral success was that the reform governments put the concerns of citizens' movements about city planning and control of development high on their agenda. As Samuels (1983 p. 190) put it, "The left came to power by convincing enough of the electorate that the conservative central government and their allies in the localities were responsible for the pollution, the lack of social programs, and the support of business interests at the expense of residents."

Krauss and Simcock (1980, p. 196) argue that there was a "veritable explosion of protest in urban and suburban areas" against industrial plants and highway interchanges, and to demand that local governments provide essential services such as sewers, parks and sidewalks. The consensus on growth had truly ended, and a new, more complex period began in which sharply differing ideas of the future of urban areas and of the country were in competition. The progressive candidates for local government office made improving the urban environment through better urban planning, more sensitivity to local people's needs, and investment in social overhead capital a central part of their programme.

It is widely agreed that it was in response to these pressures that the LDP passed new city planning legislation in 1968. For example, Calder (1988, p. 405) notes that it was just before the July 1968 Upper House elections that the LDP announced an Urban Policy Outline and passed the new City Planning Law. He argues that although the law had been in preparation for many years, it was finally passed into law as a result of the fear by LDP legislators that the increasing political opposition represented by the citizens movements would have electoral impacts at the national level. Ishida (1987, p. 303) also, in his history of Japanese planning attributes the passage of the new planning legislation of 1968 to the intensification of urban problems and chaotic land use caused by the high 
economic growth policy; and the upsurge of citizens movements and progressive local governments.

The New City Planning law of 1968 was the first general revision of city planning law since 1919, and continues to form the basis of Japan's urban planning system. The new law had five main aspects: Senbiki, which was designed to prevent urban sprawl by dividing City Planning Areas into two parts, the Urbanisation Promotion Area (UPA) and the Urbanisation Control Area (UCA); the Development Permission System which was to control land development; a reformed and strengthened zoning system; new measures for public participation in planning; and the delegation of responsibility for planning to local governments. It is the first two measures that concern us here.

Senbiki was a central part of the New City Planning System introduced in 1968, and is particularly important on the urban fringe (see Nakai, 1988; Hebbert, 1994). In essence, Senbiki (literally 'drawing the line') was a means of dividing City Planning Areas (CPA) into two parts; the Urbanisation Promotion Area (UPA) and the Urbanisation Control Area (UCA). The UPA was to include all existing built up areas, plus enough land for the next ten years of urban development, while the UCA was to include areas such as prime farmland, nature reserves and floodplains which should not be developed at all, plus areas which might in future be developed, but which were not expected to develop within ten years and where development should, therefore, be prevented for the time being. The law provided for a Senbiki review each five years which could redraw the UPA/UCA boundary to include (or exclude) land as was felt necessary to maintain the ten year supply of new building land. The intention was thus to prevent sprawl by allowing the staged development of new urban land in the UPA area, while preventing development in the UCA. Because land within the UCA areas could be rezoned in future reviews to provide more UPA development land as the existing UPA became fully built up, the intended effect on the process of urban growth was to allow staged development in manageable tranches, rather than allow the continuation of scattered development over the whole of the urban hinterland. In this way limited resources could be concentrated on the unbuilt part of the UPA where, in the words of the MOC (1991a: I-39), "urbanisation must be systematically and preferentially made within ten years." A key purpose of the Senbiki system then, was to allow local governments to focus their development and planning efforts on the undeveloped part of the UPA.

According to the Japanese Ministry of Construction (MOC), it was intended that the undeveloped part of the UPA would be comprehensively developed through LR projects, public development projects such as public housing, and large scale private development projects (see MOC, 1991a, I-41). Local governments were to actively promote planned development in the unbuilt part of the UPA through LR projects and by requiring private developers to provide their share of infrastructure through the development permission system. LR was thus the main positive planning tool, while development permission would provide the primary regulatory tool. As the MOC (1991a: I-40) put it, "UPA should not expand over a large area. It should be made in a compact manner, with the area 
undergoing or scheduled for the land readjustment projects, urban development projects and other planned development of large-scale (sic) as the core in the case of new urban area; thereby ensuring efficient public investment, and the achievement of systematic urban development." It is the unbuilt part of the UPA, and the use of LR projects as a positive planning tool to develop it, which is the subject of the case studies of Chapter 3 .

Private development projects would fall under the control of the new Development Permission System which required any development over 0.1 ha in UPA areas to provide its own infrastructure such as roads and a contribution to sewerage (MOC, 1991a, I-15). The development permission system was an important counterpart to the Senbiki system in that it was the main regulatory tool to ensure that private development in the UPA areas was carried out in a planned and orderly manner. For the first time city planners had the legal authority to withhold permission for land development projects unless a certain level of provision of roads, contributions to sewer systems and even land for parks was provided. Previously landowners could subdivide, sell, or build on land with no restrictions apart from building codes and zoning provisions, an important and hard to remedy cause of substandard development. This was a big step; as the MOC (1991a, I-16) put it, "Of all the systems in the history of Japanese city planning, it is the development permission system that was epoch-making." It was expected that these measures would help to prevent the spread of unserviced developments that had caused such problems in the 1960s. The primary goal of the 1968 system was thus explicitly the prevention of urban sprawl (supurôru) (Ishida, 1987, p. 297).

In theory, this system could have allowed planners to make land development conditional on the developer providing either infrastructure, or compensating the local government for additional burdens on local services, similar to subdivision control in the United States. And in fact, local governments were able to some degree to achieve this through development permissions, and through local 'development manuals' (kaihatsu yôkô). These manuals were local non-statutory codes indicating how much developers would have to contribute to local roads, parks and school facilities etc. in order to gain a development permit, and were thus similar to the 'Supplementary Planning Guidance' notes published by some British local governments. Municipalities were able to use their bargaining power (primarily their control over water supply) to gain local benefits from development, and the effectiveness of such development manuals is witnessed by the efforts of the central government during the 1980s to limit their use (Hebbert and Nakai, 1988a).

However, from the beginning there were significant exemptions to the development permission system, limiting its effectiveness (Hanayama, 1986; Nakai, 1988; Hebbert and Nakai, 1988a). Development permission applies to both UPA and UCA, although with considerable differences. In UPA areas the main exemption relates to the size of development, with any development of less than 0.1 ha $\left(1000 \mathrm{~m}^{2}\right)$ being exempt, while in CPA areas which have not been divided into UPA and UCA the threshold is 0.3 ha. This exemption was significant 
because it encouraged large numbers of small developments which resulted in continued sprawl development.

In both UPA and UCA all developments by central and local governments and by public developers such as the JHUDC are exempt from the requirement to obtain development permission, because state sponsored projects are likely to both conform to official plans, and provide their share of infrastructure. Therefore, this exemption is not very significant in the UPA, where public projects help to ensure systematic development. However, the exemption has been significant in the UCA, which, as Hebbert (1994, p. 83) has shown, has served as a reserve of relatively cheaper land for public projects such as roads, schools, public housing and industrial parks. He argues that of all the loopholes to development in UCA areas, such public projects probably do most to undermine its non-urban character.

Hebbert and Nakai (1988b, p. 31) have also shown that the development permission system strongly encourages smaller developments, both because of the exemption for developments under $0.1 \mathrm{ha}$, and because of the progressively higher standard of infrastructure for larger developments. The larger the development, the greater the proportion of land that must be devoted to public use, and therefore, the smaller the proportion that can be sold and the less profitable the development. Thus as Mori has recently shown, in 1990 the average plot size of agricultural land converted to housing sites (including both detached housing developments and multiple unit developments) was $423 \mathrm{~m}^{2}$ (Mori, 1998, p. 1549),

Table 1

Systematic development of Saitama UPA as of $1990^{a}$

\begin{tabular}{|c|c|c|c|c|}
\hline & Number & Area (ha) & Average area (ha) & $\%$ of UPA \\
\hline Land Readjustment Projects ${ }^{\mathrm{b}}$ & 281 & $15,996.9$ & 56.93 & $23.6^{\mathrm{c}}$ \\
\hline Development Permits in UPA & $7783^{\mathrm{d}}$ & 3528.78 & 0.45 & 5.2 \\
\hline Other State Housing Projects ${ }^{\mathrm{e}}$ & 157 & 1482.9 & 9.46 & $\begin{array}{l}2.2 \\
\% \text { of } \mathrm{UCA}\end{array}$ \\
\hline Development permits - $\mathrm{UCA}^{\mathrm{f}}$ & 52,452 & 5162.14 & 0.098 & 3.1 \\
\hline
\end{tabular}

${ }^{a}$ Source: Saitama Prefecture (1992) City Planning Basic Survey 1990.

${ }^{\mathrm{b}}$ Completed and in progress October 1, 1990.

${ }^{\mathrm{c}}$ LR projects initiated in the UCA area are rezoned to UPA, therefore, all LR projects are UPA.

${ }^{\mathrm{d}}$ For both UPA and UCA, development permits are those since 1970 under the 1968 New City Planning Law, and exclude area of permits issued under the old law.

${ }^{\mathrm{e}}$ Primarily JHUDC, and Prefectural Housing land development schemes.

${ }^{\mathrm{f}}$ Total area of UPA was $67,645.56$ ha in 1990 , and UCA area was $168,943.33$ ha. It is interesting to note that in the UCA areas the number and area of development permits are both larger than in UPA areas. This reflects both the fact that the UCA area is much larger physically, and the fact that a larger proportion of all development in UCA areas must obtain permits. Although the UCA is larger than the UPA however, the total area of permits is still quite significant, representing $3.1 \%$ of the total area of UCA. If it is remembered that much of the UCA area is physically unsuitable for development, being in the case of Saitama either flood plain or mountains, the area developed through development permits as a proportion of the developable area is quite similar between UPA and UCA. 
well within the 0.1 ha $\left(1000 \mathrm{~m}^{2}\right)$ limit for exemption from development permit requirements.

Thus the main problem with the development permission system in the UPA areas was ultimately that only a relatively small part of the total area was developed in this way. Table 1 shows that while a considerable area was developed with development permits within the UPA area in Saitama, it only amounted to $5.2 \%$ of the total UPA area after 20 years. A much larger area was developed as LR projects, amounting to $23.6 \%$ of the UPA. However, even both together total less than $30 \%$ of the UPA area. If we include public housing projects, a total of $31 \%$ of the area of the UPA has been developed 'systematically' during the last two decades. Virtually all other development in the UPA areas has occurred in a piecemeal fashion, without provision of large scale infrastructure such as roads and sewers, as shown in Chapter 3.

Although it seems clear that loopholes in the 1968 system allowed continued sprawl development during the 1970s and 1980s, it remains unclear what the role of LR has been in the development of the UPA areas. Even though sprawl was still occurring, LR projects were responsible for $24 \%$ of the systematic development in UPA areas, by far the largest share of the planned and serviced development. Without knowing more about the location of LR projects, however, how they relate to existing developed areas, main transportation infrastructure and to each other, and what their effects on patterns of build up are, it is impossible to evaluate their overall contribution to patterns of urbanisation. Those questions are the subject of the case study chapters.

\subsection{Urban sprawl and Japan}

In the analysis of urban growth and urban form the concept of urban sprawl has long played a central role, and the prevention of sprawl was one of the main motivations for the development of modern urban planning systems. The term sprawl has often been used simply as a synonym for bad patterns of urban growth or poor design, or even simply to describe rapid and/or extensive urban growth. In this paper, urban sprawl will be defined simply as the unplanned, uncontrolled expansion of urban areas into nearby non urban areas. However, it is important to note at the outset that the scale of the area under examination is critical in making sense of this definition of sprawl. For example, there is probably little disagreement that areas where there is a scatter of individual houses built in an urban fringe area along existing roads and without urban services such as sewers is a case of unplanned, uncontrolled urban expansion. However, at the broader scale of a metropolitan region, even a large planned development of several hundred houses can be considered sprawl if it is in a location which is far from existing development and is as a result difficult or expensive to connect to main roads and sewers, and lacks accessibility to the rest of the metropolitan area. Thus what is 'planned' at the local scale may still represent unplanned, uncontrolled development at the metropolitan scale. It is worth distinguishing between the main concerns of these two scales of analysis. 
The concept of sprawl at the local level, which was dominant before the second world war, was concerned with the problems presented by piecemeal and unplanned, unserviced growth on the fringe of the city. The problem was one of ensuring that new developments were laid out with adequate roads, connections to sewers and water supply, and that space was secured for other public facilities such as schools and parks. It was argued that the development of land from rural to urban use is a key moment in shaping the future form, efficiency and liveability of the city, because the patterns set in the initial phase of urban development tend to be extremely enduring. While individual buildings or land uses may change over time, the overall pattern generally shows remarkable resistance to change. The possibility of good design and high levels of amenity and accessibility is much greater in cases where relatively large areas are planned for comprehensive development, as argued persuasively by Unwin (1994).

A second argument for local planning control is efficiency in the provision of public services. Because many key public services such as sewerage, electricity, mail service, and road networks have fixed costs per linear unit, higher density compact forms of development will be cheaper to service and maintain than lower density forms (see e.g. Stone, 1970, 1988; Toronto, 1996). This has generally been understood as resulting in a preference for compact and continuous patterns of development over more expansive, leapfrog or scattered development (Ewing, 1997). Another assumption about the provision of main services such as roads and sewers is that there are significant benefits to be achieved through advance construction of such facilities before urbanisation, rather than after an urbanising area is significantly built up. These benefits result from economies of scale as well as from the ability to co-ordinate provision of facilities (i.e. laying sewer and gas lines before paving the roads).

A third argument is that the extensive land area required for public facilities such as roads and parks should be secured at the time of development. The need to secure land for public use is at one level a budget consideration, as it is usually very expensive to buy it after development has taken place and land prices have reached fully urban levels. However, there is also a more subtle argument, which is that since the urban values of land are to a large degree the creation of the community, not the individual landowner, it is unreasonable to expect the public body to pay for land at the higher prices it has itself helped to create. In Britain this contradiction has lead to repeated efforts since the beginning of the century to capture part of the betterment increase for the public purse. These have taken the form of taxation, nationalisation of development values, large scale land banking by the state, and requiring developers to contribute land and funds for community infrastructure, among others. The issues of betterment in the British case are reviewed by Cullingworth and Nadin (1994, pp. 105-117).

These arguments for local planning all require that the planning authority have the power to prevent development that does not conform to minimum standards. The prevention of small scattered developments becomes a key planning goal, as these will almost certainly make planned development more difficult in future. While at the beginning of the century they posed quite a radical, and to some 
dangerous, infringement of private property rights, the necessity for such controls is now largely non-controversial in most developed countries, though legal frameworks, responsible authority, degree of effectiveness, and outcomes have varied widely.

These issues of controlling sprawl development at the local level have, however, been to a significant degree supplanted by concerns about sprawl at the larger scale of the metropolitan region. This is probably due largely to the generally successful control of haphazard unserviced development, but is also because local issues were eclipsed by the vast scale of metropolitan expansion during the 20th century, and the enormous investment programmes for transport and sewerage that were necessitated by that growth. The broader conception of the problem of urban growth emerged just before and after the second world war. With the continuing rapid growth of large metropolitan areas, a key concern of planning strategy became the shaping of the overall growth of whole metropolitan areas. A range of arguments were made about the need to control the overall size and form of the largest cities as many observers became convinced that the problems being created by the unprecedented physical expansion of the largest cities were qualitatively different from earlier urban problems, and required new planning powers (Barlow Report, 1940; Mumford, 1940; Saarinen, 1943). It seemed to many that continued growth of metropolitan areas was creating enormous, costly and possibly irreversible dysfunctions. The main evils arising from overgrown cities were seen as congested transport systems, particularly roads; rising land costs; longer travel-to-work times which, quite apart from the time costs to individuals would result in productivity losses because of worker fatigue; increased levels of pollution; decreased access to open space and the countryside; increased need for costly investments in new infrastructure, increasing pollution of air and water, worsening health problems, and even increasing moral degeneracy and crime. The expanding metropolis was also seen as creating problems beyond its borders, by draining productive investment and population from declining areas, and swallowing up valuable nearby farmland in endless suburban housing development. The concept of sprawl was thus enlarged to include the overall patterns of growth of the metropolis, as scatteration at the city region scale came to be seen to be just as problematic as scatteration at the local scale, and new planning powers and strategies were proposed to control it (see Reade, 1987; Cherry, 1988; Hall, 1988).

Although the main ideas of metropolitan planning were questioned during the 1970s and 80s, recently issues of urban form and urban sprawl at the city region level have re-emerged as a central concern of many planners and planning theorists. Patterns of metropolitan growth have been identified as a key concern in efforts to move towards sustainable development primarily because of their enormous impacts on the use of energy for transport (Owens, 1986; Cervero, 1989; Elkin and McLaren, 1991; Newman and Kenworthy, 1992; Ewing, 1997). Although there has been an extended debate about what an efficient urban form at the metropolitan scale might be, with some arguing for a more compact, higher density form (Newman and Kenworthy, 1989; Commission of the European 
Communities, 1990; Elkin and McLaren, 1991; Sherlock, 1991), others have questioned the idea of higher densities (Owens, 1986; Breheny, 1992) and some suggest that metropolitan dispersal may result in less travel if jobs and residence are close together in the suburbs (Gordon and Richardson, 1990, 1995). The most widely agreed suggestion is that an urban form similar to the 'decentralised concentration' based on transit lines practised in Denmark and Sweden might be the most promising approach (Rickaby, 1987; Owens, 1991; Breheny and Rookwood, 1993). The development of nodes of concentrated mixed use centred on a major public transit facility would allow many needs to be satisfied within local areas, reducing the need for long trips to the city centre. Central to the urban environmental sustainability debate have thus been the issues of metropolitan urban form, and its impacts on transportation patterns, precisely the issues identified in the earlier round of concern about metropolitan planning during the 1940s (Blowers, 1993).

Japan appears to have been unable to prevent urban sprawl, seeing the continued growth of large areas of unserviced development, and extensive forms of urban development which result in long travel-to-work journeys. Still, the question of whether these issues of sprawl have any relevance to the Japanese case must be raised. Hebbert's work on Japanese planning stands out here. As he pointed out, traditional planning objections to sprawl include a number of elements that may not be important in the Japanese case, such as the western cultural inheritance of the concept of the logical separation between city and country and the importance of protecting rural areas from intrusive urban uses, as exemplified by British green belts (Hebbert, 1986, p. 142). He also notes that another factor which contributed to the enduring support for policies to control sprawl in the British case, the territorial politics described by Hall and Gracey (1973) in which both 'city' and 'country' governments support containment for quite different reasons, may not be important in Japan. He did suggest, however, that four other elements of the traditional argument against sprawl might be more relevant to the Japanese case. These he describes as: (1) the need to protect agricultural land in the interests of national food security, (2) the social costs of unregulated urbanisation which include the negative externalities caused by physical proximity of incompatible neighbours and the high travel costs to households for access to work, school and services, (3) land prices which are often raised by speculative pressures in an unregulated urban fringe land market, and (4) the traditional arguments that the cost-effective way to supply urban infrastructure is in compact and physically contiguous developments that are built comprehensively instead of in piecemeal and scattered fashion (Hebbert, 1986: 143-144). He also notes that these four arguments against sprawl are well recognised in the Japanese case, and have been important in the reasons put forward in support of the impressively complex Japanese system of land policy and city planning legislation introduced steadily since 1968 (Hebbert, 1986, pp. 144-147).

In early research on the extensive areas of sprawl development around Japanese cities, Hebbert (1986) was very cautious in his conclusions, noting that the 
agricultural protection argument is far from clear cut, because of Japan's huge surpluses of rice, and the high productivity of intensive vegetable and fruit farming in the urban fringe. The high levels of intermixture of agriculture, residences and workplaces in the urban fringe seems in the Japanese case to generate few of the negative externalities expected in the west, and is accompanied by a lack of the social segregation so common in western cities, while the infrastructure argument is complicated by the existence of huge shortfalls of infrastructure in central cities as well as in the suburbs, which are occasionally very well provided for by LR projects. He also noted the move among some Japanese planning experts to put a rather positive interpretation on Japanese urbanisation by explaining that it is only a failure if judged by European or American standards and that the Japanese idea of the 'melting' together of city and country might provide a more realistic model of development in the Asian case. Finally, he cautioned that as the process of decentralisation had only recently started it was perhaps too early to judge the balance of advantages and disadvantages of sprawl in the Japanese case, and that sprawl might look considerably less tolerable in future (Hebbert, 1986, pp. 155-157).

Interestingly, however, in more recent work Hebbert is less cautious in his conclusions about the negative effects of sprawl in the Japanese case, arguing that while clearly the strong cultural biases against scattered development are inapplicable in Japan, the problems of infrastructure provision have been appreciably increased by the extensive form of development which is so common in urban fringe areas. He argues that sprawl development is primarily a result of the fact that the local governments which are responsible for land use planning and infrastructure provision, and which are keen advocates of compact development patterns because they bear the burden of huge infrastructure backlogs, were unable to enforce planning policies in the face of the unified efforts of the development industry, landowners and central government who pushed for a looser approach to development control (Hebbert, 1994, p. 77). He suggests that a result has been the continued spread of extensive areas of unserviced and unplanned urban development which show most of the problems expected of sprawl: inadequate roads, sidewalks, and sewers, and long travel distances to work, shops and schools, thus there appear to be significant social costs associated with urban sprawl in Japan. These areas will also be increasingly costly to retrofit with basic services in future, so financial costs to local governments and ultimately to taxpayers also seem likely to be high. The impacts of sprawl on land costs are not addressed by Hebbert, nor are they discussed here. Japan's high land prices and the speculative bubble which has wreaked such damage to the Japanese economy are famous, however, and have generated an enormous literature (see e.g. Hanayama, 1986; Noguchi, 1990; Haley and Yamamura, 1992; Noguchi, 1992, 1994). Most recently, Mori (1998) has argued convincingly that weak planning and development control have indeed resulted in higher land prices for housing in Japan than would have been the case if land owners had borne the full social costs of development. Landowners avoid responsibility for the external diseconomies of the 
development they create while selling land. As Mori argues, they receive net what buyers will pay for housing sites, while leaving municipal governments to retroactively provide essential public services later (Mori, 1998). This has contributed greatly to the increasing disparities of wealth between those who own land in Japan, and those who do not (Tachibanaki, 1992). This institutional framework has allowed the continuation of unserviced sprawl type development in urban fringe areas in Japan, and in particular has encouraged the highly distinctive pattern of intermixture of farm uses and urban uses. Thus, three of the four traditional arguments about the costs of sprawl posed by Hebbert suggest that allowing sprawl does result in significant social costs in Japan, as elsewhere. Only the issue of protecting agricultural land in the interest of national food security remains unclear, and that is more an issue of national strategic interests than one of urban policy.

The role of LR projects in urban fringe development remains unclear, however. As LR projects provide needed urban infrastructure and public land at little cost to the taxpayer, surely they are one part of the solution to Japan's problems of sprawl? In this regard it is significant that the nature of the relationship between LR and urban form has been a source of disagreement in the past, with most Japanese commentators arguing that LR tends to prevent sprawl, while several western researchers have been no less certain that LR is a cause of sprawl. Hayashi states categorically, for instance, that "In Nagoya, as elsewhere, land readjustment limits urban sprawl" (Hayashi, 1982, p. 122). The MOC argues that (with LR projects) "a convenient and comfortable community is created when a comprehensive urban development is undertaken" as opposed to areas where no LR projects are organised, where "urbanisation and sprawl continue with inadequate urban infrastructure, causing deteriorating living environment (sic)" (MOC, 1991b, p. 4-2). Equally, Misra asserts that "The land readjustment process in Japan has greatly controlled urban sprawl, a problem which is acute in the developing countries" (Misra, 1984, p. 166).

On the other hand, Hebbert is no less certain: "Land readjustment undoubtedly accentuates urban sprawl. A familiar spectacle in the outer periphery of any large city is a serviced set of building sites — with roads laid out and electricity poles erected - with only one in every ten plots occupied by a house" (Hebbert, 1986, p. 152). The OECD report on urban policy in Japan arrives at a similar conclusion about LR projects: "there seems to be a tendency to locate projects further and further out on the fringes of metropolitan areas, thereby encouraging the spread of urban development. Land readjustment there is easier than in existing urban areas. The land requires neither extensive preparatory work nor the moving or demolition of existing buildings and projects can be implemented more quickly" (OECD, 1986, p. 58). It is interesting that such a basic disagreement is possible, and it suggests that understanding the relationship between LR and urban sprawl in the Japanese case may allow not only a better understanding of LR as used in Japan, but may also be revealing of differences in the understanding of urban planning and urban sprawl in Japan and the west. 


\subsection{Hypotheses and research questions}

To understand the relationship between the extensive use of LR for land development, and the continuing growth of areas of haphazard, unserviced sprawl in suburban areas, case studies were carried out in Saitama prefecture, immediately north of Tokyo and one of the three main suburban prefectures in the Tokyo Metropolitan Area (TMA) as shown in Fig. 1.

The hypothesis was that due to several aspects characteristic of the way LR projects are used in Japan, it is reasonable to expect that they will tend to promote an extensive pattern of urban development, or urban sprawl. Because LR

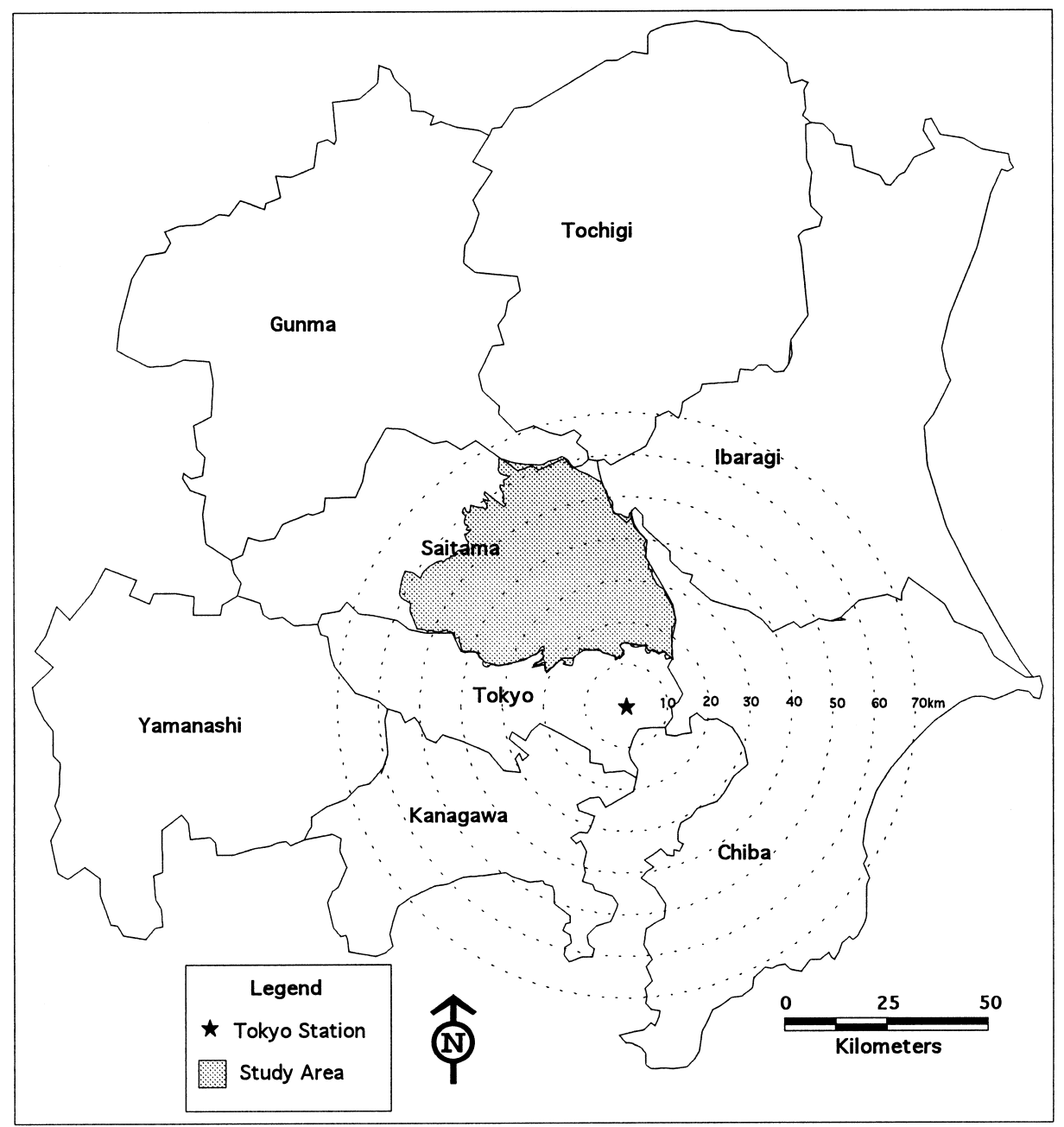

Fig. 1. Tokyo metropolitan area, Saitama prefecture, case study cities. 
projects are a particular way of organising a range of interests in the urban development process, including landowners, local and central governments, and the development industry, they may be expected to have predictable impacts on development patterns. In particular, certain aspects of how LR projects are organised and managed seem likely to have profound effects on which areas are developed, the nature of development in those areas, and the timing of that development.

As noted above, a strong distinction is generally drawn between privately initiated projects and publicly initiated projects. The fact that in Association projects, which are responsible for $54 \%$ of all projects and $35 \%$ of the total area of LR since 1954, a majority of the landowners in the project area must agree to participate before a project can be begun, and that in Individual projects all must agree, can be expected to result in a range of effects. It seems likely that in urban and partly urban areas it will be more difficult to organise LR projects than in areas farther from existing development. This is partly because for a given area more people must be convinced, but is also critically due to the fact that larger landowners tend to receive substantial benefits from projects due to increases in land value, while those who own only their own house benefit less, if at all from such increases. In areas where there has already been significant urban development, there will be more landowners who own smaller plots, therefore, more people who will gain little from the project. Also, where significant amounts of urban infrastructure are already available, particularly in the form of roads or proximity to a commuter rail station, even larger landowners may find it unattractive to join the project, as their land will already be ripe for development without the significant costs of the land contribution and time associated with project development. The first hypothesis is thus that for a number of reasons LR projects will be more likely to be started in areas away from existing built up areas and commuter rail stations, and will therefore contribute to the creation of extensive patterns of urban development, or sprawl.

A second important factor suggesting that LR projects are more likely to encourage sprawl than prevent it is a planning policy designed to encourage increased use of LR projects. The 'Flexible Senbiki' policy, described in Chapter 2, grants an upzoning to UPA for LR projects within UCA areas, even though the UPA/UCA zoning is the main planning measure designed to prevent sprawl development in suburban areas. The second hypothesis is thus that by encouraging large scale developments in UCA areas, Flexible Senbiki projects will tend to undermine the Senbiki system, and will result in more extensive, sprawling patterns of urban development.

Further, projects typically take a very long time from initial conception to completion, 10-20 years is normal, and 30 years not unusual. Because of the fact that most development is restricted within project areas until the replotting is completed, it seems likely that the long development period required for projects will mean that some development activity will be forced to leapfrog over current LR projects into previously undeveloped area while the project is in process. The third hypothesis is thus that if LR projects are not developed comprehensively in 
urban fringe areas, long project development times, and higher land prices within LR areas would tend to delay urbanisation within LR projects and would result in higher rates of development in other nearby, non LR locations. That seems likely to encourage haphazard sprawl development in those areas.

This paper examines these questions at two spatial scales, metropolitan and local. The impacts of the widespread use of LR projects on patterns of land development at the metropolitan scale are analysed in Chapter 2 which examines the locational attributes of all LR projects within the Suburban Development Area of Saitama Prefecture. That area includes the whole of Saitama which lies within $50 \mathrm{~km}$ of Tokyo station, and most of the developable part of the prefecture, the rest being mountainous. Chapter 3 undertakes a more detailed study of patterns of land development and infrastructure provision in three case study cities, and analyses the effects of LR projects on patterns of urban development at the local scale. 


\section{CHAPTER 2}

\section{Saitama: a case study of LR and urban form at the metropolitan scale}

This chapter examines the role of LR projects in shaping patterns of land development at the city region scale through an analysis of the location of all new LR projects in Saitama Prefecture from 1960 to 1994. The analysis of the locational patterns of new LR projects should help understand how the widespread use of LR has affected patterns of urban development at the metropolitan scale.

Section 2.1 describes the main factors affecting urbanisation in Saitama prefecture; the geographical setting, historic patterns of urban development, basic infrastructural factors, and key planning policies in order to better understand the context of urban growth, and the role of LR projects in that growth. Section 2.2 is devoted to the locational analysis of the LR projects, while Section 2.3 summarises the findings.

\subsection{Urban growth and planning in Saitama}

\subsubsection{The context of urbanisation in Saitama}

The overwhelming factor in the development of Saitama throughout the postwar period has been its location immediately to the north of Tokyo. Even in the early post-war years towns in the south of the prefecture close to Tokyo were serving as bedroom communities for the capital. Most urban development in the prefecture has been the result either of residential migration from areas in central Tokyo in search of better housing, or of the decentralisation of factories from Tokyo in search of cheaper space. Of the three prefectures surrounding Tokyo, Saitama was the second to experience significant suburban development after Kanagawa to the south and before Chiba to the east.

Fig. 1 showed the prefectures in the Tokyo Metropolitan Region (TMR) with distance bands from Tokyo Station indicated. Urban development pressure was earliest and most intense in those locations most accessible to central Tokyo, gradually spreading further out over time. Urban development in Saitama thus started in the south east along the border with Tokyo. The study area indicated in Fig. 1 is the whole "Suburban Development Area" designated in the National Capital Region Development Plan (NCRDP) discussed below, and comprises virtually the whole of Saitama that is not mountainous. The omnipresence of the giant neighbour to the south is clearly visible in official Saitama prefectural planning maps which are routinely oriented towards the capital by a set of circles showing radial distance to Tokyo Station. Apart from this general dominance of the capital in the development of the region, however, urbanisation has been structured by natural features such as rivers and their floodplains, the historic settlement pattern which was based on the main feudal era highways, and the railway network which was developed at the turn of the century.

The study area is the part of the prefecture within roughly 50 kilometres of 
Tokyo Station. It forms the central part of the Kanto Plain, the largest plain in Japan. The Kanto plain is composed of alluvial lowlands and diluvial uplands which seldom rise more that 20 meters above the level of the lowlands. It is crossed by three main rivers, the Tonegawa which forms the northern boundary of the study area and which flows east towards the Pacific Ocean, and the Arakawa and Edogawa which both flow south towards Tokyo bay as shown in Fig. 2. Between the two latter is a long low diluvial upland which extends from Gyoda in the north to Urawa in the south. To the east of this ridge is a large area of irrigated alluvial plain drained by the Edogawa and Nakagawa rivers which had little urban population until the post-war period. To the west of the ridge is the broad floodplain of the Arakawa river, the main river flowing through Tokyo from the north. On the western side of the Arakawa is another area of upland, which rises gently until it meets the mountains which form the western half of Saitama prefecture. The traditional centre of this second upland is Kawagoe,

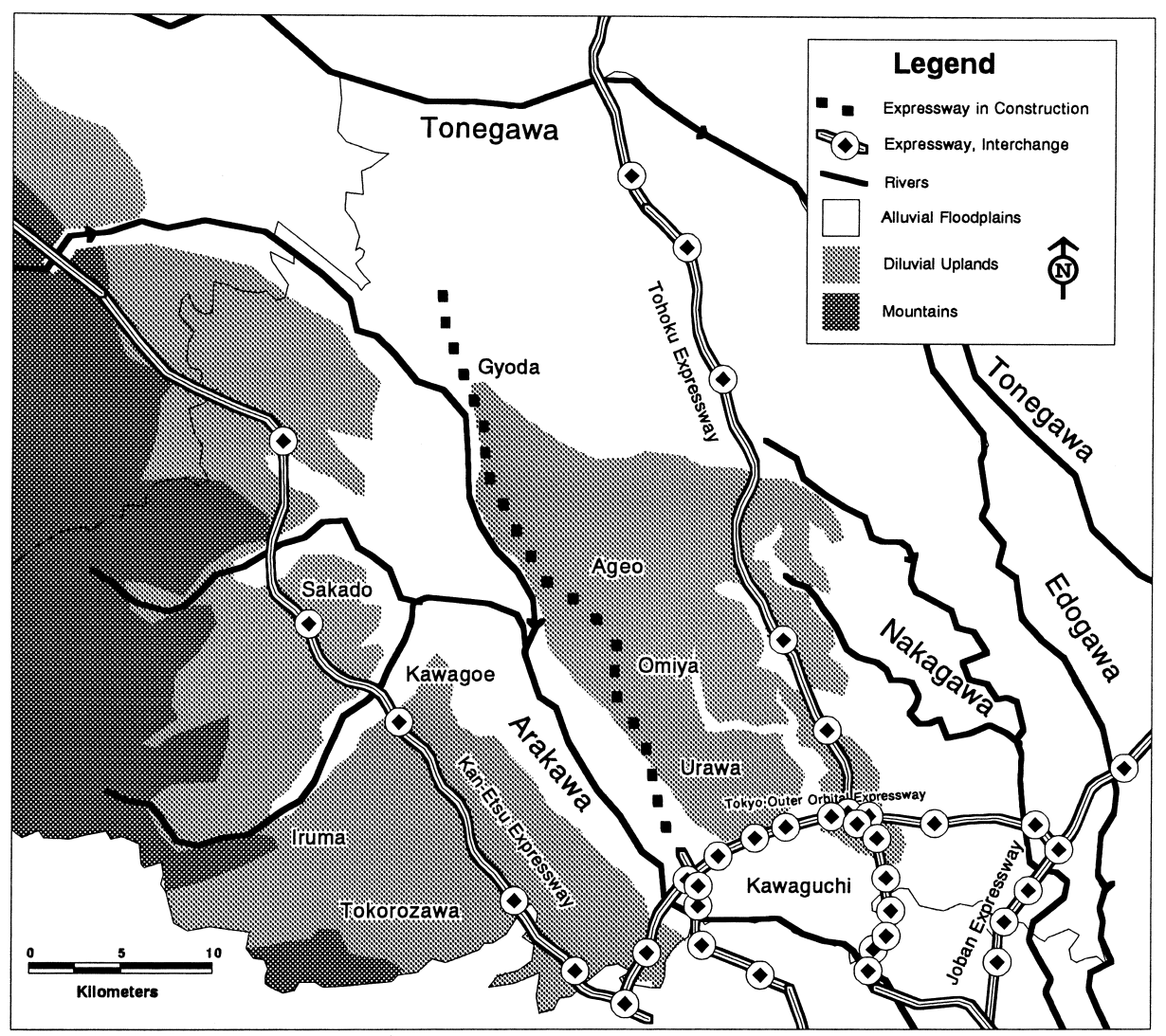

Fig. 2. Case study area landforms, cities, expressways. 
which has been a noted furniture making centre since the Edo period (Yamaga, 1970, p. 74).

The central upland, which has traditionally been the core area of Saitama, was traversed by the feudal era Nakasendo which was one of the main highways to Kyoto and the west during the Edo period (from circa 1600 to 1867). Literally translated as 'Interior Road' it led through the mountains and was the main alternative to the Tokaido road which followed the Pacific coast and was susceptible to flooding. The same favourable location along this ridge of high ground was chosen for the main railway line north from Tokyo built just before the turn of the century (Arisue and Aoki, 1970, p. 193). Along this upland are still found the main settlement areas of Saitama, including Urawa, the seat of the prefectural government, Omiya, the most important commercial and transport centre, and Kawaguchi, immediately north of Tokyo which was traditionally an iron forging and casting centre (Yamaga, 1970, p. 74).

One final point must be added with regard to the physical setting. Almost the entire area of alluvial floodplain, indicated in white in Fig. 2, was prior to

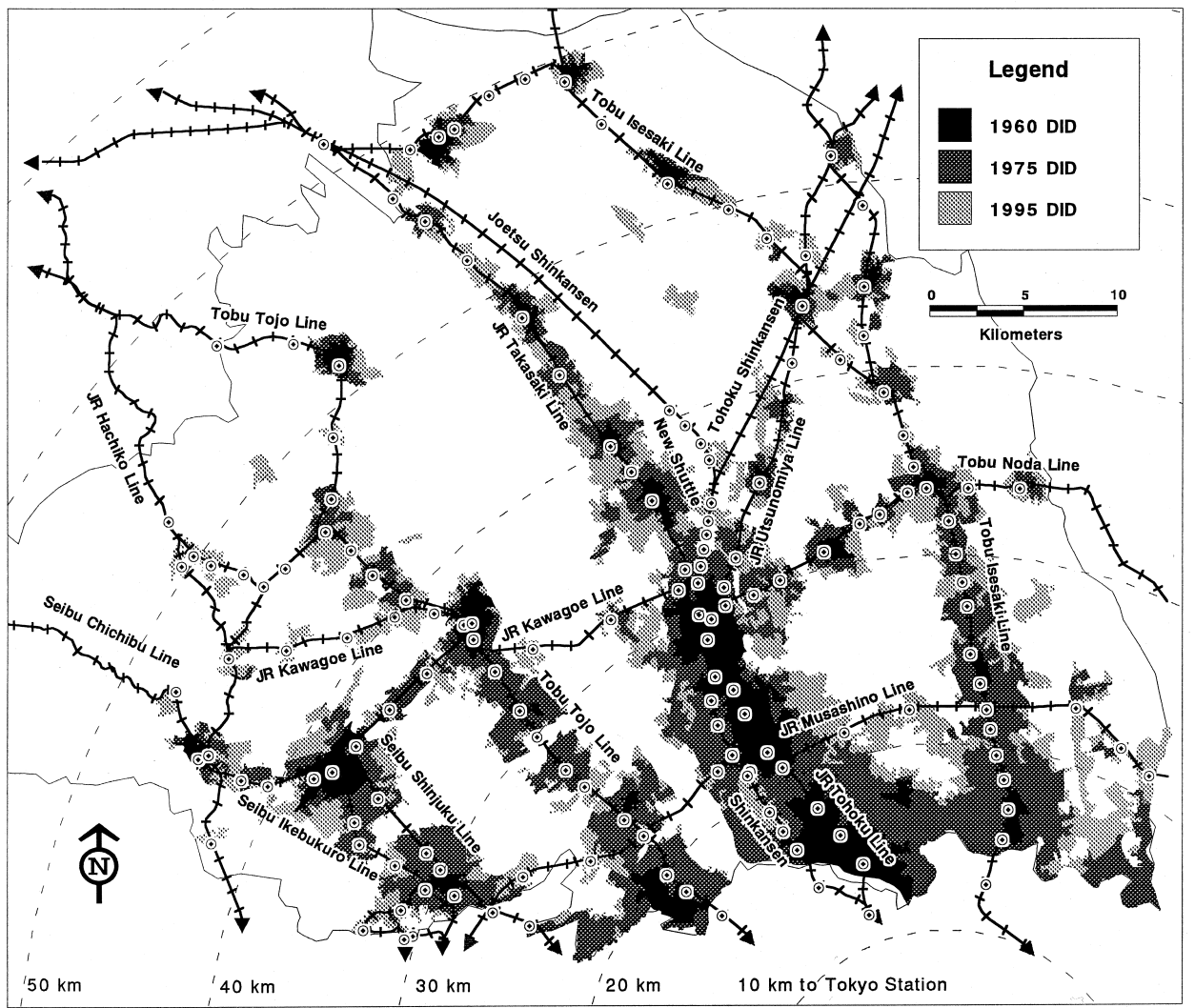

Fig. 3. Case study area, urban growth 1960-1995. 
urbanisation irrigated wet paddy (Suiden) for rice production, while almost the entire upland area, indicated in light grey, was dry field (Hatake) for the production of vegetables, and fruits.

As is clear from the pattern of growth of Densely Inhabited Districts (DID) shown in Fig. 3, urbanisation in Saitama has taken the form of radial corridors centred on rail lines which converge on central Tokyo. The main corridor is that in the centre of the study area which developed along the old Nakasendo highway. It had numerous locational advantages including the best access to Tokyo, a good highway, an existing series of urban settlements based on the highway post-towns of the feudal era, the national railway lines to the north and to the Japan Sea coast, and extensive areas of buildable land on the upland corridor which were protected from the floods which were a recurrent source of destruction until post-war river engineering controlled them. The other three corridors, from the east, are that based on the private Tobu Isesaki railway line, that based on the private Tobu Tojo line to Kawagoe, and that based on the private Seibu Ikebukuro and Seibu Shinjuku lines to Tokorozawa and Iruma as shown in Fig. 3. These corridors are discussed further below, here it should simply be noted that the physical features of the prefecture, the traditional settlement pattern, and the main transport infrastructure have worked together to concentrate development along radial corridors spreading from Tokyo.

\subsubsection{Saitama urbanisation}

The southern part of Saitama has consistently provided a lower cost residential location in comparison with the western suburbs of Tokyo or areas in Kanagawa prefecture to Tokyo's south as shown so clearly by the Tokyu Real Estate Corporation's land value maps (see Wegener, 1994, p. 97). However, the south east part of the prefecture in the floodplains of the Edogawa and Nakagawa rivers provided a particularly unfavourable location for urban settlement, and lower land prices even than other areas in the south of Saitama. Moreover, the Tobu Isesaki line provided direct access from the great manufacturing centres of Sumida and Koto wards of eastern Tokyo. Along this rail line developed housing areas for large numbers of industrial workers who used the rail line to commute to jobs in the capital. The communities along this rail line form one of the main concentrations of crowded and substandard minikaihatsu development in the Tokyo area (Katsumata, 1993, p. 824).

The central corridor is rather different. It has a favourable site on higher ground, and is the location of the prefectural capital, Urawa, as well as many of the prefecture's most prosperous towns such as Omiya and Kawaguchi. It was traditionally served by the main Japan National Railways (JR) line to the north which splits north of Omiya into the Tohoku and the Takasaki lines. More recently the Tohoku and Joetsu Shinkansen (high speed rail) lines serving northern and eastern Japan, which were built from the mid 1970s to the mid 1980s were located here, and most recently the new shinkansen to Nagano which opened in October 1997 uses the Joetsu track as it passes through Saitama. The shinkansen lines have had important impacts on urban development in Saitama. 
First, the centre of gravity has shifted northward toward Omiya which, as the first shinkansen station north of Tokyo Station has become a major transfer point comparable to Shin Yokohama Station in Kanagawa to the south. Second, shinkansen lines have allowed the dispersal of Tokyo dependent residential development over greater distances as their use for daily commutes is on the increase (Taniguchi and Nakagawa, 1995, p. 196). Third, access to Tokyo was significantly increased in the early 1990s for residents along the route of the shinkansen line with the building of the New Shuttle (Nyu Shatoru) a commuter line built in the right of way under the shinkansen tracks as part of a negotiated settlement to appease local opposition to the shinkansen route. All of these developments have served to reinforce the dominance of the central KawaguchiOmiya corridor.

The Tobu Tojo line to Kawagoe and Sakado forms the third major corridor and is located immediately to the west of the Arakawa floodplain on the second major area of upland. In 1960, Kawagoe was the only substantial settlement along this line, but by 1995 the corridor had filled in almost continuously with development and new stations all the way to Sakado in the north west. The fourth corridor is that which formed along the Seibu Ikebukuro and Seibu Shinjuku lines through Tokorozawa and Iruma. One important difference between the three corridors based on private commuter railways and the Omiya corridor which is based on a JR railway line is that JR has long been prohibited from engaging in speculative real estate development, whereas such activity is a major raison d'être of the private lines. This can be seen in the closer spacing of stations on the private lines, where land development subsidiaries of the rail companies have repeatedly centred land development schemes on new stations developed on existing lines, and profited from the huge increases in land value that result.

Although all of these railways were already established by 1920 (Arisue and Aoki, 1970, p. 193), they have seen a constant upgrading through electrification, establishment of new stations, double tracking, and the introduction of express services since then. In particular train speeds and capacity in the Tokyo area have been steadily increased since the 1970s to cope with increasing demand and train overcrowding with the assistance of large government subsidies to elevate private rail lines to eliminate level crossings and increase to four tracks (Japan National Land Agency, 1987, p. 125). Apart from the shinkansen lines, the major new line developed in the post-war period was by JR, the orbital Musashino line in the late 1960s. Thus, the railways, the key structuring feature in Saitama's urbanisation were well established before the post-war suburbanisation commenced.

As shown in Fig. 3, urbanisation in Saitama has consistently been centred along these rail lines. Compared with other developed countries the strong focus of new suburban development along rail lines during the post-war period is exceptional, and is similar to the pattern of development seen around London during the inter war period for example, which was also based on commuter rail lines. In the automobile suburbs and 'Edge Cities' (Garreau, 1991) of the United States and even in some European countries with excellent public transit systems the greater use of private cars for commuting and the greater provision of roads has resulted 
in much more dispersed patterns of suburban development in the post-war period. In the Japanese case the strong role of commuter rail lines in shaping patterns of suburban growth can be attributed to the low levels of car ownership which prevailed until the 1970s, the continuing lack of roads and resulting congestion that prevent commuting by car, and the shortage of parking spaces in most built up areas.

Urban development in Saitama during most of the post-war period is thus an excellent example of a highly efficient pattern of urban development described as 'star' shape development (Blumenfeld, 1967, p. 36; Lynch, 1981, p. 373; Pressman, 1985 , p. 355) along major radial transport corridors which converge on the metropolitan centre. The sort of linear suburban corridor seen in Saitama has long been advocated as an ideal type which is efficient in its use of resources, allows high levels of accessibility, and supports high levels of public transport use while preserving accessible open space close to built up areas (Blumenfeld, 1967, p. 76; March, 1967; Echenique, 1994). That this pattern seems to have been a result primarily of market forces rather than of either land use planning or metropolitan structure planning as discussed below underlines the fact that a star shaped metropolitan form is a natural pattern of growth in a case with a strong central employment base and a reliance on rail transport for commuting, just as the increasingly dispersed low density exurban development seen in the post-war United States is a natural form of growth of an automobile based transport and employment system. It is worth noting also that the pattern in Saitama contrasts strongly with that in Kanagawa, to the south of Tokyo, where the important subcentre of Yokohama has its own radial rail network which is overlapped by that of Tokyo, and the greater accessibility that resulted produced a more overall pattern of development.

It is widely accepted that one of the major factors limiting the greater use of private automobiles in Japanese metropolitan areas has been the poor quality of the road system compared to that in the metropolitan areas of other developed countries (Ohta, 1994, p. 118). In this regard, it is important that major improvements to road networks have recently been completed, are under construction and are planned, shown in Fig. 2. The first limited access road through Saitama was the Kan-etsu expressway in the west of the study area which

Table 2

Japanese traffic volume by type of transport (billion passenger $\mathrm{km})^{\mathrm{a}}$

\begin{tabular}{llll}
\hline & Bus & Automobile & Rail (incl. subways) \\
\hline 1970 & 103 & 181 & 289 \\
1975 & 110 & 251 & 324 \\
1980 & 110 & 321 & 314 \\
1985 & 105 & 384 & 330 \\
1990 & 110 & 576 & 388 \\
\hline
\end{tabular}

${ }^{a}$ Source: Japan Statistical Yearbook (1996, p. 372). 
Table 3

TMR traffic volume growth (1000 vehicle trips $)^{\mathrm{a}}$

\begin{tabular}{llllll}
\hline & Core area & $\begin{array}{l}\text { Central } \\
\text { area } \\
\text { (internal trips) }\end{array}$ & Central area & $\begin{array}{l}\text { Tokyo } \\
\text { metropolitan } \\
\text { government area }\end{array}$ & $\begin{array}{l}\text { Tokyo } \\
\text { metropolitan region }\end{array}$ \\
\hline 1971 & 1740 & 4690 & 5720 & 6820 & 11,360 \\
1974 & 1780 & 4870 & 6130 & 7410 & 13,120 \\
1977 & 1910 & 5970 & 7240 & 8680 & 16,630 \\
1980 & 1740 & 4910 & 6370 & 7960 & 17,280 \\
1985 & 1950 & 5600 & 7260 & 9460 & 21,170 \\
Growth & $(1.12)$ & $(1.19)$ & $(1.27)$ & $(1.31)$ & $(1.86)$ \\
index $(1971=1.0)$ & & & & & \\
\hline
\end{tabular}

a Source: Ohta (1994, p. 114) (Ministry of Construction Road Traffic Census).

opened in the early 1970s, followed shortly by the Tohoku expressway in the east which was in operation by 1980. In the early 1990s the Saitama portion of the Tokyo Outer Orbital Expressway was completed, linking these two radial expressways with a third, the Joban expressway to the north-east. These roads were built primarily as long-distance inter city routes and for trucks, but also seem likely to have long term effects on patterns of suburban development. With improvements in the road system and increasing affluence the amount of car travel has increased exponentially, while bus and rail ridership have remained stable and increased slowly respectively as shown in Table 2 .

Particularly important in the present context is the fact that much of the growth of road use is in the outer areas of the metropolitan regions rather than in the core areas. This is for reasons similar to those prevailing in other developed countries. In outer metropolitan areas origins and destinations of trips are more diverse and thus more difficult to serve by public transit, especially for suburb to suburb trips that do not follow the main radial lines to the centre. Congestion is often much less severe in suburban areas as overall densities are lower, road provision is easier and parking facilities are more widely provided because of lower land costs. In the case of the Tokyo Metropolitan Region, the vast majority of the increase in vehicle trips is in the outer area, as shown in Table 3, which indicates rapid growth in vehicle trips in the metropolitan region as a whole while the number of trips grew much more slowly in the central area, and very little in the core area because of road saturation (Ohta, 1994, p. 114).

In Table 3, the Central Area is defined as the 23 wards, an area roughly within a radius of $15 \mathrm{~km}$ from Tokyo Station, and approximately the same size as Greater London. That area accounted for 1.5 million new vehicle trips between 1971 and 1984. As growth in the whole TMR was 9.8 million vehicle trips, it is clear that the vast majority of new trips ( 8.3 million) were in the suburbs.

Probably of greater importance for road travel within suburban areas than the expressways are arterial roads. In this paper the term arterial roads refers to the City Planning Roads (Toshi Keikaku Doro) which are indicated in both the 
Prefectural plans and City Plans. The City Planning Roads are eligible for national government road construction subsidies and are planned to form a comprehensive network in Saitama. Some of those planned are to be built by widening and straightening existing routes, while others are completely new roads. According to the 1990 Saitama Basic City Planning Survey (Saitama Prefecture, 1992 , p. 54), of the very extensive planned network of $2575 \mathrm{~km}$ of arterial roads in the prefecture, $1361 \mathrm{~km}(53 \%)$ were built or under construction, an increase of $178 \mathrm{~km}$ since the last survey of 1985 . However, while undoubtedly the road network will be much improved with the completion of the planned arterial roads, at current rates that will take another 35 years. With increasing numbers of vehicle trips, some of which will be generated by the new roads themselves, it seems likely that congestion will remain a serious problem whatever the rate of new road completion.

With the continuing increase of suburban population, the push to decentralise employment from Tokyo to subcentres such as Omiya/Urawa discussed below, the steady improvement of the road system and the increasing ownership of cars the possibility exists for substantial shifts to greater car use for both the to journey work and for other travel in suburban areas. The efficient rail based star pattern of metropolitan growth that has developed could thus be undermined as further suburban dispersal takes place. The question of whether the reliance on rail for most travel continues, or whether Japan sees a shift to private automobile use to the degree common in other developed countries is likely to be a fundamental issue affecting Japanese metropolitan areas for the foreseeable future.

\subsubsection{The role of national government planning}

Mention must be made of the National Capital Region Development Plans (NCRDP) and the Comprehensive National Development Plan (CNDP). The NCRDP is the national government metropolitan structure plan of which the fourth went into effect in 1986 and will be current until the year 2000. One factor limiting the impact of these plans is that their role is primarily indicative, and the plans carry no budget allocation or legal requirement that other plans, budgets, or bodies (government of private) follow their recommendations. In the context of the present research, however, the primary factor limiting any significant impact of the NCRDP on the patterns of metropolitan growth in the study area is that the whole study area is uniformly designated as 'suburban development area'. A very brief examination of the successive plans will make this point clear.

As can be seen in Fig. 4 the first NCRDP of 1958 designated a broad greenbelt around the existing built up area of Tokyo, in emulation of Abercrombie's Greater London Plan (Hanayama, 1986, p. 26). Controls were placed on the location or expansion of industries and universities within the existing 'Built Up Area,' with development to be channelled to satellite towns beyond the greenbelt of which Omiya, Urawa, Kawagoe, Sayama, Kumagaya, and Fukaya were located in Saitama. The greenbelt was to act as a cordon sanitaire around the existing built up area and maintain a clear separation between Tokyo and its suburban satellites (Alden, 1986, p. 72). However, this plan was defeated by a combination 


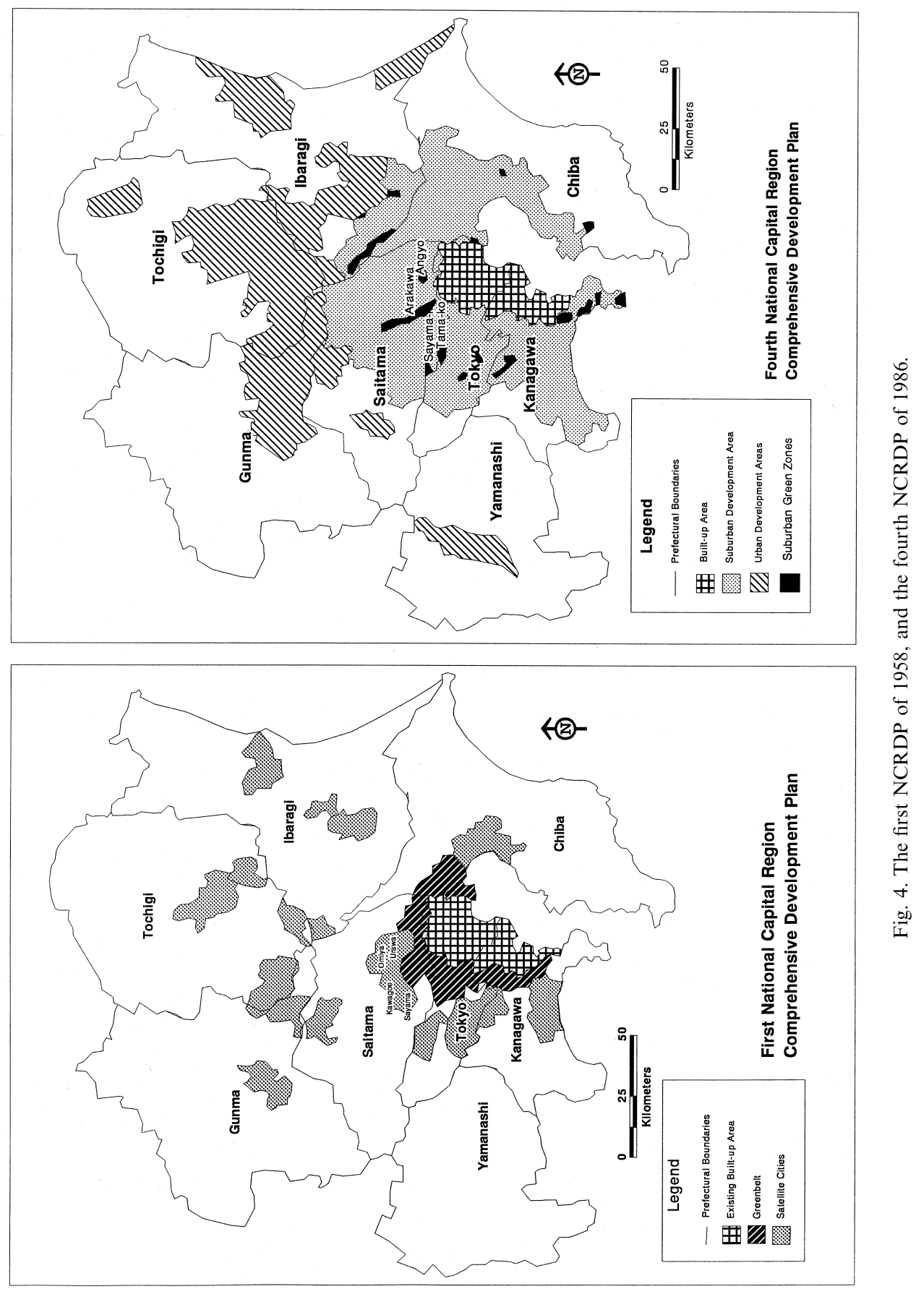


of greater than expected economic and metropolitan growth, and active opposition to implementation of the plan. A recent study of the failure of the first NCRDP to shape actual patterns of growth suggests that the lack of concrete legal measures to enforce provisions of the plans, and the fact that the local governments affected were pursuing contrary pro growth policies were the key factors in undermining the effectiveness of the plan (Kurosawa and Teraoku, 1996). Through a combination of political lobbying and landowner strategies of actively subdividing and selling farmland in the proposed greenbelt area forces opposed to the plan were able to ensure that its greenbelt provision would be unenforceable.

In response the Second NCRDP of 1968 eliminated the greenbelt and effectively designated the whole area outside the existing built up area and within a $50 \mathrm{~km}$ radius of Tokyo Station a Suburban Development Area while retaining the satellite cities in the northern part of the region. This second approach to planning the metropolitan structure has continued to form the basic strategy of the Fourth plan implemented 1986, shown in Fig. 4, the 'Suburban Development Area' of which is identical to that first designated in 1968. The major element distinguishing the second, third, and fourth plans is the steady expansion of the Urban Development Areas, to the point that virtually all of the Kanto Plain outside the Suburban Development Area is now so designated. Also, in the Third NCRDP, 17 'Suburban Green Zone Conservation Areas' were designated where development was to be restricted. However, these conservation zones consist primarily of areas which are in any case unbuildable. For example in Saitama the main such zones are the floodplain area of the Arakawa River, and the Sayamako and Tama-ko lakes with the small mountainous area surrounding them, which are Tokyo's principal drinking water reservoirs. The only green zone designated in a prime development area in Saitama, that at Angyo in Kawaguchi City, has, perhaps coincidentally, recently seen the construction along its full length of the Tokyo Outer Orbital Expressway mentioned above, and its cloverleaf 'Kawaguchi Interchange' with the Tohoku Expressway and the Iwatsuki Kaido (National Highway 122), one of the larger such interchanges in Japan.

Since the Second NCRDP the whole of Saitama apart from the western mountainous region has been designated 'Suburban Development Area.' It is striking that in this way the NCRDP have taken account neither of the strong urban structure seen in Fig. 2 of linear corridors of DID development based on railways, nor of the Senbiki division into UPA and UCA areas described in the next section. As the area examined in this section is the whole of Saitama Prefecture which has been designated Suburban Development Area, it seems safe to conclude that it is unlikely that the National Capital Region Development Plans have had a significant impact on the structure of urban growth and development within our study area since the passage of the second plan in 1968 .

Possibly of greater long-term significance is the fundamental restructuring of the TMR urban structure proposed in the current Fourth Comprehensive National Development Plan (CNDP). The basic concept proposed is that Tokyo should be ringed by five major new "Business Core Cities" of which Urawa/Omiya in 
Saitama would be one. These would be developed as major employment and services subcentres in order to draw development pressure away from central Tokyo and create a multinucleated metropolitan structure (Japan National Land Agency, 1987, p. 124). It is too soon to know whether this plan will have the effects envisioned, but if the Urawa/Omiya area does become an important employment centre as planned it is certainly likely to relieve pressure on central Tokyo. However, whether this is likely to lead to shorter or longer distances travelled overall, and how it will affect the modal split between road and rail are still uncertain. One immediate response has been the Saitama prefectural government's plan to merge the cities of Yono, Urawa, Omiya and Ageo to form a new city of over a million population. Apart from possible administrative advantages of larger scale the primary motivation is the prestige and added fiscal powers associated with 'designated city' status which is conferred on cities of over 500,000 population. The main practical outcome to date has been the preparation (by Land Readjustment project) of a 47.4 ha site for the new city centre by the Japan Housing and Urban Development Corporation on disused railway yards at the intersection of Yono, Urawa, and Omiya cities.

\subsubsection{Saitama prefectural planning}

The main planning issue in Saitama at the end of the 1960s when the new planning system was put into place and the first Senbiki was being carried out was identified as the problem of urban sprawl. A decade of rapid economic growth had resulted in extraordinary population increases, especially in the suburbs of metropolitan areas. The huge demand for housing, combined with a very weak land use planning system had resulted in the creation by small private builders of large areas of substandard development without basic services, in Saitama as elsewhere (Katsumata, 1993, p. 823). By the end of the decade it was widely recognised that the deteriorating living environment in suburban areas was a very serious problem. The primary goal of the first Senbiki as outlined in prefectural planning documents was therefore identified as Sprawl Prevention (Supurôru Bôshi) (Doi, 1986, p. 71; Capital Region Comprehensive Planning Institute, 1987, p. 11).

Senbiki has been described as a policy in Chapter 1. Here is a chance to see how it was implemented on the ground. As shown in Fig. 5 the UPA areas closely follow the main radial rail lines in to Tokyo. The structure that results is a starshaped pattern with wedges of UCA between the fingers of the star. Although it appears that the Senbiki zoning has created a strong radial structure following the rail lines, in fact the UPA zoning largely followed existing patterns of settlement and served primarily to reinforce them. Also clear from Fig. 5 is the fact that in 1970 the UPA area was much larger than the then DID area, reflecting the anticipated continuation of high rates of growth. As Doi, one of the architects of the first Senbiki in Saitama has argued, the main problem in the case of Saitama's first Senbiki was that it was done at the very peak of the prefecture's population growth based on population projections that were to prove too high, and overdesignation of UPA area was one significant outcome (Doi, 1986, p. 74). 
The over designation of UPA was the result of a combination of factors, including encouragement from the MOC to designate as large an area as possible to ensure adequate stocks of raw development land in suburban areas to reduce inflationary pressure of housing demand on land prices, political pressure from developers and other landowners who wanted their land designated UPA, and the fact that at the time that the Senbiki was carried out growth pressures, especially in the metropolitan areas, were very strong (Hebbert, 1994, p. 77). This was especially true in the case of Saitama, which had recorded one of the highest rates of population growth in the country in the 1965-70 period with an increase of 851 thousand people, or $28.2 \%$. As shown in Table 4, although population growth has continued strongly until the present, the highest 5-year rate of increase was just before the first Senbiki of 1970, while the largest increase in population was in the following period with almost a million new residents between 1970 and 1975 . Since then both the rate of increase and the absolute number of net immigrants

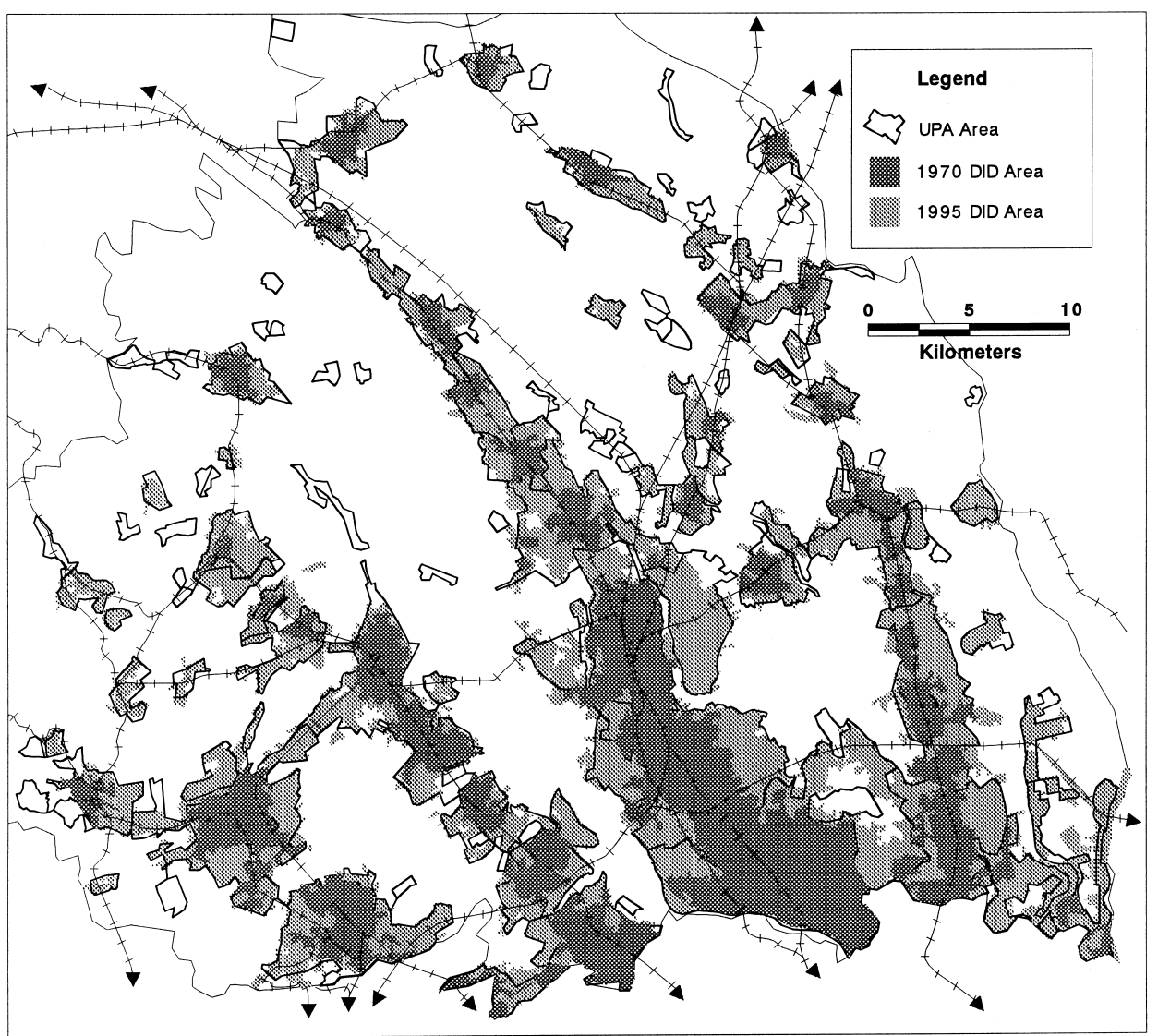

Fig. 5. Saitama UPA, DID 1970-1995. 
has dropped rapidly, though the prefecture is still experiencing substantial population growth. It is understandable, therefore, that the population predictions (and UPA designations) which were based on extrapolating these growth rates were too high.

The target population density for UPA areas in Saitama is 100 persons per hectare (Interview, Saitama Prefecture City Planning Bureau, Urawa 15.07.95). As can be seen in Table 5, an area substantially larger than necessary was designated UPA in 1970. The urban population as measured by the inhabitants of DIDs in 1970 would have had to triple to fully populate the UPA designated in 1970. Even at the then current high rate of population increase this would have taken much longer than 10 years. Although shrinking household sizes would also have increased demand for residential land, that effect does not seem to have countered the dramatically lower population growth than expected. Also, because of the rapid inflation of land prices in Japanese metropolitan areas during the period under study, housing plot sizes actually decreased during the period, instead of increasing as might be expected during a period of increasing incomes. The loose fit of development land supply and demand has meant that although by 1990 most of the UPA area had become DID, development was scattered throughout the UPA area, frustrating attempts to achieve the comprehensive serviced development of the UPA area that had been the main goal of the Senbiki system. Whereas the objective had been to concentrate development into a smaller area where planned development with basic infrastructure could be carried out, by designating 30 years supply of development land all at once the opportunity to manage development by staging the release of development land was lost.

It is important to note that the pattern of DID growth shown in Fig. 5 significantly exaggerates the extent to which the UPA areas are built up and UCA areas have been protected from development. To qualify as DID, areas need have only 40 persons/ha, whereas according to a report on Senbiki in Saitama by the Capital Region Comprehensive Planning Institute (Capital Region Comprehensive Planning Institute, 1987, p. 43), the gross population density of 'existing built up areas' in Saitama (areas considered fully built up, a smaller area than that designated DID) in 1970 was 105 persons/ha. DID designation thus in no way means that an area is fully built up, as DID status can be triggered with as little as $30 \%$ of the land actually converted to urban use. In this regard it is significant that even in 1995 Saitama prefectural planning officials were not expecting any

Table 4

Population increase rate in Saitama $(1000 \mathrm{~s})^{\mathrm{a}}$

\begin{tabular}{lllllllll}
\hline & 1960 & 1965 & 1970 & 1975 & 1980 & 1985 & 1990 & 1995 \\
\hline Total & 2431 & 3015 & 3866 & 4821 & 5420 & 5864 & 6405 & 6759 \\
Population increase & 170 & 584 & 851 & 955 & 599 & 443 & 542 & 354 \\
\% Increase over previous census & $7.5 \%$ & $24.0 \%$ & $28.2 \%$ & $24.7 \%$ & $12.4 \%$ & $8.2 \%$ & $9.2 \%$ & $5.5 \%$ \\
\hline
\end{tabular}

${ }^{a}$ Source: Population Census of Japan, various years. 
significant expansion of the UPA areas to accommodate future growth, as it was felt that this could easily be accommodated in the present UPA. The open texture of development in new DID areas is examined further in Chapter 3. One further caution is necessary about the reading of Fig. 5. It should not be forgotten that the UCA areas are not a reserve of unbuilt agricultural land. Even though DID areas seem neatly confined to the UPA areas, development and urban uses have not been so tidily corralled. Many of the developments in UCA areas, as Hebbert (1994, p. 83) has shown, are space-intensive facilities such as roads, schools, police stations, garbage incinerators and gasoline stands which, while giving a decidedly urban look to the UCA areas, do not result in significant population increases.

The problem of continuing scattered unserviced development became a central focus of attention at the time of the first Senbiki Review, which was started in 1975 and completed in 1979. As seen in Table 6, infrastructure provision in the UPA was seriously backlogged by the early 1970s. In effect virtually all the new DID area developed since 1960, apart from the areas developed by LR lacked basic urban services such as roads, sewers and parks. Whereas by 1990 virtually all the UPA was DID area, as shown in Table 6 only some $34 \%$ had basic infrastructure, and much of this portion was the area that was already fully built up in 1970. Large new areas of unserviced sprawl have continued to be created under the Senbiki system.

This problem of the continuing development of unserviced sprawl areas is underlined by data on the location of population increases. While only $35 \%$ of the total prefectural population increase from 1970-80 was in the existing built up area of 1970 , and another $30 \%$ was in the area with completed basic services, $51 \%$ of the total population increase was accommodated in the area without basic urban services (Capital Region Comprehensive Planning Institute, 1987, p. 43). Considering that the existing built up area represented $20 \%$ of the UPA, the serviced area $24 \%$ and the unserviced area $56 \%$, it is clear that development was occurring rather evenly throughout the unbuilt part of the UPA without regard to the availability of urban services.

Table 5

Population increase in Saitama DID and UPA areas ${ }^{\mathrm{a}}$

\begin{tabular}{llll}
\hline & 1970 & 1980 & 1990 \\
\hline Area of DID & 26,820 ha & 51,390 ha & 62,670 ha \\
Population of DID & $2,126,398$ & $3,781,440$ & $4,873,319$ \\
Population density of DID & $79 / \mathrm{ha}$ & $74 / \mathrm{ha}$ & $78 / \mathrm{ha}$ \\
Area of UPA & 63,809 & 66,547 & 67,645 \\
Population of UPA & $2,751,832$ & $4,069,437$ & $4,908,257$ \\
Population density of UPA & $43 / \mathrm{ha}$ & $61 / \mathrm{ha}$ & $73 / \mathrm{ha}$ \\
Population required to reach target & $6,380,900$ & $6,654,700$ & $6,764,500$ \\
UPA population of 100/ha & & & \\
\hline
\end{tabular}

${ }^{\text {a }}$ Sources: National Census, Saitama City Planning Basic Survey. 


\subsubsection{Flexible Senbiki in Saitama}

After the first Senbiki review in Saitama was completed in 1979, it became clear to prefectural planners that the system was not operating in the way intended. While the primary goal of Senbiki was to prevent sprawl and promote planned development, the first decade of the new system had seen an increase in the tendency to minikaihatsu in the UPA area, and continued disorderly development in the UCA area (Narai and Doi, 1991). Local governments were struggling with the enormous costs of trying to catch up with substantial infrastructure backlogs. It is in this context that the 'Flexible Senbiki' system emerged. As it was clear that local governments were not likely to gain greater regulatory power or increased financial support from the central government, existing powers had to be used more creatively. The powers of Senbiki zoning could be used as a bribe to induce landowners to join a Land Readjustment project, and LR was the land development method that could be relied on to achieve some measure of planned and infrastructured urbanisation at low cost. With the support and encouragement of the MOC each of the three suburban prefectures surrounding Tokyo (Kanagawa, Saitama, and Chiba), started to use the Senbiki system more aggressively in the 1980 s, although as no new national laws were passed, the details of each prefecture's approach varied (Capital Region Comprehensive Planning Institute, 1987; Narai and Doi, 1991).

The prefecture, therefore, reviewed its long-term strategy through the "Saitama Basic City Planning Policy Review" (Saitama-ken Toshi Kihon Keikaku Sakutei Chôsa) of 1983. In order to encourage more planned developments and achieve infrastructure targets, the prefecture developed two new techniques for modifying the operation of the Senbiki system, the Yotei Senbiki Keikaku Kaihatsu Hôshiki (literally translated as the Pre-arranged Senbiki Planned Development Method, hereafter referred to as the YTS method) and the Zantei Gyaku Senbiki Hôshiki (or Temporary Reverse Senbiki Method, henceforth the ZGS method). They were ready for use starting in 1984. The YTS method was applied to the UCA areas, and the ZGS method to the UPA areas. If the YTS method can be described as the 'carrot' approach, the ZGS method was the 'stick'.

2.1.5.1. The YTS carrot. Put simply, the YTS method was a way of encouraging planned large-scale development projects through the granting of a zoning bonus. Developments in UCA areas which would provide their own roads, sewers and other public facilities such as parks received a rezoning to UPA area upon their

Table 6

UPA infrastructure provision ${ }^{\mathrm{a}}$

\begin{tabular}{lllll}
\hline & 1975 & 1980 & 1985 & 1990 \\
\hline $\begin{array}{l}\text { Percent of UPA that is fully equipped } \\
\text { with basic urban infrastructure (roads and sewers) }\end{array}$ & $22.2 \%$ & $28.1 \%$ & $31.9 \%$ & $34.06 \%$ \\
\hline
\end{tabular}

a Sources: Saitama Prefecture City Planning Basic Surveys (Saitama Prefecture, 1987, 1992). 
legal initiation. This zoning incentive was primarily directed at encouraging the initiation of LR projects, although a significant number of large-scale private developments were also granted rezoning to UPA. For example, during the 7 years from 1984 to 1990, (inclusive) there were a total of 2104 ha of land transferred to the UPA as a result of this method, of which 485 ha were private developments, and the remaining 1619 ha were LR projects. Thus, LR projects accounted for $77 \%$ of the total. During the same seven year period, a total of 3297 ha of new LR projects were initiated in Saitama, so slightly under half of all new LR projects initiated in the period were a result of the YTS method (Narai and Doi, 1991, p. 701; Saitama Prefecture, 1995).

2.1.5.2. The ZGS stick. The ZGS half of the method applies to undeveloped land within UPA areas and follows the same logic of using Senbiki as a tool to persuade landowners to consent to LR projects. The essence of the policy was that designated problem areas would be downzoned to UCA from UPA if agreement could not be reached on initiating a LR project. The impact of such a downzoning was potentially substantial, as land values are significantly lower in UCA areas (Mori, 1998), and allowable development more limited than in UPA areas.

Following the first Senbiki review of 1975-79 the prefectural planning department designated some 10,000 ha of existing UPA zoned land as 'Designated Problem Areas' (Mondai Shiteki Chiku) representing some $27 \%$ of that part of the UPA that was not DID in 1970. These were areas which had remained predominantly in farm uses, and where there was neither a planned comprehensive development such as LR nor a minimum of residential development. The 'problem areas' were thus areas where sprawl type development could be expected in future if they were not developed comprehensively. Chapter 3 examines the 'problem areas' in greater detail. Areas which were already substantially developed, even in a haphazard, unserviced manner, could not be ZGS downzoned to UCA, and would in any case have been difficult to develop as LR. These areas, often quite extensive, were left to other future remedial measures.

In practice, the required 'agreement on comprehensive development' to prevent downzoning was defined as the consent of a group of the larger landowners within each area to form a LR Organising Committee (Hokininkai). It is important to note that the requirement was to start a committee to initiate LR, not to have actually legally initiated a project, as it was felt that this would take some time. This was to have important consequences later. The job of negotiating landowner consent fell to the local government planning departments, as they are the ones with city planning responsibility and existing relationships with individual landowners in the areas in question (Narai and Doi, 1991: 701).

Of the 10,000 ha initially designated problem areas local governments were able to establish LR organising committees for a total of 7500 ha, or $75 \%$ of the area. Another 1550 ha were acknowledged to have enough development to escape downzoning as 'Existing Urbanising Areas' (Kisei Shigai Chiku), and the remaining 950 ha were in fact ZGS downzoned to UCA areas. Importantly, however, as of 1997, 12 years after the LR organising committees were 
established, LR projects had been legally initiated in only $46 \%(3,457 \mathrm{ha})$ of the area which had escaped downzoning (7500 ha) by agreeing to do so (Saitama, 1997). Further, despite the best efforts of the local governments involved, it seems increasingly likely that much of the remaining area will never be converted to LR projects, as many small developments have been built in the meantime, as shown in Chapter 3. Also the easiest areas to organise were initiated first, leaving a remnant of those which have for one reason or another been more difficult.

It should also be noted that the LR projects started as a result of the YTS and ZGS policies are a significant proportion of the total new LR during the period the policy was in place. Of 6758 ha of new LR projects initiated between 1980 and 1995 , some 4600 ha, or close to $70 \%$, were directly a result of the two policies. It thus seems that the policies have been very successful as a means of promoting greater use of LR projects for land development. However, as will be examined in Section 2.2, by definition all YTS projects result in the conversion of UCA land to UPA, and thus may contribute to increasing the spread of sprawl development.

The operation of this policy shows clearly the division of responsibilities between the two tiers of Japanese local government with respect to urban planning. While the prefecture has control of a potentially powerful tool in the Senbiki system, the local governments have the actual city planning responsibility in terms of zoning, district planning, LR, building control, development permits, and the building of roads and sewers. This division of responsibilities brings certain advantages and disadvantages. The main advantages generally anticipated in a two tier system are that the upper tier can co-ordinate broader structural issues, and can promote approaches which are for the benefit of the whole area yet which may be opposed in particular places. The lower tier, on the other hand, is more familiar with and sensitive to local concerns, and can act as a check on the power of the upper tier. In the case of the use of Senbiki described here, the prefecture was able to implement a policy which generated substantial opposition amongst many of the landowners affected. This opposition was entirely predictable, as the threatened downzoning from UPA to UCA would result in a decrease in the value of the land so rezoned, associated with the reduction in permitted development. The municipalities were able to ally themselves with the landowners affected, and direct the blame to the prefecture, while working with the landowners affected to mitigate the effects of the policy. The way to avoid the downzoning, of course, was to organise consent to form a committee to start a LR project, a goal which was very much in line with the wishes of the local governments which are the keenest supporters of the LR method.

It appears that the threat to downzone was credible enough that most 'problem areas' did establish organising committees. However, it seems that a majority of the original problem areas which were thus able to avoid ZGS downzoning proved impossible to convert into LR projects. Chapter 3 examines in greater detail the 'Designated Problem Areas' and resulting LR projects in each of three case study areas in order to show how the policy operated on the ground. According to prefectural officials, ZGS will no longer be used because "it aroused too much opposition, doing it again would be really like beating up the 
landowners with a stick, and would not be effective again" (Interview Saitama Prefecture City Planning Department 15.07.95). On the other hand, it is expected that YTS will be increasingly used in future to encourage the use of LR.

\subsubsection{Summary}

Saitama, in the lee of the greatest and most dynamic metropolitan area in Japan and experiencing rapid population growth throughout the study period was clearly a difficult environment for the new planning system introduced in 1968, though not so very different from other prefectures immediately adjacent to the three main metropolitan areas of Tokyo, Osaka and Nagoya. Conditions were also probably no more difficult than in several of the countries which are trying to adopt LR practices today, so the prefecture presents a useful case study of the role of Land Readjustment in suburban development.

Because of rapid population growth since the 1960s large areas of unserviced sprawl development have been created in Saitama. The Senbiki system did not stop the spread of unserviced development, but did largely restrict it to the UPA areas as shown in Fig. 5. As a measure to promote the use of LR for land development, in the 1980s the prefecture launched an aggressive campaign to persuade landowners in UPA areas to start LR projects by threatening a downzoning of their land to UCA. That initiative appears to have been highly successful in encouraging new LR projects in UPA areas and possibly in preventing sprawl through the planned development of the UPA area.

The complementary YTS method which grants an upzoning bonus to UPA for LR projects in UCA areas was also successful in encouraging new LR projects, but seems more likely to have encouraged sprawl than prevent it as new developments are developed outside existing UPA areas. The overall impact of LR projects on patterns of development in the prefecture, however, remains unclear without a detailed examination of where projects are actually located. That is the subject of the next section.

\subsection{Locational analysis of $L R$ projects in Saitama}

As LR projects are primarily a means of developing land from rural to urban use, and some 20,581 ha in the prefecture have been developed in this way, it is reasonable to assume that LR projects have had important impacts on overall patterns of urban growth and development at the regional scale. The analysis of locational patterns of new LR projects undertaken here will examine where projects are located, and what patterns of location, if any, may be discerned. The main question addressed is whether projects are located near rail stations and existing developed areas, or are scattered throughout the developing fringe area. The equally important question of what kind of development takes place in the other $79 \%$ of new DID area, and its relationship to the LR project areas is the subject of Chapter 3. 


\subsubsection{Assumptions}

The analysis here will focus on two key aspects of urban form at the regional scale; the relationship of new urban development to public transit networks, and the relationship of new development to existing developed areas. Current road systems are extremely congested and any development that increases the use of cars for daily commutes will increase congestion and add to pressure for increased investment in roads. A key challenge in the Japanese case will be to prevent increasing rates of private automobile use in the suburban areas as the process of metropolitan dispersal continues. From the point of view of minimising future road investment requirements, and to prevent increased congestion and pollution, the location of new LR projects in locations with good access to existing heavy rail commuter stations will be assumed to promote a good urban form at the regional scale. Projects which on the other hand are far from rail facilities will be considered likely to contribute to the use of cars of daily commuting trips and will be assumed to contribute to sprawl at the metropolitan scale.

The second key factor in the analysis is the relationship of new development to existing development. Throughout the suburban development area of Saitama local governments are struggling with a massive infrastructure backlog. The policy of allowing unserviced development has meant that large areas within the Saitama UPA have developed without proper roads, sewerage or other basic public goods such as parks and sidewalks. Therefore, LR projects which are developed within existing DID areas will contribute to reducing the infrastructure backlog by providing needed public facilities in areas that have already started to develop in haphazard fashion. Where LR projects are initiated adjacent to existing DID areas the impact will be not quite as positive as the former case as it will not contribute to solving existing backlogs, but will at least allow an orderly and well serviced expansion of the urban area. On the other hand in cases where a project is developed well away from existing built up areas as represented by DID, it is very likely that the project will increase infrastructure and public facilities deficits. Even though the project area itself will be well provided, it will require local government resources to be devoted to its planning and administration, connections to larger networks such as main sewers and roads, will possibly require new schools and other public facilities, and will tend to attract development which might have contributed to the build out of existing partially developed areas and the efficient use of existing facilities. Where projects are developed outside the existing UPA as in the case of YTS projects, it seems certain that one result will be to make it more difficult to achieve planned development within the existing UPA areas.

In terms of development at the metropolitan region scale, therefore, a project which is developed adjacent to a train station within an existing DID area will be assumed to prevent sprawl as new development is being focussed in a location with good access to public transport, and where there is already a significant level of development. Conversely a project which is developed far from existing rail stations, outside the current UPA and separate from existing development will be likely to promote sprawl as it will generate increased car traffic, increased 


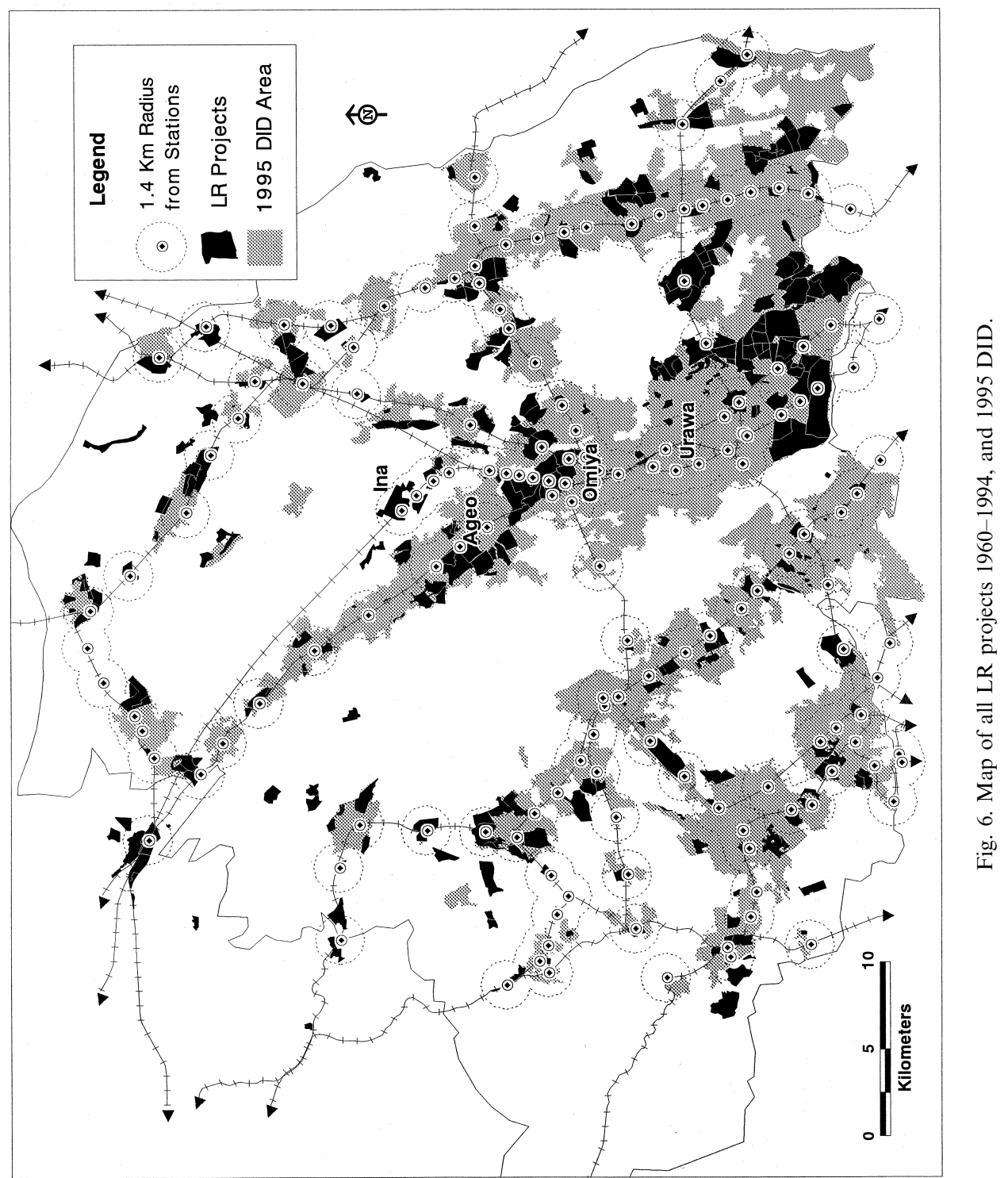


demands for infrastructure in currently unserviced areas, and will be likely to slow the full development of existing partly built up UPA areas

The first analysis is of all projects in the Saitama Suburban Development Area from 1960 to 1994. The second analysis looks at one sub group of LR projects, those YTS LR projects that have involved rezoning of UCA to UPA, as these constitute an important ongoing strategy to increase the use of LR, and seem likely to promote sprawl. Unfortunately a similar analysis of ZGS projects is not possible as there is no reliable way of distinguishing between projects in UPA areas started because of the ZGS policy and those that would have started anyway. In the case of YTS projects such data is available as all changes to UPA/ UCA areas must be recorded and the reason for the change given.

Fig. 6 is a map of all LR projects initiated within the Suburban Development Area of Saitama prefecture from 1960 to 1994 overlaid on a map of the DID areas of 1995 with rail lines and stations marked. As this map makes clear, there are a lot of projects, in a variety of locations. Without knowing when projects were developed, or the extent of surrounding development when individual projects were started, it is difficult to arrive at any concrete conclusions about the role LR projects have played in urbanisation. The goal of the next section is, therefore, to disaggregate projects in time, by location, and by actor to be able to gain a clearer understanding of the locational patterns of LR in the study area.

\subsubsection{Method of categorisation of LR projects}

In order to analyse the location of the 407 LR projects started during the period from 1960 to 1994 in Saitama a simple analytical framework was adopted. In line with the assumptions outlined above, two main locational attributes of new projects were examined: their location in relation to public transit (heavy rail), and their location in relation to existing development as represented by DID areas. For each attribute three possibilities were designated, as shown in Table 7.

As shown in Table 7, it is possible with the two basic attributes of location relationship to commuter rail stations and relationship to existing development to divide projects into nine possible types with varying propensities to promote a good urban form. As suggested in the table, projects in locations such as 1A are most likely to promote a compact and rail accessible form of new urban development, while those in $3 \mathrm{C}$ type locations will be most likely to result in sprawl development which encourages increased private automobile use. Locations such as $1 \mathrm{~B}$ and $2 \mathrm{~A}$ seem likely to prevent sprawl though perhaps less so than $1 \mathrm{~A}$, while locations such as $2 \mathrm{C}$ and $3 \mathrm{~B}$ seem likely to increase the tendency towards sprawl. Although $2 \mathrm{C}$ is in a location which is within walking distance of a rail station, the fact that it is well away from existing development suggests that it will increase overall problems of infrastructure provision. It is more difficult to predict the overall effect on urban form of projects in the final three categories. While 1C will result in a new development separate from existing developed areas, being based on a station it will clearly be highly rail accessible. Although 2B will involve green field development outside the existing DID area, it is in a location contiguous with existing development and within walking distance of a station. 


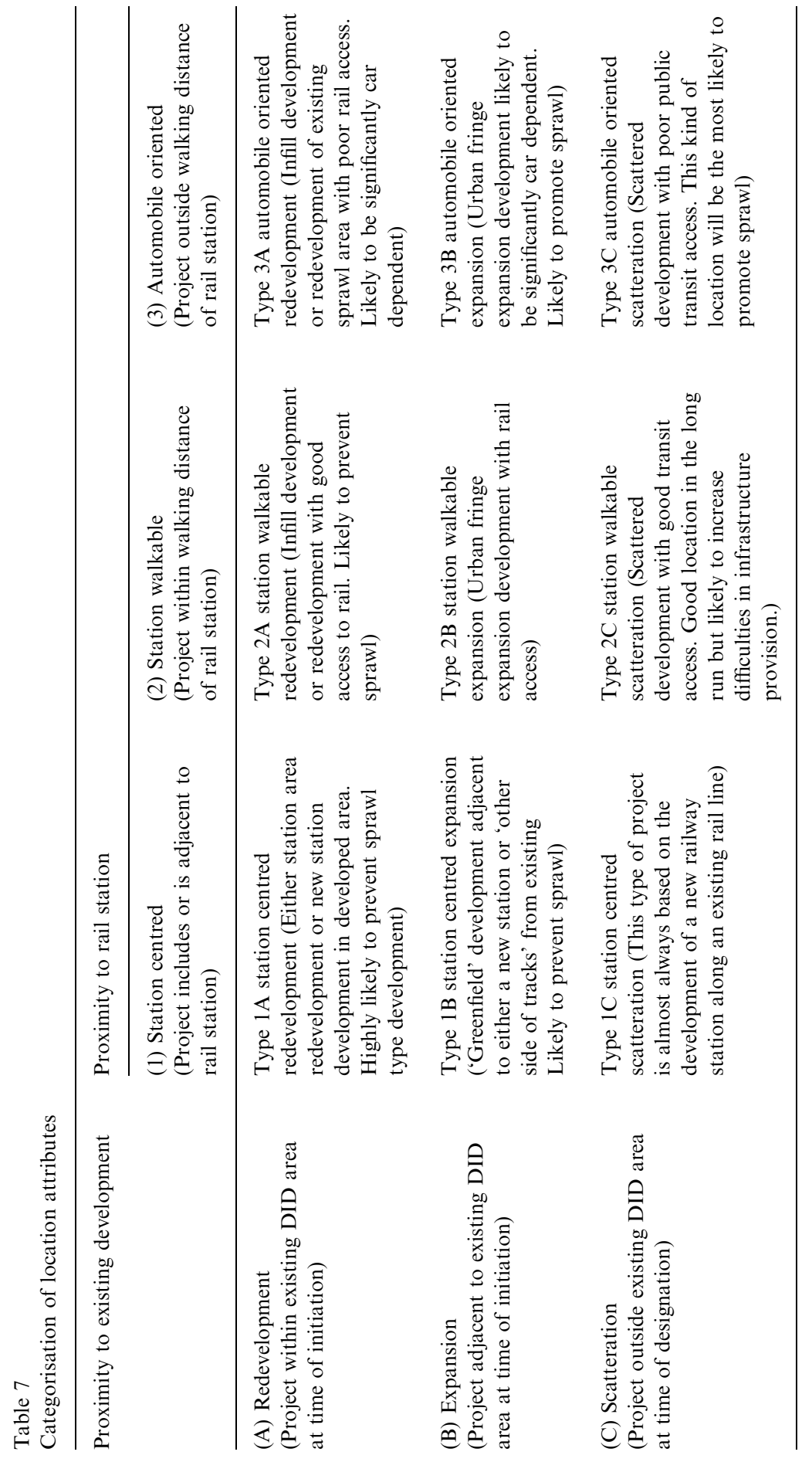


Table 8

Index numbers key

\begin{tabular}{llr}
\hline $1 \mathrm{~A}=1$ & $2 \mathrm{~A}=2$ & $3 \mathrm{~A}=3$ \\
$1 \mathrm{~B}=2$ & $2 \mathrm{~B}=3$ & $3 \mathrm{~B}=4$ \\
$1 \mathrm{C}=3$ & $2 \mathrm{C}=4$ & $3 \mathrm{C}=5$ \\
\hline
\end{tabular}

And while $3 \mathrm{~A}$ is outside easy walking distance of a rail station, it is within the existing DID area and so will help restructure an existing sprawl area. Therefore, it seems fair to suggest that projects in $1 \mathrm{C}, 2 \mathrm{~B}$ and $3 \mathrm{~A}$ type locations will be relatively sprawl neutral.

Following the logic of Table 7, it is possible to create a simple index of overall propensity to create or prevent sprawl development of a combination of projects, for example in a given year. As shown in Table 8 this index can be created by assigning a value to each category. In the present case a value of one is assigned to $1 \mathrm{~A}$, the most likely location to prevent sprawl, while a value of five is assigned to $3 \mathrm{C}$ which is considered the most likely to promote sprawl. In this case then the index number three represents the neutral locations which will be likely neither to promote or prevent sprawl development. To arrive at an index number for any given mix of different projects, the total area of projects in each category is multiplied by the index number of the category, the results for all categories are added together and then divided by the total area of projects in all categories. ${ }^{5}$

A resulting index number greater than three will, therefore, indicate a relative tendency towards promoting sprawl, while an index number less than three will suggest a relative tendency towards preventing sprawl. Such an index will not necessarily measure the degree to which particular projects promote sprawl or not. However, it should help in comparing different mixes of projects, and shifts over time.

In the classification of projects the major problem was that neither of the main criteria were static over the 35 year period of the analysis. Several new rail lines were built, and many new stations on both new and existing lines. As shown in Fig. 3, the expansion of DID areas was inexorable. Because the analysis had to be of the location of projects in relation to existing patterns of development at the time of initiation, the period was divided into seven 5-year periods $(1960 / 1964$, $1965 / 1969,1970 / 1974,1975 / 1979,1980 / 1984,1985 / 1989,1990 / 1994)$ based on the dates of the national census when new sets of DID maps were recorded (1960, 1965, 1970, 1975, 1980, 1985, 1990, and 1995). A template of existing DID areas and rail stations at the beginning of each 5 year period was created, and new projects initiated during the subsequent 5 years were mapped. Once the templates had been set up as a GIS database it was a relatively simple matter to automate

\footnotetext{
${ }^{5}$ Therefore, the Index \# $=[(1 \mathrm{~A} * 1)+(1 \mathrm{~B} * 2)+(2 \mathrm{~A} * 2)+(1 \mathrm{C} * 3)+(2 \mathrm{~B} * 3)+(3 \mathrm{~A} * 3)+(2 \mathrm{C} * 4)+(3 \mathrm{~B} * 4)+$ $(3 \mathrm{C} * 5)] /(1 \mathrm{~A}+2 \mathrm{~A}+3 \mathrm{~A}+1 \mathrm{~B}+2 \mathrm{~B}+3 \mathrm{~B}+1 \mathrm{C}+2 \mathrm{C}+3 \mathrm{C})$
} 
the classification of each project into one of the nine categories, and tabulate the results.

Various ways of determining a walkable distance to the rail stations were considered. For example real estate advertisements in Japan invariably describe the walking distance to the nearest train or subway station in minutes, with a walk of less than 10 minutes considered essential for marketability and closer to 5 minutes clearly preferred. A limit of the distance considered walkable could have been derived from a survey of these ads. In the end the maximum acceptable distance was considered to be revealed by the actual locations of train stations. That is, the maximum walking distance is set at half the average distance between stations. In the case of Saitama the total length of rail lines (excluding inter city Shinkansen lines) in the study area is $416.01 \mathrm{~km}$, while the total number of stations is 148 . The average distance between stations is thus $2.81 \mathrm{~km}$, which halved indicates a market preference for access to rail stations of no more than $1.4 \mathrm{~km}$, or within 15 to 20 minutes walking time $(17$ minutes at $5 \mathrm{~km} / \mathrm{h})$ which seems reasonable. If we consider that in the outer parts of the urban area the distances between stations is considerably greater this revealed preference for accessibility of stations probably overestimates the actual case. In fact the spacing between stations on the private commuter lines is considerably closer, less than 1 $\mathrm{km}$ in populated stretches. On the other hand, the actual distance which people are willing to travel to a station on a daily basis may be considerably farther, for example, for those using a bicycle, being delivered by car, or taking a bus to the station. Thus, the figure of $1.4 \mathrm{~km}$ seems reasonable.

\subsubsection{Results of the categorisation}

Maps of projects, DID areas and rail facilities in each period are not reproduced here for space reasons (see Sorensen, 1998, pp. 289-296). However, the resulting data tables from which the following charts were created are included as Table 9. Here I simply examine the charts and index numbers.

Fig. 7 charts the total area of new projects initiated in each category during each of the seven time periods from 1960-64 to 1990-94. In the left chart categories are stacked so the top line of category $3 \mathrm{C}$ shows the total area of all projects initiated in each 5 year period. In the right half, the percentage share of each category is graphed. As is clear from the chart the overall area of new projects initiated was fairly steady at between 1500 and 2000 ha of projects in each five year period except for the period 1970-74 (the 'Building a New Japan' boom) and the period 1985-89 (the 'Bubble Economy' boom). The composition of area of different categories of projects shifts significantly over the period. While in the 1970-74 period the greatest increase in share is in 1C (station centred scatteration) projects reflecting the development of scattered new urban areas based on new stations on both new and existing rail lines, in the latter boom of 1985-89 the largest area is in projects of type 3A (automobile oriented redevelopment), 3B (automobile oriented expansion) and 3C (automobile oriented scatteration), reflecting the spread of development farther away from rail stations and perhaps increased car ownership and better roads. 
Table 9

LR Project Area by actor, category ${ }^{\mathrm{a}}$

\begin{tabular}{|c|c|c|c|c|c|c|c|c|c|c|}
\hline Private area $\left(\mathrm{km}^{2}\right)$ & $1 \mathrm{~A}$ & 1B & $1 \mathrm{C}$ & $2 \mathrm{~A}$ & $2 \mathrm{~B}$ & $2 \mathrm{C}$ & $3 \mathrm{~A}$ & $3 \mathrm{~B}$ & $3 \mathrm{C}$ & Total \\
\hline \multicolumn{11}{|c|}{ LR projects } \\
\hline $1960-64$ & 0.0 & 15.8 & 0.0 & 0.0 & 0.0 & 55.5 & 0.0 & 110.0 & 9.6 & 190.9 \\
\hline $1965-69$ & 0.0 & 107.3 & 6.8 & 0.0 & 96.0 & 40.5 & 34.0 & 17.2 & 38.9 & 340.7 \\
\hline $1970-74$ & 0.0 & 99.8 & 8.7 & 12.0 & 399.8 & 132.6 & 17.9 & 0.0 & 140.5 & 811.3 \\
\hline 1975-79 & 0.0 & 0.0 & 9.0 & 24.4 & 176.2 & 117.5 & 0.0 & 35.9 & 50.0 & 413.0 \\
\hline 1980-84 & 1.9 & 18.3 & 78.0 & 66.4 & 86.5 & 32.9 & 62.8 & 33.6 & 255.8 & 636.2 \\
\hline $1985-89$ & 4.0 & 72.6 & 22.3 & 82.8 & 75.3 & 9.6 & 13.8 & 349.8 & 211.6 & 841.3 \\
\hline 1990-94 & 18.3 & 0.0 & 0.0 & 325.0 & 146.9 & 135.0 & 225.1 & 49.7 & 132.4 & 1032.4 \\
\hline Public area $\left(\mathrm{km}^{2}\right)$ & $1 \mathrm{~A}$ & 1B & $1 \mathrm{C}$ & $2 \mathrm{~A}$ & $2 \mathrm{~B}$ & $2 \mathrm{C}$ & $3 \mathrm{~A}$ & 3B & $3 \mathrm{C}$ & Total \\
\hline $1960-64$ & 36.6 & 202.7 & 542.7 & 89.8 & 100.0 & 233.0 & 0.0 & 183.0 & 105.6 & 1492.9 \\
\hline 1965-69 & 6.9 & 275.8 & 126.7 & 73.6 & 239.9 & 224.6 & 80.5 & 53.2 & 278.1 & 1359.3 \\
\hline $1970-74$ & 106.6 & 245.3 & 1380.0 & 174.4 & 554.2 & 390.4 & 121.2 & 364.0 & 247.8 & 3736.9 \\
\hline $1975-79$ & 0.0 & 24.9 & 212.1 & 25.2 & 417.8 & 45.3 & 174.3 & 150.6 & 425.0 & 1475.2 \\
\hline $1980-84$ & 55.1 & 0.0 & 250.2 & 197.9 & 139.3 & 104.7 & 238.8 & 0.0 & 35.3 & 1021.3 \\
\hline 1985-89 & 416.0 & 121.1 & 418.8 & 204.7 & 182.5 & 30.1 & 206.3 & 269.8 & 222.0 & 2071.3 \\
\hline 1990-94 & 48.7 & 41.4 & 70.8 & 137.6 & 152.4 & 0.0 & 0.0 & 0.0 & 281.5 & 732.4 \\
\hline Total & $1 \mathrm{~A}$ & $1 \mathrm{~B}$ & $1 \mathrm{C}$ & $2 \mathrm{~A}$ & $2 \mathrm{~B}$ & $2 \mathrm{C}$ & $3 \mathrm{~A}$ & $3 \mathrm{~B}$ & $3 \mathrm{C}$ & Total \\
\hline 1960-64 & 36.6 & 218.5 & 542.2 & 89.8 & 100.0 & 288.5 & 0.0 & 293.0 & 115.2 & 1683.8 \\
\hline $1965-69$ & 6.9 & 383.1 & 133.5 & 73.6 & 335.9 & 265.1 & 114.5 & 70.4 & 617.0 & 2000.0 \\
\hline $1970-74$ & 106.6 & 345.1 & 1388.7 & 186.4 & 954.0 & 523.0 & 139.1 & 364.0 & 568.3 & 4575.2 \\
\hline $1975-79$ & 0.0 & 24.9 & 221.1 & 49.6 & 594.0 & 162.8 & 174.3 & 186.5 & 475.0 & 1888.2 \\
\hline $1980-84$ & 57.0 & 18.3 & 328.2 & 264.3 & 255.8 & 137.6 & 301.6 & 33.6 & 291.1 & 1657.5 \\
\hline 1985-89 & 420.0 & 193.7 & 441.1 & 287.5 & 257.8 & 39.7 & 221.1 & 619.1 & 433.6 & 2913.6 \\
\hline 1990-94 & 67.0 & 41.4 & 70.8 & 462.6 & 299.3 & 135.0 & 255.1 & 49.7 & 414.0 & 1764.9 \\
\hline Private area $\left(\mathrm{km}^{2}\right)$ & $1 \mathrm{~A}$ & 1B & $1 \mathrm{C}$ & $2 \mathrm{~A}$ & $2 \mathrm{~B}$ & $2 \mathrm{C}$ & $3 \mathrm{~A}$ & $3 \mathrm{~B}$ & $3 \mathrm{C}$ & Total \\
\hline \multicolumn{11}{|c|}{ YTS projects } \\
\hline $1975-79$ & 0.0 & 0.0 & 0.0 & 0.0 & 8.0 & 0.0 & 0.0 & 0.0 & 0.0 & 8.0 \\
\hline $1980-84$ & 0.0 & 0.0 & 46.6 & 0.0 & 54.0 & 0.0 & 0.0 & 0.0 & 141.7 & 242.3 \\
\hline $1985-89$ & 4.0 & 0.0 & 0.0 & 0.0 & 75.3 & 9.6 & 0.0 & 24.9 & 104.6 & 218.4 \\
\hline 1990-94 & 0.0 & 0.0 & 0.0 & 33.1 & 55.6 & 135.0 & 0.0 & 33.8 & 33.7 & 291.2 \\
\hline Public area $\left(\mathrm{km}^{2}\right)$ & $1 \mathrm{~A}$ & 1B & $1 \mathrm{C}$ & $2 \mathrm{~A}$ & $2 \mathrm{~B}$ & $2 \mathrm{C}$ & $3 \mathrm{~A}$ & 3B & $3 \mathrm{C}$ & Total \\
\hline $1975-79$ & 0.0 & 0.0 & 118.3 & 0.0 & 0.0 & 0.0 & 0.0 & 0.0 & 111.2 & 229.5 \\
\hline $1980-84$ & 0.0 & 0.0 & 209.9 & 0.0 & 69.8 & 104.7 & 0.0 & 0.0 & 35.3 & 419.7 \\
\hline $1985-89$ & 298.7 & 0.0 & 120.1 & 0.0 & 182.5 & 30.1 & 0.0 & 41.2 & 222.0 & 894.6 \\
\hline 1990-94 & 0.0 & 41.4 & 0.0 & 0.0 & 0.0 & 0.0 & 0.0 & 0.0 & 238.7 & 280.1 \\
\hline Total & $1 \mathrm{~A}$ & 1B & $1 \mathrm{C}$ & $2 \mathrm{~A}$ & $2 \mathrm{~B}$ & $2 \mathrm{~B}$ & $3 \mathrm{~A}$ & $3 \mathrm{~B}$ & $3 C$ & Total \\
\hline $1975-79$ & 0.0 & 0.0 & 118.3 & 0.0 & 8.0 & 0.0 & 0.0 & 0.0 & 111.2 & 237.5 \\
\hline $1980-84$ & 0.0 & 0.0 & 256.5 & 0.0 & 123.8 & 104.7 & 0.0 & 0.0 & 177.0 & 662.0 \\
\hline 1985-89 & 302.7 & 0.0 & 120.1 & 0.0 & 257.8 & 39.7 & & 66.1 & 326.6 & 1113.0 \\
\hline 1990-94 & 0.0 & 41.4 & 0.0 & 33.1 & 55.6 & 135.0 & 0.0 & 33.8 & 272.4 & 571.3 \\
\hline
\end{tabular}

${ }^{\mathrm{a}}$ Source: Calculated from GIS mapping. 
Plotting the percentage share of each category makes somewhat clearer the changes in the relative share of the total area of each category over the period. While there are clearly substantial variations between periods in the mix of categories, some general trends can be discerned. First, there appears to be a shift from locations close to stations to locations farther away from stations. The total share of $3 \mathrm{~A}, 3 \mathrm{~B}$ and $3 \mathrm{C}$ (automobile dependent) appear to increase from a share of about $20 \%$ of the whole project area in 1960-64 to around a $40 \%$ share after 1975. The largest loss of share is by $1 \mathrm{~B}$ and 1C (station centred) which start with over 40 per cent of the whole area and decline to less than $10 \%$. Second, shares of 1A (station centred redevelopment), 2A (station walkable redevelopment) and $3 \mathrm{~A}$ (automobile dependent redevelopment) appear to increase markedly over the period. To make these trends more visible categories are aggregated based on relationship to rail stations and DID areas in Fig. 8.

Fig. 8 shows more clearly the trends described above. As suggested, the share of projects outside walking distance from stations increased while the share of projects including or adjacent to railway stations decreased. A simple explanation for these trends is that over time the easiest locations in which to develop new stations or redevelop areas fronting a station have already been developed, so there is less development of projects adjacent to stations in later years. The increase in the share of projects outside walking distance is significant, however, in that the strongly rail-centred development pattern of the 1960s is changing to one with a greater number of projects further from rail stations.

The obvious explanation for the increasing share of projects within the existing DID area seen in Fig. 8 is that the DID area expanded to such an extent over the previous 20 years that it was much more likely that projects would be initiated within the large DID area of the 1980s than in the relatively small DID area of

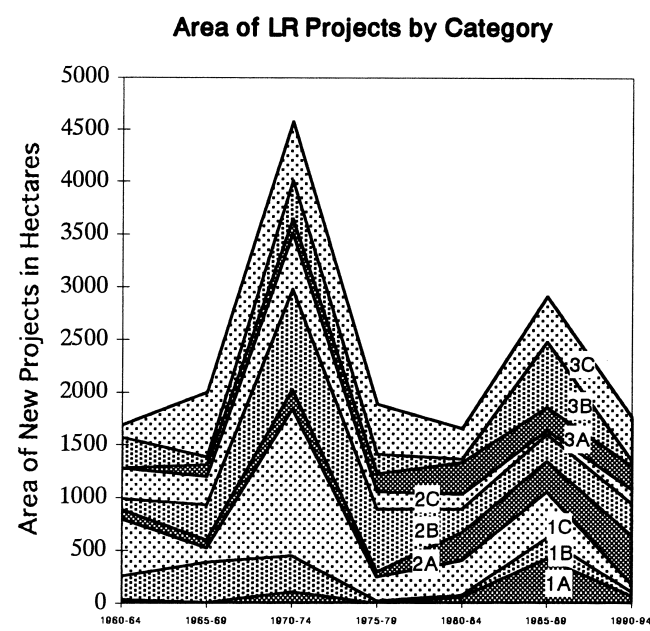

Share of Total LR Project Area by Category

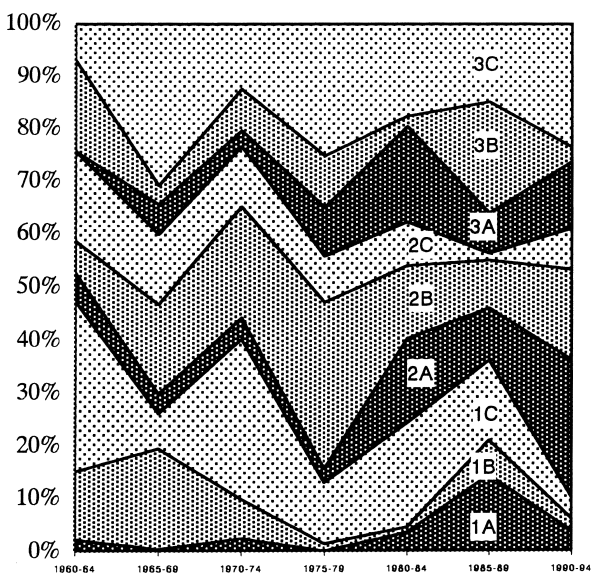

Fig. 7. Area of LR projects by category. 
the 1960s. Another factor is probably significant, however, and would explain the sudden increase in share during the period 1980-84. This is shortly after the introduction of the new ZGS policy of threatening the downzoning of UPA areas where LR projects were not implemented. A brief look at the areas involved confirms that this is probably an important factor. While the area of $1 \mathrm{~A}, 2 \mathrm{~A}$ and $3 \mathrm{~A}$ combined averaged some 244 ha in each of the four earlier five-year periods, in the last three periods the average was 768 ha, totalling 1550 ha between 1980 and 1989, and 2305 ha between 1980 and 1994. It is safe to say that most of these new projects initiated within the existing DID areas were a result of the ZGS policy which itself resulted in roughly 2800 ha of new projects within UPA areas during the period 1982-1990. This large area of ZGS projects is significant because they were mostly projects in locations which were clearly likely to prevent sprawl development, and they accounted for between a third and a half of all projects initiated between 1980 and 1994. Clearly the successful use of the ZGS policy seems to have encouraged LR projects in locations that prevent urban sprawl. It thus seems fair to suggest that there was a secular trend towards greater sprawl in LR projects, which was offset by the ZGS policy during the 1980s. Unfortunately it is not possible to distinguish reliably between projects which were a result of ZTS and which were not in order to isolate the effect of the policy in the way possible with the YTS policy analysed below. In any case, as noted above, the ZGS policy has been discontinued, while the YTS policy continues as the main prefectural policy to promote LR projects.
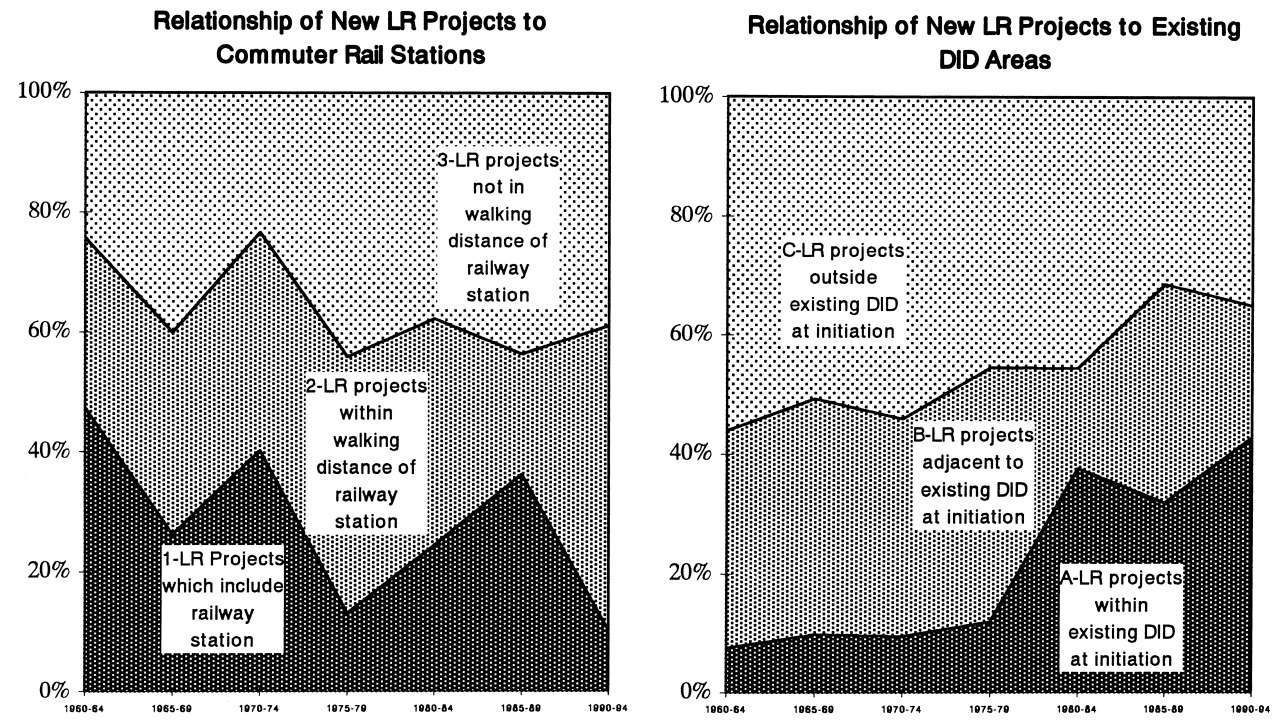

Fig. 8. Relationship of new LR projects to commuter rail stations and existing DID area. 
These two major trends seen in Fig. 8 are contradictory in terms of the analytic framework outlined in Table 7. While the increase of project share outside walking distance from rail stations indicates an increasing tendency towards sprawl inducing locations, the shift towards more projects within existing DID areas suggests a greater area of projects in sprawl preventing locations. This is reflected in the index of All Projects shown in Table 10, which, while generally indicating a pro-sprawl tendency, shows neither an increase or decrease in that tendency.

The index numbers shown in Table 10 indicate that overall the mix of projects is somewhat biased towards categories that are likely to promote sprawl. The values are consistently higher than 3.0 (averaging 3.30), although perhaps not very significantly so. Although the index numbers indicate that the overall mix of project locations has consistently been pro-sprawl, it would be unwise to draw any firm conclusions from this. The index numbers will be most useful in the comparison of the different sub-groups of projects below.

In Fig. 9, the composition of projects initiated by private sector initiators (Associations and Individuals), is compared with that of public sector bodies (Local Governments and Central Government agencies). It is important to note that the area of projects initiated by public sector actors is much greater than that by private sector actors until the 1980s. Thus at the peak of LR project initiation in the 1970-74 period public actors initiated some four times the area of projects than private sector initiators. However, in the beginning of the 1980s, the area of private sector projects increased, while the area of public sector projects decreased. In the final period 1990-94, the area of private projects was larger than that of public projects for the first time. The reasons behind this shift and its overall significance are discussed further in Chapter 3.

The first point suggested by Table 9 is that the locational patterns of public and private sector projects are quite different, with private sector projects showing a much greater tendency towards sprawl-promoting locations. Between 1975 and 1990 over half of the total area of private projects are in sprawl promoting locations. Although it is interesting that the 'car based' category (3A, 3B, 3C) peaks in the 1980s, and during the 1990s there is a large area of 'station walkable' (2A, 2B, 2C), as reflected in the much lower index number of the 1990-94 period.

Overall, private projects are clearly more likely to be in sprawl promoting locations than public projects. The index numbers of private and public projects

Table 10

Index numbers of All projects, Public, and Private

\begin{tabular}{lllllllll}
\hline & $1960-64$ & $1965-69$ & $1970-74$ & $1975-79$ & $1980-84$ & $1985-89$ & $1990-94$ & Average $^{\mathrm{a}}$ \\
\hline All projects & 3.26 & 3.55 & 3.28 & 3.65 & 3.22 & 3.07 & 3.21 & 3.30 \\
Private projects & 3.88 & 3.08 & 3.37 & 3.55 & 3.77 & 3.74 & 3.09 & 3.45 \\
Public projects & 3.18 & 3.35 & 3.26 & 3.68 & 2.87 & 2.80 & 3.39 & 3.20 \\
\hline
\end{tabular}

${ }^{\mathrm{a}}$ Note: all index averages are weighted by the relative area in each period. 
shown in Table 10 show that those of projects initiated by private actors are higher than those of publicly initiated projects, averaging 3.45 compared to 3.20 for public projects and 3.30 for all projects, showing a significantly more sprawlbiased mix of projects than public projects. This bias can be at least partly explained by the fact that initiators of private sector projects must gain the consent of most or all of the landowners in the project area before initiating a project, so it will be much easier to start projects in areas that are less built up as there are simply less landowners to consult. The incentive to join projects may also be greater in more remote locations, as it is likely to be more difficult to individually develop land in locations farther from existing development. Privately initiated projects thus appear to be significantly more likely to be in sprawl promoting locations than public projects, as was hypothesised. This fact may well become more significant in future as greater areas of private projects have been initiated than public ones in recent years.

Fig. 9 also shows a consistently greater mix of locations by public sector actors than by private sector actors. This can be explained by the fact that because public sector actors can subsidise projects they are able to initiate projects in locations that would not be financially viable for private actors. It is thus much more likely that a public sector project will be started in an area already significantly built up, as there is not legal requirement to gain the consent of a majority of landowners in the project area, and such projects tend to be much more expensive because of the number of buildings which must be moved or demolished and replaced. In this regard it is notable that in Table 10 public projects during the two periods from 1980-89 have index numbers below 3, the first example of such a low index number.
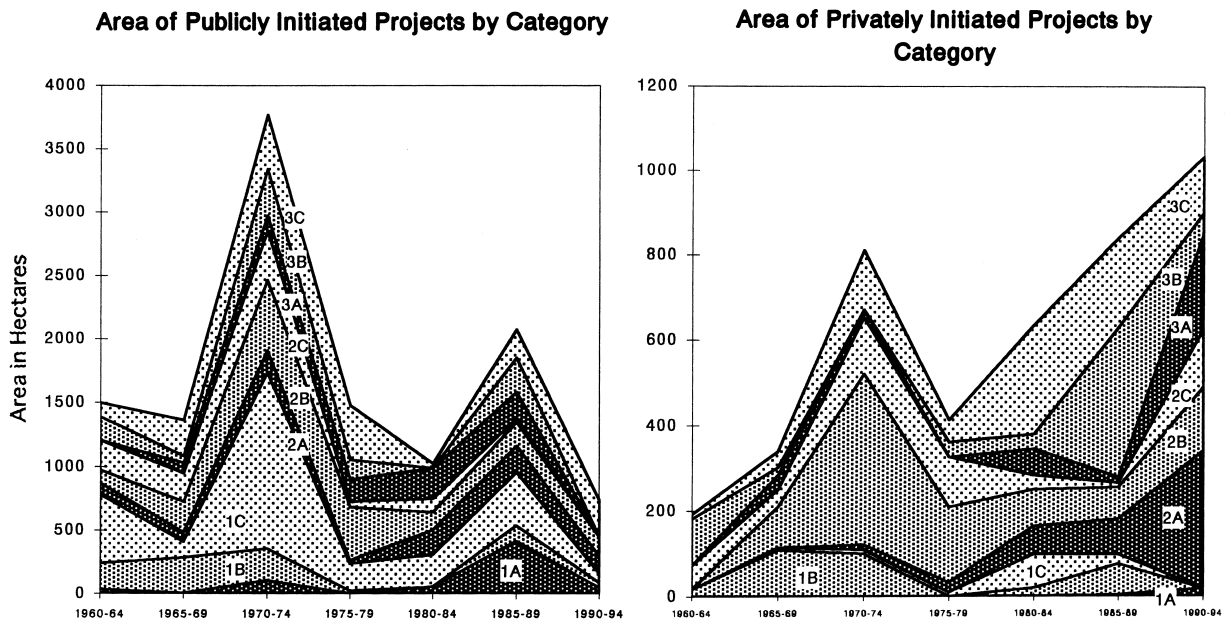

Fig. 9. Area of privately and publicly initiated projects by category. 


\subsubsection{YTS projects}

The other important subgroup of projects to examine is that which was a result of the YTS policy of encouraging LR projects by granting an upzoning from UCA to UPA. Apart from the fact that the UPA area is being enlarged, it has been suggested that this policy will be highly likely to encourage LR projects in locations that will increase scatteration of residential development. Fig. 10 shows all YTS projects initiated up to 1994 mapped on to the 1995 DID area with railroads, rail stations and the $1.4 \mathrm{~km}$ radius walkable area indicated. It is striking how many projects are adjacent to a station or within walking distance of a station, even in this group which by definition are located in areas which were UCA before project initiation.

There are also, however, many large projects that are both well outside DID areas and outside walking distance from stations. As seen in the map these projects are also in areas furthest away from central Tokyo. Total travel times to central Tokyo for those projects outside the $50 \mathrm{~km}$ range including the trip to the

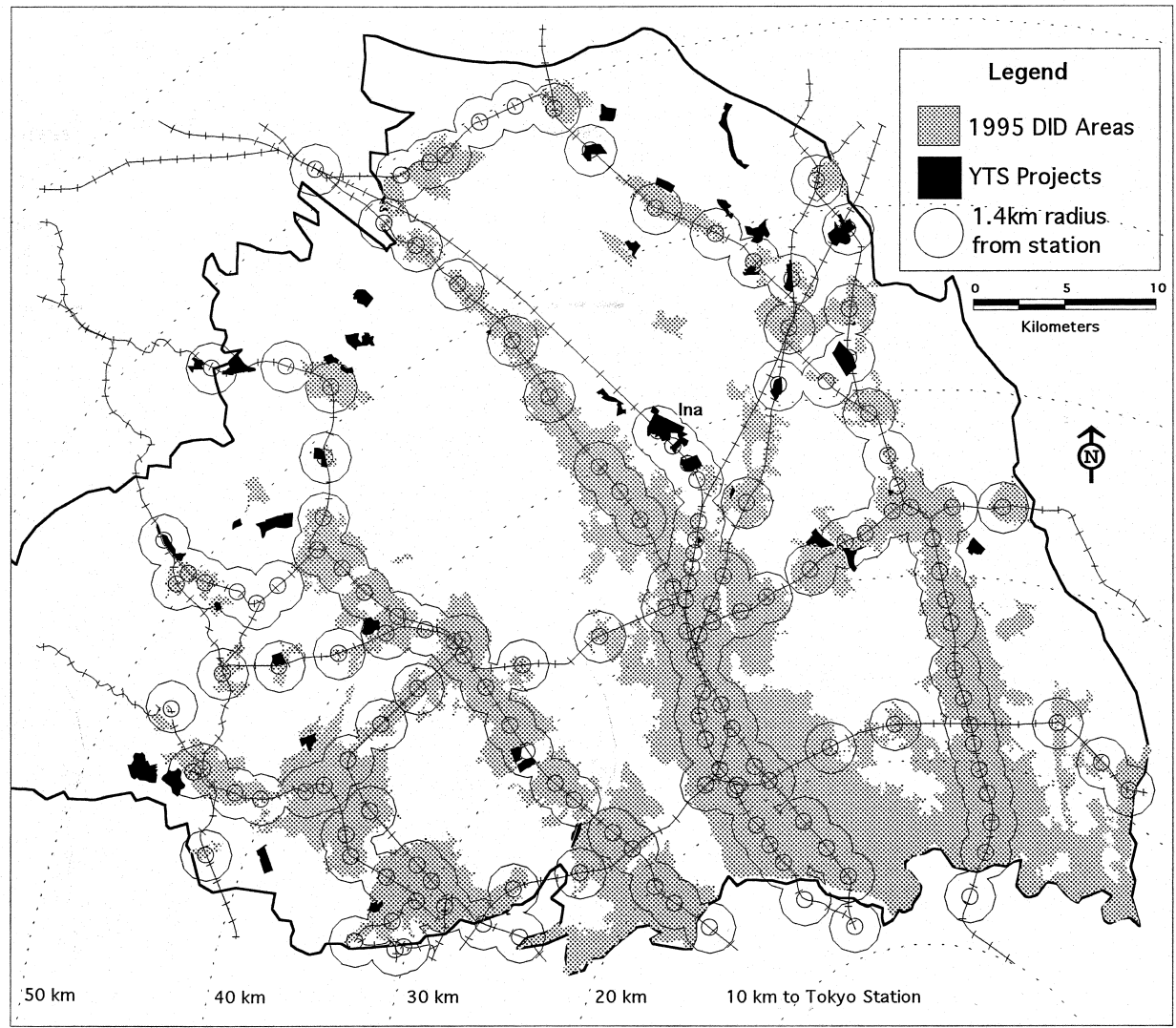

Fig. 10. All YTS projects and 1995 DID areas. 
Table 11

Index number of YTS projects

\begin{tabular}{llllll}
\hline & $1975-79$ & $1980-84$ & $1985-89$ & $1990-94$ & Average \\
\hline All YTS & 3.94 & 3.69 & 3.14 & 4.12 & 3.57 \\
Private YTS & 3.00 & 4.17 & 4.08 & 3.70 & 3.95 \\
Public YTS & 3.97 & 3.42 & 2.91 & 4.56 & 3.41 \\
\hline
\end{tabular}

station by bus or car will be long, in the 1.5-2.5 h range each way. Many of these large projects are also entirely separate from any existing settlement as represented by DID. It is precisely these $3 \mathrm{C}$ type projects which will do most to increase scatteration of residential development in Saitama. The $3 \mathrm{C}$ projects are consistently about a third of the area of YTS projects. The result is the highest average index levels yet, averaging 3.57 as shown in Table $11 .{ }^{6}$

It is worth noting that while the overall areas of land developed are still large, because this is a small subgroup of all LR projects, individual projects make more of a difference. Thus, a very large area of 1A projects in the years 1985-89 is accounted for by two projects, both in Ina village (indicated in Fig. 10). These two projects, virtually a new town in themselves totalling 299 ha, were developed by the prefectural and local governments as a part of the agreement which also produced the 'New Shuttle' under the shinkansen tracks mentioned above. What had been a small farming village has been transformed by a timely protest movement and a major investment of public funds into one of the fastest growing settlements in the TMR, with excellent access to Omiya and Tokyo. While this is clearly good urban form according to our criterion, the relationship of costs to benefits is unknown, and it is a good example of the sort of political use of national railway construction projects that eventually led to the privatisation of the JNR and the assumption of several trillion yen of its debt by the national government.

Fig. 11 shows that, as with LR projects generally, among YTS projects there are significant differences in locational patterns between those initiated by private and public initiators. Privately initiated YTS projects are virtually all in locations considered likely to promote sprawl, whereas publicly initiated projects can be seen to have a much greater mix of location types. While private index scores are the highest of any yet seen, the publicly initiated YTS projects also have higher than average scores, indicating that YTS projects generally can be considered sprawl promoting, according to our definition. The only exception to the high

\footnotetext{
${ }^{6}$ It should be noted that the average of index values for YTS projects is not quite comparable to the earlier averages as the YTS index values are averaged over only the last four periods. Recalculating average index values for only the last four periods in the other cases yields essentially the same result however, with the average of All Projects being 3.26, Private Projects being 3.49, and Public Projects being 3.14 .
} 
index scores is that of public projects in 1985-89, which was a result of the large projects in Ina village discussed above.

Overall it can be said that YTS projects, both public and private, are as expected significantly more likely than other groups of projects to be in sprawl promoting locations. This is significant because by 1994 a total of 2584 ha of YTS projects had been started, a very large area of new urban development which will continue to affect urban development patterns for many years. It is also important because the YTS policy continues to be the main method used by the prefectural government to encourage new LR projects.

\subsection{Conclusions}

In conclusion it seems clearly wrong, on the evidence for Saitama presented here, to suggest that LR projects necessarily create sprawl at the metropolitan level. In fact, some $54 \%$ of all projects are in locations that do not seem likely to promote sprawl or will help to prevent it. A major factor behind this appears to have been the ZGS policy described above which aggressively promoted the use of LR projects to develop the existing UPA area during the 1980s. As seen in Fig. 5 the expansion of DID areas has largely been constrained to the UPA area, which follows the radial rail corridors, producing what is a rather desirable urban form by reference to the criteria outlined above. Thus the high priority given to proximity to rail stations in residential location decisions seems to have been a very powerful factor in shaping urban form. The large areas of LR that have been developed near new or existing rail stations and within existing DID areas seem certain to have contributed positively to the development of the UPA areas. The fact that during the thirty five year study period over 40 new rail stations have been developed in the Saitama Suburban Development Area has certainly
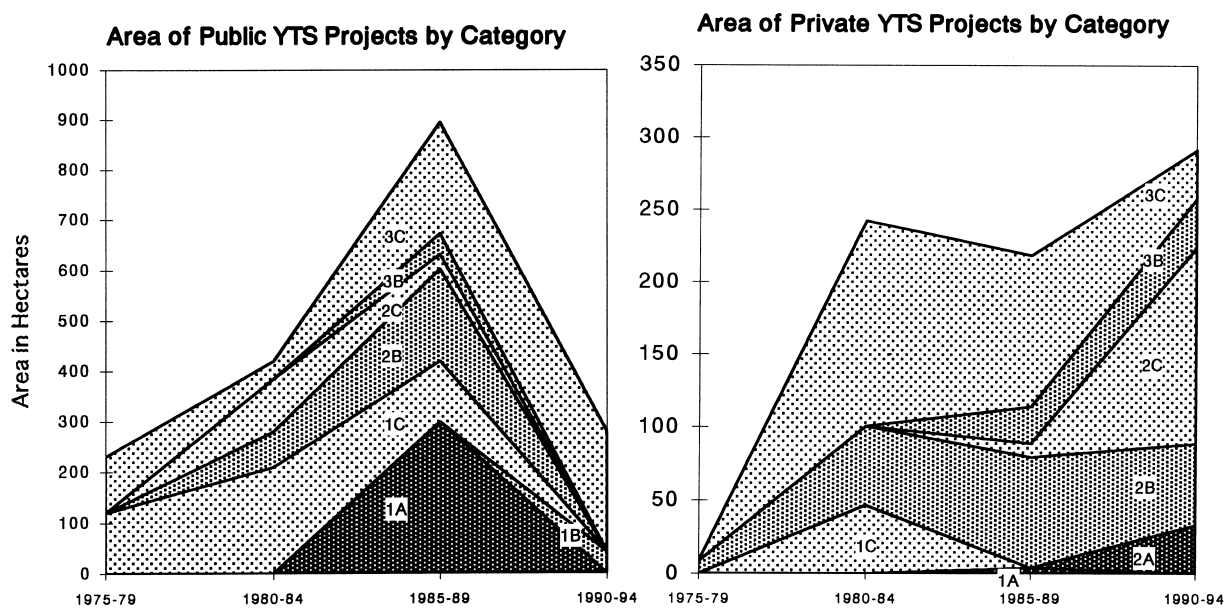

Fig. 11. Area of private and public YTS projects by category. 
contributed to the fact that a large proportion of the new LR projects were in station centred, non-sprawl locations. The majority of the new stations were developed by the Japan National Railway company as part of the new Musashino orbital rail line in the 1970s and the Tohoku and Joetsu Shinkansen lines in the 1980s (including the new shuttle service for local commuters), and many of the new stations were developed in conjunction with LR projects.

What also seems clear, however, is that a large number of projects, some $44 \%$ of the total, have been in locations which clearly seem to promote an extensive, scattered urban settlement pattern, or sprawl. From 1980 to 1994, for example, there were some 1500 ha of new projects started in $3 \mathrm{C}$ type locations. Thus there have been large areas of new development in places where urban development should probably have been prevented, and which would probably have remained undeveloped without the projects. These projects are important because they will have effects on the location of new residential development for many years to come. This pattern of development, it has been argued, will result in higher infrastructure costs, and greater reliance on private automobiles for daily trips. The end of the ZGS method while YTS continues seems likely to promote sprawl in the long run.

Since the failure of the First NCRDP in the 1960s attempts to control this type of urban sprawl, termed metropolitan scale sprawl in Chapter 1, seem to have been abandoned by Japanese planners. There has been little appetite to attempt to shape or control the overall pattern of metropolitan growth, as is suggested by the fact that virtually the whole Kanto Plain is now designated either Existing Urban Area, Suburban Development Area or Urban Development Area. Instead planners pay much more attention to problems of sprawl at the local level, the basic issues of preventing disorderly unserviced development, of achieving rational road layouts, functional sewer systems, and accessible parks. Massive infrastructure deficits focussed attention on the immediate problems of trying to get basic infrastructure in place in areas which had already seen significant unplanned, unserviced urban development. Given the heavy costs of remedial measures to improve such areas, and the enormous areas that have been so developed in the post-war period, such a concern is understandable and perhaps justified. However, in the longer term, and metropolitan scale planning is always primarily directed at the longer term, the cumulative effects of the large land areas developed with land readjustment in problematic locations are likely to be profound.

Although DID areas have largely been confined to the UPA areas, as has been argued above DID designation does not mean that an area is fully built up, nor does it give any indication of the nature of the urbanisation which has occurred. To gain some understanding of the relationship between LR projects and urbanisation at the local scale a different level of analysis is required. That is the subject of the next chapter. 


\section{CHAPTER 3}

\section{Local planning, land development and land readjustment}

The goal of this chapter is to gain a better understanding of the relationship between LR, land development and urban sprawl at the local level. It is at the local level that LR projects have been expected to play a key role in the provision of the basic urban infrastructure which is of paramount importance in preventing the sort of unregulated, unserviced sprawl development that so plagued Japanese metropolitan areas in the rapid growth period. This section thus examines the relationship of LR and urban development in greater detail than was possible in Chapter 2.

This analysis will also permit the testing of a number of explicit and implicit assumptions in the analysis of Chapter 2. Perhaps most important of these assumptions is that the increasing proportion of projects begun by private initiators (associations and individuals) is likely to have important long-term impacts on locational patterns of LR projects. The underlying assumption is that there is a significant and increasing role for private decision makers in location decision making because privately initiated projects form an increasing share of the total area of new projects, and are more likely to be in sprawl promoting locations. It was also assumed that such projects were significantly less constrained by local or regional planning policy and might, therefore, be expected to result in the greater scatteration of future LR projects. The basic question that needs to be addressed here is what are in practice the most important factors determining the location of new LR projects, whether public or private. Which actors are involved in the decision making processes which result in new LR projects? How do organisational factors affect where projects are located, where they are not located, and why? These questions are addressed in Section 3.2.

Also important is the assumption that the location of LR projects does indeed affect subsequent patterns of urban growth and development. This may seem a safe assumption, but it is in fact not at all clear. As discussed in Chapter 1, LR projects are notorious for the slowness with which land is actually built up, with extensive areas remaining in active agricultural use long after projects are completed. Further, delays in development resulting from long project development times may have significant impacts on overall patterns of growth. If the long term rate of conversion from agricultural use to urban use within LR areas is the same as that in non LR areas then projects could be said to have little impact on the location of new built development, resulting simply in the provision of infrastructure. If project areas saw less conversion from agricultural use to urban use than comparable non LR areas, then it could be concluded that LR has a perverse effect on the pattern of development by pushing development into non LR areas. Clearly that would make any broad generalisations about LR impacts on patterns of urban growth extremely difficult. If LR project areas are actually built up more quickly than comparable 
areas, then they will have a direct positive impact on the location of new development, and the patterns of location of new projects discussed in the previous section will have significant impacts on long term patterns of growth. These issues are examined in Section 3.3.

The third big assumption is that eventual patterns and quality of development are significantly different within LR projects than without. It is, however, possible that in areas outside LR projects other planning policies, projects, or frameworks result in the long run in fundamentally similar results in terms of the provision of basic infrastructure such as roads parks, sewerage, etc. as in LR areas. An analysis of the urban areas developed with LR compared to comparable non LR areas is undertaken in Section 3.4.

Section 3.1 begins with a brief description of the case study cities, their location, growth rates, and use of LR. The case study areas within each city are first identified and the basis of their selection described.

\subsection{The case study cities and case study areas}

The criteria for the selection of Urawa, Omiya and Ageo in the central rail corridor as the case study cities were as follows. Potential case study cities were those which had started four or more new LR projects of over 10 ha between 1985 and 1994. Of the eight possible cities, the three cities selected seemed best suited as they had a large number of projects begun over the previous 30 years, by the full range of possible initiators, Individual, Association, Local Government and Prefectural Government. The three cities also each had large areas of UPA outside the 1970 DID area which had become DID by 1995. This was the area where LR projects were intended to be the main vehicle for comprehensive planning and land development within the framework of the 1968 planning system. Within this area, however, the three cities had rather different patterns of LR development. Urawa had one large Local Government initiated project and a large number of small scattered Association projects. Omiya had a very large area of Local Government initiated projects and some smaller Association projects, while Ageo had a number of large Association projects and one smaller Local Government project. Each of the three cities also had large non LR areas which had urbanised during the previous 20 years which could serve as an area to compare with the LR areas.

Within each case study city a smaller area within which land and infrastructure development patterns could be studied more closely was chosen. With limited resources it was impossible to map the whole city area, and in any case areas within the pre-1970 DID area which is considered the 'existing urbanised area' in the Saitama City Planning Basic Survey (Saitama Prefecture, 1992), and outside the UPA area were not relevant to the present research. It was the area within the UPA, outside the 1970 DID area where it was expected that LR projects would make a major contribution to planned development within the framework of the 1968 City Planning Law. Case study areas within that area were selected which showed a rough balance between land developed through LR projects and land 


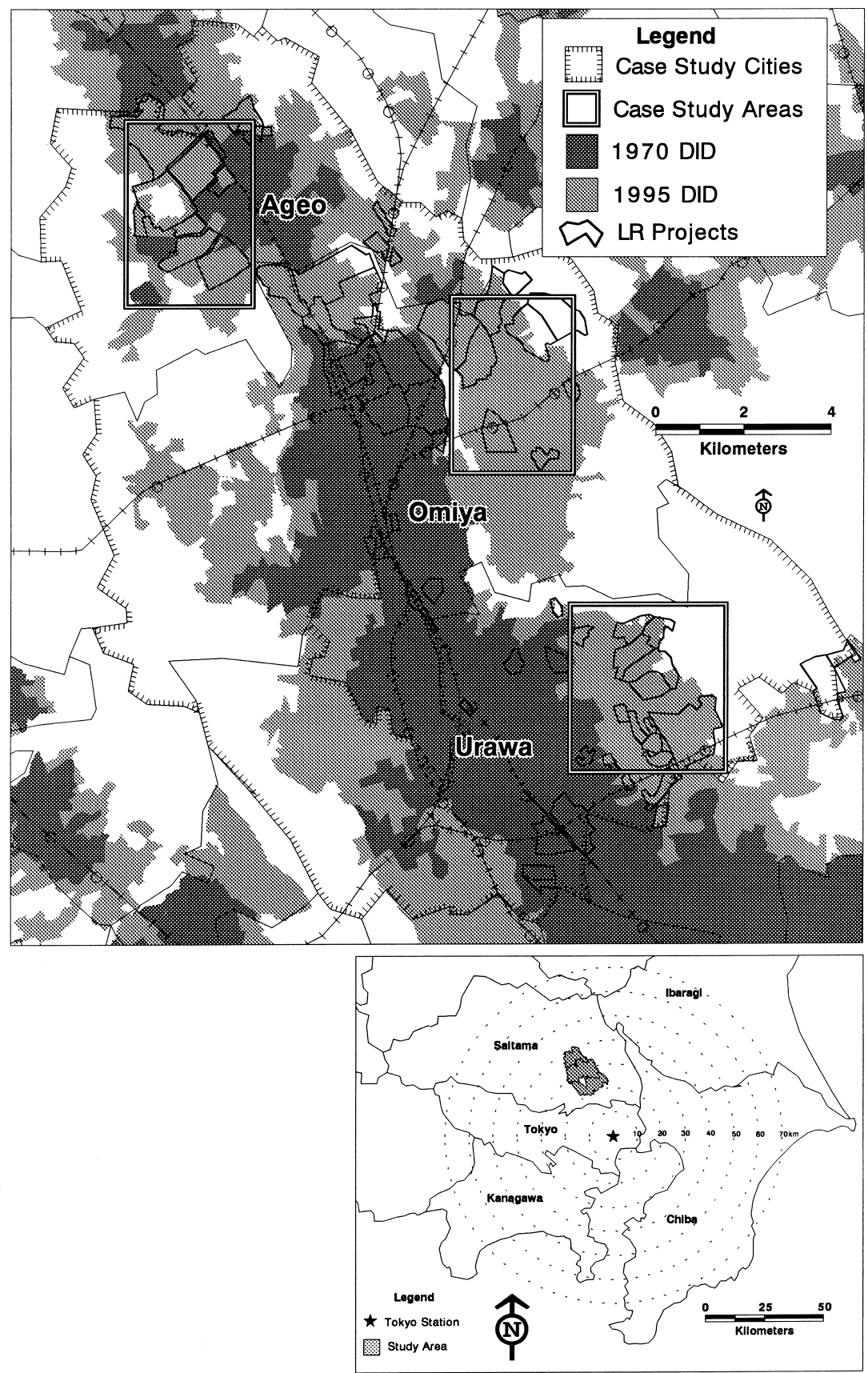

Fig. 12. Case study cities. 
not so developed, and which included LR and non LR areas that were roughly equally accessible to rail stations, although it was impossible to expect precisely comparable areas of non LR and LR.

As shown in Fig. 12 the three case study areas selected include UPA areas which were outside the 1970 DID and which became DID during the period 1970-1995. They are thus areas which experienced rapid population growth during the period under examination. Due to the linear nature of development in the case study cities, each city had two main urbanising areas, on the west and east sides of the rail corridor. In each city, the case study area is the area (defined below) with the largest number of LR projects, along with most of the rest of the undeveloped UPA area nearby.

In the case of Urawa, the case study area is bounded by UCA on the north and east sides, 1970 DID on the west, and is arbitrarily bordered on the south to include an area of just over 700 ha. The whole case study area was DID by 1995, and LR projects represent $43 \%$ of the area. The Omiya case study area is bounded on the east and west sides by UCA areas, on the north to include the large LR projects, and arbitrarily on the south to include over 700 ha. LR projects represent $33 \%$ of the Omiya case study area, all of which was DID in

Table 12

Selected characteristics of case study cities ${ }^{\mathrm{a}}$

\begin{tabular}{|c|c|c|c|}
\hline & Urawa & Omiya & Ageo \\
\hline Area (ha) & 7103 & 8938 & 4556 \\
\hline Population 1990 & 418,271 & 403,776 & 194,947 \\
\hline Gross density (persons/ha) & 59 & 45 & 43 \\
\hline \multicolumn{4}{|l|}{ Population increase (persons) $(\%)$} \\
\hline $1960-1970$ & $94,960(54 \%)$ & $98,781(58 \%)$ & $71,903(185 \%)$ \\
\hline $1970-1980$ & $88,788(33 \%)$ & $85,307(32 \%)$ & $55,451(50 \%)$ \\
\hline $1980-1990$ & $60,086(17 \%)$ & $49,692(14 \%)$ & $28,704(17 \%)$ \\
\hline DID area 1990 (ha) & 4260 & 4830 & 2290 \\
\hline DID population 1990 & 397,120 & 359,208 & 167,537 \\
\hline Gross density DID 1990 (persons/ha) & 93 & 74 & 73 \\
\hline \multicolumn{4}{|l|}{ Increase in area of DID (ha) $(\%)$} \\
\hline $1960-1970$ & $980(84 \%)$ & $880(69 \%)$ & $450(204 \%)$ \\
\hline $1970-1980$ & $1730(80 \%)$ & $2100(98 \%)$ & $1160(173 \%)$ \\
\hline $1980-1990$ & $380(10 \%)$ & $580(14 \%)$ & $460(25 \%)$ \\
\hline \multicolumn{4}{|l|}{ Day-time/night-time population ratio } \\
\hline 1970 & 87.80 & 90.10 & 83.00 \\
\hline 1980 & 89.50 & 92.50 & 86.00 \\
\hline 1990 & 86.00 & 95.50 & 80.80 \\
\hline$\%$ Commuting to Tokyo $(1990)^{\mathrm{b}}$ & $38 \%$ & $29 \%$ & $25 \%$ \\
\hline
\end{tabular}

a Source: Compiled from Population Census, various years.

${ }^{\mathrm{b}}$ Commuting population is defined as all those above age 15 who make daily trips either to school or work. It excludes trips for recreation or shopping. The percentage of all those in employment in each city who travel to Tokyo for work is higher than the figure given above. 
1995. The Ageo case study area is bounded on the west, south and north by the limit of the UPA in 1968 (thus the limit of the 1968 city planning maps which provided the baseline data on land use) and on the east by the JR Takasaki railway line and a vertical line drawn south from Ageo station. The Ageo area is also just over 700 ha in size and $52 \%$ of the area is LR project. Almost all of the area was DIDs by 1995 .

The case study areas are thus the area which became DID during the study period, which have the most intensive use of LR, in cities which were actively using LR. Therefore, they are not representative of urban development as a whole, but should allow a fair examination of the results of LR.

As shown in Table 12, all three case study cities experienced rapid population growth in the 1960s, slowing in the 1970s and 1980s, but with substantial net migration in to the cities continuing. In each case a large majority of the population lives in the DID area, which expanded rapidly in area during the 1960s and 70s, also slowing in the 1980s. Gross population densities in the DID areas range between 73 persons/ha in Ageo and 93 persons/ha in Urawa.

The day-time/night-time population ratios are all below the unity indicating that the cities all are primarily dormitory cities. However, Omiya's ratio has been rising steadily and the city is now approaching the point where it will attract as many commuters as it sends out. As discussed in the previous chapter, therefore, its role as a regional employment subcentre is increasing. The main destination for commuters from each of the case study cities is central Tokyo where about one third of the workforce of each of the cities works. It should be noted that the big

Table 13

Planning and development in the case study $\operatorname{cities}^{\mathrm{a}}$

\begin{tabular}{llll}
\hline & Urawa & Omiya & Ageo \\
\hline Total area (ha) 1990 & 7091 & 8891 & 4560 \\
UPA area (ha) 1990 & 4378 & 4761 & 2502 \\
UCA area (ha) 1990 & 2713 & 4130 & 2058 \\
LR projects (as of 1990) & & & \\
Currently being prepared No. & 14 & 13 & 18 \\
Currently being prepared area & 536.6 & 908.3 & 740.5 \\
Under way No. & 8 & 3 & 5 \\
Under way area & 368.5 & 145.7 & 250.3 \\
Completed No. & 6 & 7 & 9 \\
Completed area & 168.1 & 635.2 & 354.1 \\
1995 floor space per household (m ${ }^{2}$ ) & 70.7 & 77.7 & 77.1 \\
$1990 \%$ of dwellings fronting on substandard road (<4 m) & $32 \%$ & $34 \%$ & $34 \%$ \\
1990 completed and underway LR projects as $\%$ of DID & $15 \%$ & $25 \%$ & $26 \%$ \\
1990 city planning roads completion rate in UPA & $41 \%$ & $59 \%$ & $56 \%$ \\
1990 park area (m ${ }^{2} /$ person) & 5.8 & 2.9 & 3.8 \\
1990 sewerage diffusion rate $(\%$ of UPA served) & $81 \%$ & $27 \%$ & $41 \%$ \\
\hline
\end{tabular}

${ }^{\text {a }}$ Source: Saitama City Planning Basic Survey 1990, Population Census 1995. 
increases in DID area during the 1970s relative to the population growth of that decade are not the result of a larger use of land per person, but are rather the result of a threshold effect where large areas which were already partly developed passed the 40 persons per hectare threshold and became DID.

As seen in Table 13, in each of the case study cities the UPA area accounts for more than half the total area of the city. Major use has been made of LR projects in all three cities, with a large area of new projects currently being planned in each case. The projects completed or under way as of 1990 , however, were only $25 \%$ or less of the DID area. Houses are on average small, and about one third front onto narrow lanes where two cars would have difficulty passing.

All three case study cities have significant infrastructure shortfalls. Only about half of the planned arterial roads in each city were completed or under construction, while the percentage of UPA serviced with sewers ranged from a low of $27 \%$ in Omiya to $81 \%$ in Urawa. Park area per person is considerable, but this includes some very large parks in the UCA areas outside the populated UPA.

Another measure of the levels of infrastructure in the recently developed suburban fringe areas is shown in Table 14, which records the area developed in a planned manner in the three case study cities and Saitama prefecture as a whole. It shows that while Omiya is about one third planned development, about the same level as the prefecture as a whole, Urawa is significantly lower, at $16 \%$, while Ageo is significantly higher at $46 \%$. This data is from the Saitama City Planning Basic Survey, and relates to the area that became

Table 14

Planned development ${ }^{\mathrm{a}}$ in Saitama as of 1990 (\% of new DID 1965-85)

\begin{tabular}{|c|c|c|c|c|}
\hline & $\begin{array}{l}\text { Urban development } \\
\text { projects }^{\mathrm{c}}\end{array}$ & $\begin{array}{l}\text { Public land } \\
\text { developments }^{\mathrm{d}}\end{array}$ & $\begin{array}{l}\text { Development } \\
\text { permission }^{\mathrm{e}}\end{array}$ & Total \\
\hline Ageo City & 31.96 & 8.06 & 5.63 & 45.65 \\
\hline Omiya City & 27.22 & 3.56 & 3.81 & 34.59 \\
\hline Urawa City & 9.52 & 1.13 & 5.78 & 16.43 \\
\hline Saitama prefecture & 23.02 & 3.55 & 7.50 & 34.06 \\
\hline
\end{tabular}

${ }^{a}$ Men Seibi Ritsu. Men means area, while Ritsu means rate, or percentage. The Japanese word Seibi has no exact translation in English, and is variously translated as equipping, improve, consolidate, repair, preparation. Menseibiritsu in this context means areas that have been developed in a planned manner so that roads, sewers, and other public facilities have been provided during the process of development.

${ }^{\mathrm{b}}$ Source: Saitama City Planning Basic Survey, Table E-1, Saitama Ken: March, 1992.

${ }^{\mathrm{c}}$ This refers almost entirely to LR projects, both completed and in progress (also included are Saikaihatsu (redevelopment) projects, which are very small in total area).

${ }^{\mathrm{d}}$ Completed and in progress housing developments by the JHUDC, prefectural and city government housing departments.

${ }^{\mathrm{e}}$ Private developments issued permits under the development permission system. In all categories areas developed prior to 1965 are included. 
new DID between 1965 and 1985. The case study areas are a part of this area. The case studies below will help to determine the significance of these figures. Are these indeed the only areas which have been developed with basic urban infrastructure, as suggested by the City Planning Survey data, or is this merely a bureaucratic record of the fulfilment of certain planning initiatives?

It should be noted that the table shows all areas of planned development completed by 1990, including the large JHC housing estates, and the substantial areas of LR completed during the 1950s and 1960s. The table shows the relative importance of LR in area development, and the relatively small areas developed through the development permit system. It is unclear, however, what the nature of development has been in the balance of the newly urbanised areas. That is examined further below.

\subsection{LR project initiation and location decisions}

This section is based primarily on a series of semi structured interviews with officials in the City Planning and Land Readjustment departments of Saitama Prefecture, Urawa, Omiya and Ageo cities during 1995 and 1996. In all interviews were conducted with 27 officials on 12 occasions. In the interviews with local government planners a basic goal was to find out where the decisions are made about where projects are located, why projects are developed here and not there, and who is involved in the decision making process. As shown in Chapter 1, in the literature a strong distinction is drawn between privately initiated projects and publicly initiated projects. It is widely suggested that private projects are self-started and managed, whereas public projects are the work of the various levels of government and public bodies. It was thought important to answer a number of questions such as whether it is true that public projects are the responsibility of local governments, and private projects primarily that of small groups of public spirited and/or profit-oriented local landowners as suggested in the internationally oriented literature. Does national or prefectural planning policy play a role in project planning and location through the leverage of subsidies? Are there national or regional scale policies promoting or restricting the initiation of LR projects in certain locations or circumstances? All of these questions are important to understanding how LR projects have affected patterns of development, yet are not at all clear from a careful reading of the literature.

\subsubsection{The pre-eminent role of local government}

My interviews with local government staff made it quite clear that local governments planned and initiated virtually all LR projects, whether they were ultimately 'Association' or 'Local Government' managed. As shown below, even the decision of whether the project would be 'public' or 'private' is ultimately taken by local planners. In the three case study cities, out of a total of 66 LR projects, all but one small project had been designated, planned, and actively 
promoted by local government officers. ${ }^{7}$ Of those, only 18 were 'public' projects, of local, prefectural and national governments and agencies. The remaining 47 were 'Association' projects.

This is an important finding, and needs to be explored more fully. A closer examination of the process of planning, initiating and managing new projects will make clear the process of project initiation and the main factors which affect project location. There are three aspects which deserve greater attention; the process of project planning and initiation, the arrangements for project management after they are begun, and the role of 'Flexible Senbiki' in project planning and initiation.

Initiating LR projects, whether public or private requires a major investment of local government staff time and resources. The process is a classic example of the Japanese practice of nemawashi (literally root binding) or preparing the ground for group agreement through extensive prior consultation and persuasion. According to local government planners the normal time from the beginning of active work to start a project and its legal initiation is from 5 to 10 years. During this time three to five local government staff work full time holding public information meetings (Setsumeikai), talking to every landowner within the designated area, explaining the project, promoting the benefits of LR, and finally convincing each individual landowner to sign a legal document declaring their consent. Association projects can only legally be started after more than two thirds of the owners owning two thirds of the land have signed. In each of the case study cities the goal is $100 \%$ consent, although projects are normally started after $80 \%$ agreement is achieved.

If we consider that within a typical target project area of 50 ha there are from 1000 to 2000 residents, and 300 to 600 property owners, it can be appreciated that it is a challenging task to organise consent to an LR project. The project will take from 5 to 20 years to complete, during which time significant restrictions are placed on the rights of landowners to build new buildings. Further, during the project many households and businesses will be moved, and all property owners will have to contribute a portion of their land for public use and to pay project costs. While larger landowners are quick to appreciate the benefits of such development, it is apparently much more difficult to convince the owners of small houses on small housing plots that the scheme will benefit them. The main benefits of being able to connect to mains sewers, improved local roads and other community facilities such as parks have to be weighed against the loss of a portion of the land holding, and the years of disruption during the project. According to planners involved in starting projects it usually takes many local

\footnotetext{
${ }^{7}$ There are certainly exceptions to this rule elsewhere, for example in Kanagawa prefecture the Tokyu Real Estate subsidiary of the Tokyu Railways Corporation has been heavily involved in LR project initiation. It may also be the case that in areas outside metropolitan regions where development pressures are less intense that more Association projects are in fact self-started.
} 
meetings, both in groups and individually to convince enough landowners to consent to a project.

The central role of local governments in initiating Association projects is a direct result of the amount of time and energy required to launch such a project. Individual landowners are unlikely to be able to invest the time and money required to get a project started, particularly since they can very easily develop their land in a piecemeal fashion. In each of the three case study cities, there was a heavy commitment of local planning resources to LR project planning, initiation and management. Table 15 shows the numbers of local government staff involved in LR project initiation and management in several of the main cities in Saitama. In each case approximately half of the City Planning department was directly involved with LR projects.

As discussed in Chapter 1, at the time of the first Senbiki it was expected that virtually the whole area of UPA that was not DID in 1970 would be developed by LR. There was a considerable sense of urgency about the need to start LR projects quickly in this area before haphazard development spread further. The whole area was divided into manageable project sizes of between 30 and 100 ha, the most important and achievable projects were chosen and the process of actually initiating the projects was begun.

In the case of local government initiated projects there is no legal requirement to gain landowner consent. Instead there is a requirement for public display of plans, a procedure to allow public feedback and objections and the requirement to gain the approval of the prefectural governor. This more streamlined procedure allowed many local governments to initiate large public LR projects quickly in the early 1970s. However, it was found that it is extremely difficult to actually carry out projects without the active agreement of the land owners involved. This is understandable given the complexity of projects involving the reconfiguration of already densely settled areas where there are hundreds of houses, businesses and active farms. Non-co-operation of even an individual landowner can seriously

Table 15

Local government LR staff of selected major cities in Saitama ${ }^{a}$

\begin{tabular}{lcccccc}
\hline & $\begin{array}{l}\text { Total } \\
\text { No. of current projects }\end{array}$ & Public & Private & $\begin{array}{l}\text { Total } \\
\text { area } \\
\text { (ha) }\end{array}$ & $\begin{array}{l}\text { LR } \\
\text { full-time staff }\end{array}$ & $\begin{array}{l}\text { Hectares } \\
\text { per staff member }\end{array}$ \\
\hline Ageo & 8 & 1 & 7 & 335.8 & 39 & 8.6 \\
Omiya & 7 & 2 & 5 & 218.7 & 84 & 2.6 \\
Urawa & 11 & 4 & 7 & 427.5 & 48 & 8.9 \\
Kawagoe & 2 & 1 & 1 & 8.5 & 39 & 0.2 \\
Kawaguchi & 9 & 6 & 3 & 492.1 & 109 & 4.8 \\
Koshigaya & 6 & 6 & 0 & 275.3 & 51 & 5.4 \\
Soka & 4 & 2 & 2 & 199.4 & 37 & 5.4 \\
Tokorozawa & 4 & 3 & 1 & 137.9 & 56 & 2.5 \\
\hline
\end{tabular}

${ }^{\text {a }}$ Source: Compiled by Ageo City Land Readjustment Department. Figures are for April 1, 1995. 
disrupt construction schedules, delaying the project and adding to overall costs. Local governments are highly reluctant to proceed with project implementation in cases where individuals are opposed even though they have the legal right to do so. For example, in one case a Local Government project was delayed for almost ten years because a single large landowner had refused permission to work on his land. In other cases projects which had been begun were abandoned because of stiff local opposition.

Many of the projects initiated in a hurry in the early 1970s thus experienced major problems in implementation. This experience led to a change in strategy at the initiation stage. Because it was clearly essential to do the groundwork and engage the active support of landowners to be able to carry out a project once it had been started, it made more sense to initiate projects as Association projects. The main advantage of the Local Government project, ease and speed of designation, had proven a mixed blessing. According to local government officers the main advantage of Association projects is that it is easier to enlist the active involvement of landowners than with local government initiated projects. It is felt that local community members can be much more effective than city employees in persuading reluctant neighbours to co-operate, whether in initiating the project, or in carrying it through. For this reason it is seen as essential to gain the support of the larger local landowners early on as they are often also influential members of the local community. In cases where local support is not strong, yet a project is considered important, it is still possible for the local government to initiate the project itself. However, while this was standard practice in the 1960s and 1970s it is now considered a second-best option. The greater investment of time and energy at the beginning of Association projects is paid back later in smoother project implementation. Thus paradoxically, in practice, initiating Association projects requires a greater investment of local government staff time, not less, especially in the early stages of organising.

Whether the project is public or private, however, many elements remain the same. For example, the design of LR projects is mostly done by consulting firms which specialise in LR projects. The main design criterion is to achieve an equitable distribution of new plots and a high increase of land values. Road layouts are highly standardised and primarily determined by the main arterial roads included in the project. The arterial road network (the City Planning Roads or Toshi Keikaku Doro described in Table 13) was largely planned in the 1960s and forms part of both the Saitama Prefectural plans and the local government plans. Both public and private projects are eligible for the same national government subsidies which are determined primarily by the length of arterial roads within the project area. The main difference in financing is that with Local Government projects the government guarantees any losses, whereas in Association projects landowners themselves bear the risk of losses. In practice, there is less difference even here than might be expected as local governments during the post-bubble decline of land prices were reassuring landowners in Association projects that they would cover losses if such occurred. It is reasoned 
that allowing such a loss to landowners would make it much harder to get agreement for future projects.

\subsubsection{Project management arrangements}

The central role of local government extends also to project management, the job of carrying the projects through to completion. Such project management involves a range of specialist skills such as scheduling and tendering construction contracts, negotiating household and business moves, financial management, and land sales. As might be expected, all local government projects are managed directly by local government LR departments. However, local governments also manage the Association initiated projects. ${ }^{8}$ In the case study cities there were two arrangements for managing Association projects. That followed by Ageo (and most of the other cities in Saitama prefecture) is that the local government LR departments directly manage all the projects they initiate, whether they are 'Local Government' projects or 'Association' projects. The other method, which was adopted in the largest cities of Saitama; Omiya, Urawa and Kawaguchi, is to set up a foundation or non-profit corporation (Zaidanhôjin) to manage the Association projects. In the case of Omiya and Urawa these organisations, confusingly named the Omiya (or Urawa) Land Readjustment Association (Tochi Kukaku Seiri Kyôkai $)^{9}$ were set up in the early 1970s and are responsible for managing Association projects once they are legally begun. They have their own staff (of 8 and 12 for Omiya and Urawa, respectively) ${ }^{10}$ and are formally separate from the local government LR departments, although in practice they work closely together, and local government LR staff are routinely seconded to the LR Association. Because they manage several projects at once the body can pool project funds, thus reducing the external borrowing needs of projects which tend to have high outlays in the beginning and high revenues towards the end. In 1990 for example, the Urawa Land Readjustment Association was managing five Association projects and had completed 9. In the same year its total income and expenses were just under $¥ 240$ million (Urawa City Land Readjustment Association, 1992).

Association projects are, therefore, neither self initiated nor self managed. While a meeting of Association members is the final decision making body, and

\footnotetext{
${ }^{8}$ In some cities consultants also organise and manage Association projects, especially in cases where a private corporation such as a railway is the prime instigator. However this practice was not followed in the three cities studied here.

${ }^{9}$ The confusion arises from the fact that in the English literature on LR the phrase Kukaku Seiri Kumiai indicating an individual project management body has normally been translated as Land Readjustment Association, and that usage has been followed here. The Kenkyusha New Japanese English dictionary translates Kumiai as association, society, union, guild, or co-op, while it translates Kyôkai as society, association or league. Thus in Japanese the use of Kumiai for a specific project, and Kyôkai for an organisation which manages several projects makes a distinction in scale of organisation which is lost in the English language translation.

${ }^{10}$ Not included in Table 15.
} 
landowners form the Association board of directors, the actual day-to-day operations are the work of either local government staff or of the foundation. This means that each project does not need to hire a staff of its own, and the local government is able to build a team of experienced personnel. It does, however, clearly reinforce the central role of local governments in Association projects as well as Local Government projects. It should not be inferred that land owners do not participate at all in LR projects, as a related study found that some landowners, and particularly those owning large areas, do sometimes become active in projects (Sorensen, 1998, Chapter 9), but the lead role is clearly taken by the local government LR departments and their "Associations".

\subsubsection{The role of Flexible Senbiki in project initiation}

An examination of the use of Flexible Senbiki in the process of initiating projects supports the claims of local government officers that they had actually started all projects including both Association and Local Government projects. All but one of the six new projects initiated within the case study areas since the Flexible Senbiki policy was initiated in the early 1980s have been in locations targeted as 'Designated Problem Areas' in the Second Senbiki Review. Problem areas and the resulting LR projects have been mapped for each case study area.

Figs. 13-15 show the areas designated as 'problem areas' by the second Senbiki Review in 1981, and the current, completed, and projected projects in each case study area. As discussed in Chapter 2 the 'Designated Problem Areas' were UPA areas which had not seen much development in the first ten years of Senbiki, and where the prefectural government threatened ZGS downzoning to UCA unless steps were taken to organise LR projects. The criterion to prevent downzoning was the establishment of a LR organising committee (Tochi Kukaku Seiri Hokininkai) of local landowners. As shown in the figures, most of the case study area that was not already LR was designated as 'problem area' to be developed by LR.

As also shown in Chapter 2, however, not all problem areas eventually became LR projects. Within the case study areas some 808 ha were designated 'Problem Area' in 1982. Within that area five new LR projects totalling 281 ha $(35 \%$ of the total) had been started by 1995. Of those five, all were initiated as Association projects. In the 1990s the 'problem areas' that were not converted to LR projects, and had not been downzoned were renamed LR 'promotion areas' in the city plan, reflecting the decision to abandon the ZGS policy described in Chapter 2. There were significant differences between the three case study cities in their success rate in converting 'problem areas' to LR projects, however, which are worth noting.

As shown in Fig. 13 in the case of Urawa only one new project of 28.1 ha has been started in the case study area since 1981, covering half of one designated problem area and representing some $10 \%$ of the problem areas originally designated. The city LR department is actively continuing to trying to start new projects in only about half of the area originally designated in 1982. This is not because it is no longer considered desirable to carry out projects in the other 

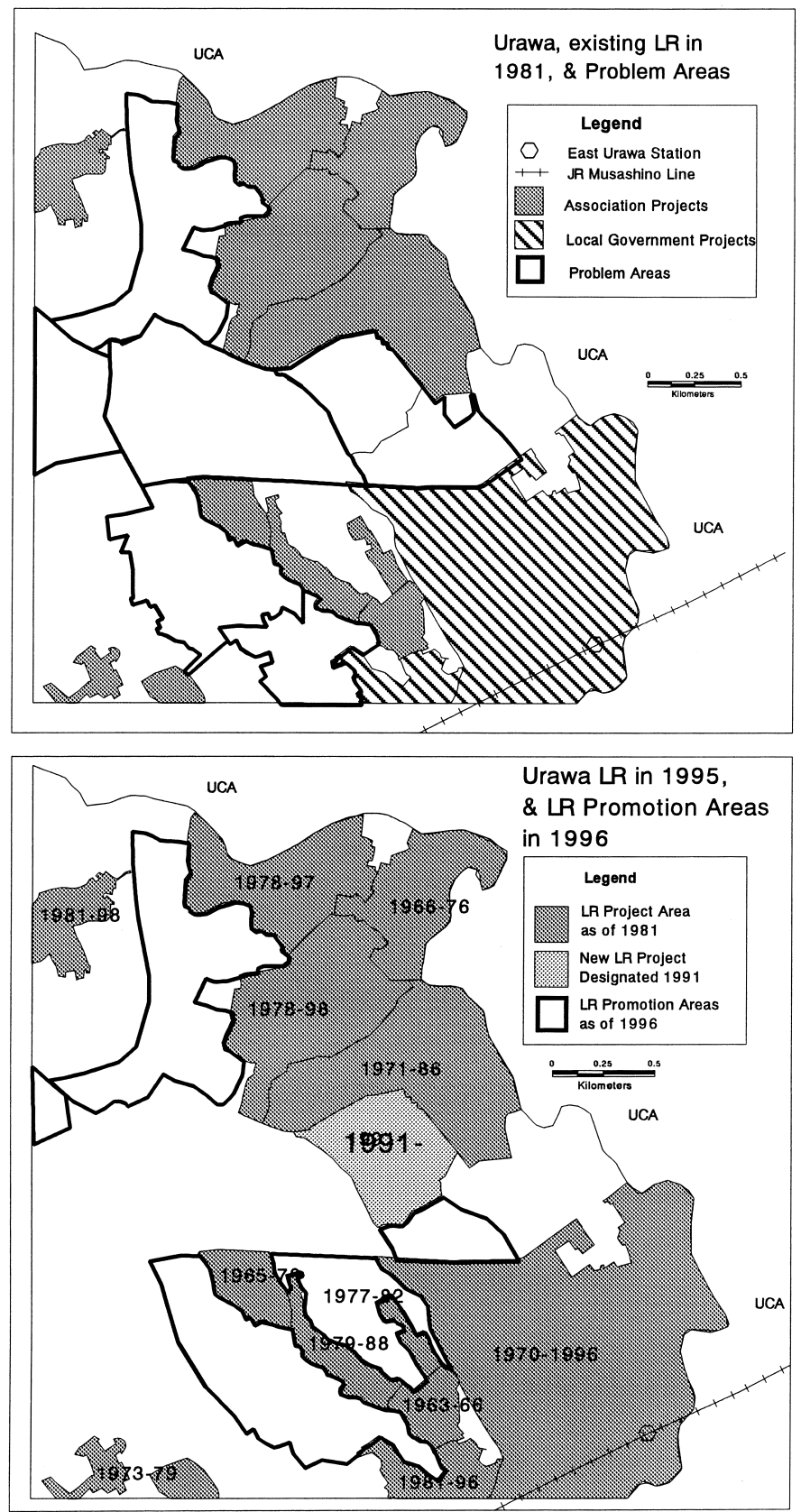

Fig. 13. 1981 problem areas, 1995 current and planned LR, Urawa. 

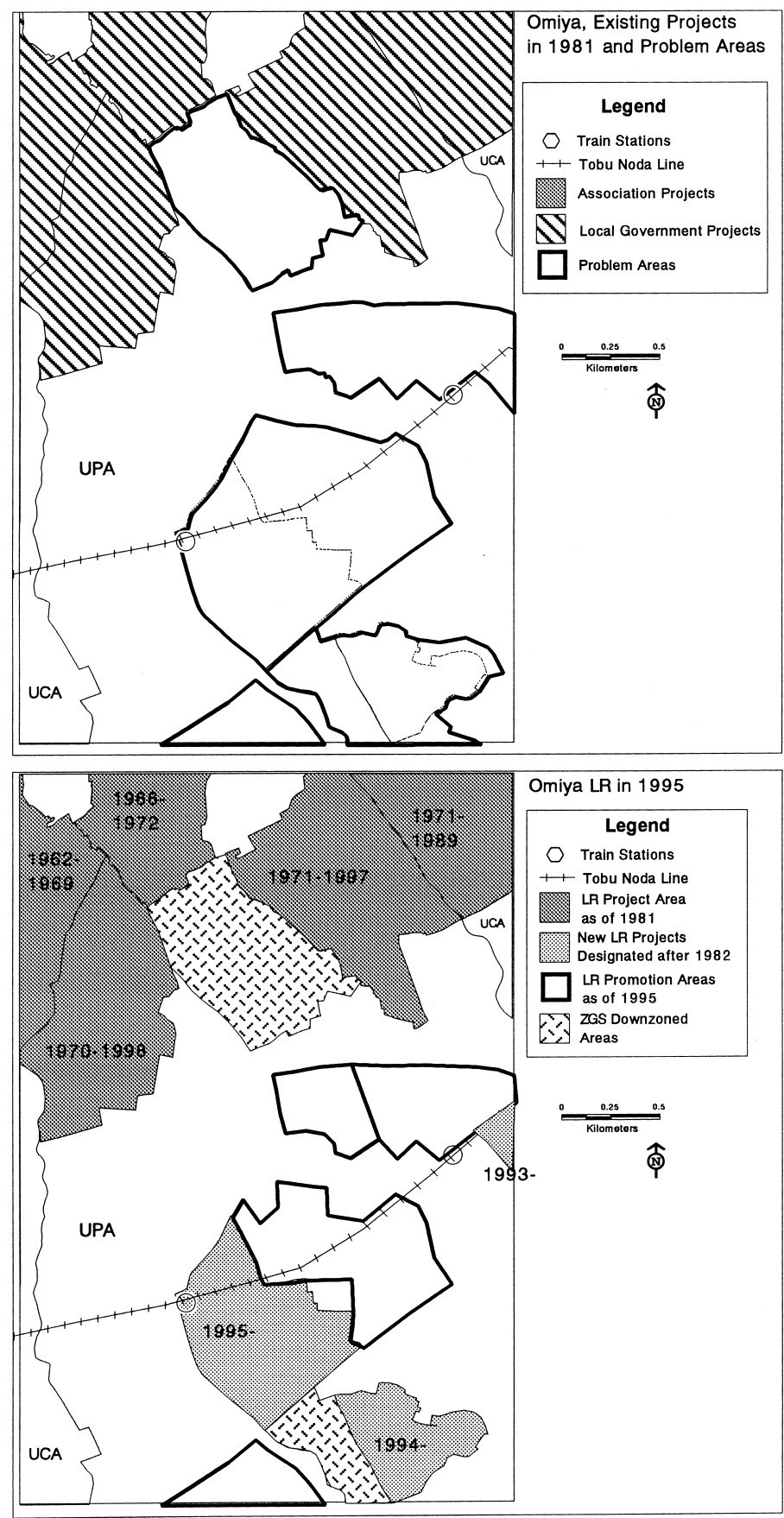

Fig. 14. 1981 problem areas, 1995 current and planned LR, Omiya. 

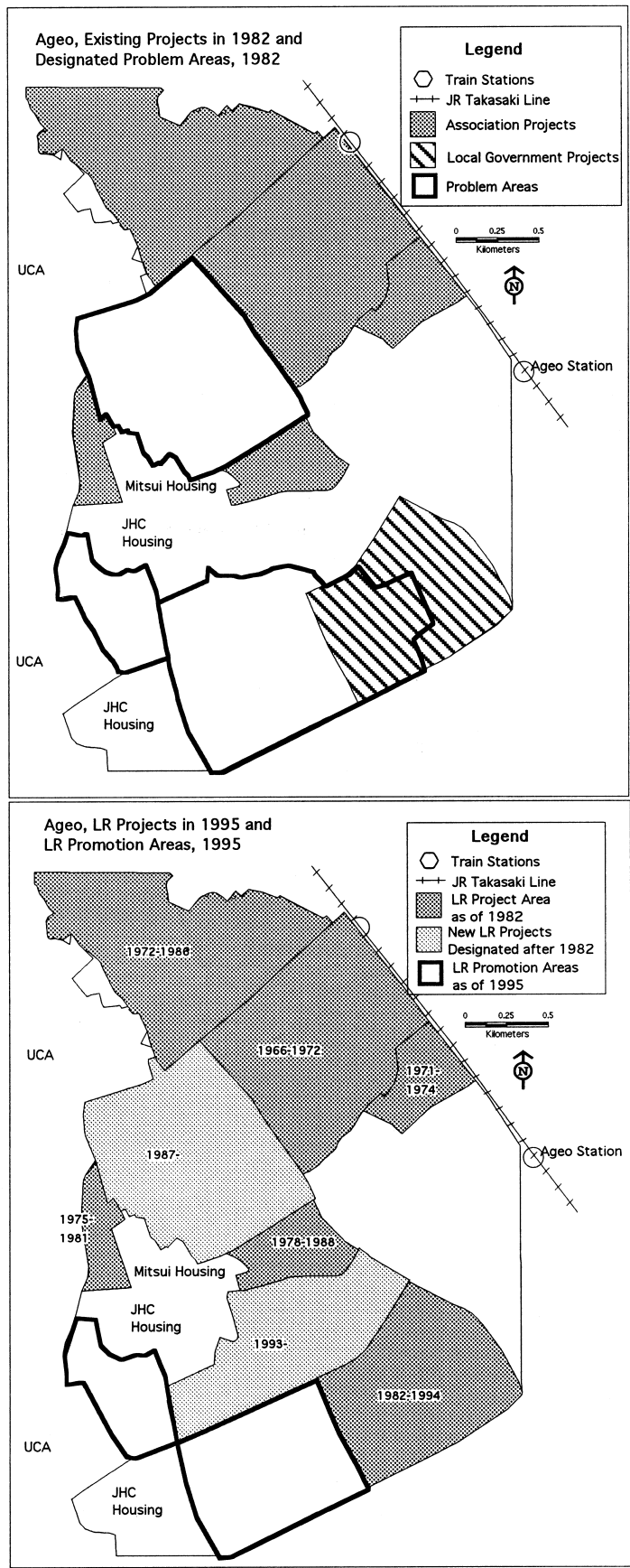

Fig. 15. 1981 problem areas, 1995 current and planned LR, Ageo. 
areas, but because it is seen as impossible to gain the agreement of enough landowners. This underlines how difficult it can be to convince landowners to agree to projects even with persistent efforts. In each project area city staff have conducted two or three detailed surveys of conditions, have prepared a development plan, and have conducted numerous Setsumeikai or explanation meetings. In Urawa even though many areas that were designated problem areas in 1982 have not become LR projects, there has been no ZGS downzoning anywhere in the city.

In the remaining LR promotion areas shown in the lower half of Fig. 13 developments built during the last 13 years will make project initiation ever more difficult. Although legally the LR promotion area status allows the city government to restrict development until a project is started, the planners assured me that in practice they are unable to do so without incurring claims for compensation. The surveys of the problem areas undertaken by local government staff make this point clearly. In the six problem areas within the Urawa case study area, all of which were designated LR Promotion Areas, the population increased from 11,060 in October 1985 to 12,010 in May 1991, an increase of 950 people, or $8.6 \%$ in 5.5 years. Of a total area of 311 ha that occupied by housing increased from 56.2 ha $(18.1 \%)$ to 60.6 ha $(19.5 \%)$. Virtually all of these developments are small detached houses, precisely those whose owners will benefit least from LR. Thus, the longer it takes to get a project started, the more difficult it will be to get agreement, and the more expensive the project will be.

The Omiya case study area is shown in Fig. 14. In contrast to Urawa only about half of the area not LR in 1982 was designated problem area. However, Omiya has been more successful in initiating new projects than Urawa. Of a total of 260 ha of problem area within the case study area, two new projects totalling 74 ha were started in 1993 and 1995 representing $28 \%$ of the designated problem areas. The planners told me that they were confident of several more new projects in coming years.

One other difference from Urawa is that several areas were ZGS downzoned, including two in the study area. One of these, in the north of the case study area was originally planned for development by Local Government LR project, but the project was abandoned because of vigorous local opposition. As shown in the next section, the result has been a major hole in the city's planned arterial road network, with major portions of three key roads left unfinished. It is not clear which factors were more important in Omiya's success in converting problem areas to LR projects. Possible factors include its willingness to ZGS downzone, the degree of local land owner support for or opposition to LR, and the amount of effort expended by local government organisers.

In Ageo most of the area that was not LR in 1981 was designated as problem area, as shown in Fig. 15. In Ageo, moreover, most of the problem areas had become LR projects by 1995 . Of an original 270 ha of problem area, two new projects totalling 179 ha had been begun, representing $66 \%$ of the total problem areas within the case study area. Most of the area within the case study area that was not designated problem area was already DID in 1970, being either close to 
the Ageo train station, or one of the two very large JHC housing projects completed in the 1960s. These areas were too heavily built up to be considered problem areas. In this sense Ageo may represent a good example of how the Senbiki and Flexible Senbiki systems were supposed to work. The case study area is virtually the whole of the UPA area west of the train line. Of that area, almost all that was not DID in 1970 has seen either LR, or other planned development such as JHC housing or development permit.

The relatively high level of new LR project initiation in Ageo is in no way spontaneous, however. Local government LR department staff gave me a detailed explanation of the literally hundreds of local explanation sessions, research group meetings, committee meetings, and preparatory meetings held between 1981 and 1987 that went into organising landowner approval for the large Koizumi LR project (the more northerly of the two new LR projects shown in the lower part of Fig. 15), which prevented the area being ZGS downzoned.

On the whole it seems that Flexible Senbiki has provided a powerful incentive which local governments have used aggressively. It is also clear, however, that even with persistent efforts by local government officers to initiate projects, they were still unable to initiate projects in many areas even 13 years after the process was begun. The failure to initiate projects in the majority of the designated areas also clearly shows the reluctance of local governments to proceed with LR projects on their own where they feel they do not have adequate support. The question is why there is such a difference between the three case study cities. It is possible that it is simply a result of different planning styles or priorities of the local governments. It seems likely, however, that the differing development pressure in the three cities may play a role. Urawa is closest to Tokyo, while Ageo is the farthest. If Urawa fringe areas were already experiencing strong development pressure when the Flexible Senbiki policy was begun, while in Ageo development pressure was still relatively weak the pattern of LR projects seen above could be explained. In Ageo it seems to have been possible to complete enough projects in advance of the period of strong urbanisation pressure that the completed projects themselves could provide the majority of new building land. In the case of Omiya particularly, because many planned projects were not carried out, and several projects took a very long time to complete, development within the projects was delayed and instead took place outside the LR areas, resulting in further sprawl and making future projects more difficult. This suggests that for LR to play a primary role in urban land development, it is important to start early, before significant development has occurred, and before development pressure intensifies. It could also be the simple result of differing conditions in the three cities, however, and without further evidence it would be premature to be overly confident of this interpretation.

Whatever the reason for the differing patterns of development in the three cities, it seems quite clear that LR projects are organised primarily by local governments rather than by individuals. The hypothesised role of individual landowners in the development of projects in sprawl promoting locations away from existing developed areas and public transport facilities seems incorrect, as all projects are 
initiated by local government LR departments. How then to explain the fact that in the previous chapter Association projects were found to be significantly more likely to be in sprawl promoting locations than Local Government projects?

This pattern can be explained with reference to a basic difference between Association projects and Local Government projects, that Association projects legally require a high degree of consent by landowners, while Local Government projects can be started simply with the approval of the prefectural governor. As noted, the goal of local government LR departments is wherever possible to initiate LR as Association projects. Because only a small proportion of all planned projects are actually initiated, then it appears that a significant veto power is held by landowners as a group. This could have a strong influence on aggregate patterns of LR project location. The locational patterns shown in the previous chapter suggest that landowners are more willing to consent to projects in locations that are farther away from existing development and public transport. This would follow both from the fact that larger land owners near stations can reasonably expect to develop their land without LR projects, and that those areas will have more existing residential developments whose households would resist LR. If at the same time local governments sometimes do initiate Local Government projects in areas closer to existing development and public transport facilities, (with or without the consent of the land owners concerned) then the pattern observed in Chapter 2 would result. Instead of the positive role of landowners in initiating Association projects that is suggested in the literature, it appears that their influence on project location may be best understood as a form of veto in the face of local government attempts to initiate projects.

\subsection{Patterns of land development}

The primary concern here is to examine the patterns of development in the three case study areas during the period from 1968 to 1992. Particular attention is paid to comparing the location and rate of building activity in LR and non LR areas. Unfortunately, data on land use change at a scale that would allow a differentiation between LR and non LR areas is not recorded by either the local or prefectural governments. Therefore, the analysis is based on a GIS mapping of patterns of land use change and building activity in the three case study areas. The primary data source is the official 1:2500 scale City Planning Maps (Toshi Keikaku $\mathrm{Zu}$ ) of the three cities which record all buildings, structures and land uses. The kind of GIS analysis of existing planning documents undertaken here has become possible only in the last several years with the development of GIS software, and opens up interesting new possibilities for urban research. It is now possible to create quantitative data on urban change and development from archival paper maps. Data that was not recorded at the time except as city planning maps and surveys can be made available by digitising the maps and analysing them with GIS software. Whereas maps have long been a means of recording and displaying geographical and urban information, it was rather difficult to use them as a source of quantitative data about land use or land use 
change if such was not actually recorded at the time the map was made. Now, with GIS techniques they can become sources of quantitative information that is no longer available in any other way. The chief limitation of using historical maps in this way is the question of the reliability of the data obtained. The data acquired through the type of analysis of urban land use change undertaken here will clearly only be as accurate as the original maps, which must be both spatially accurate, and consistent in the recording methods, projection, etc. between periods. In the present case the source maps, which are the official City Planning Maps at a scale of 1:2500 can be considered a highly accurate source of such information. An explanation of the technical aspects of the mapping and the accuracy and limitations of the data acquired is provided in Sorensen (1998, Appendix B). Here it should be noted that the time periods examined in each city are not fully comparable. Each city provided three complete sets of maps at as close to a 10 year interval as possible as the maps are not revised every year (Urawa was 1968, 1982 and 1992, Omiya was 1968, 1979 and 1991 and Ageo was 1969, 1981 and 1991). As the comparison of build-up rates was to be between LR and non LR areas within each city within each time period, the variation of duration of periods was not thought to be critical. It should be noted, however, that the data on land use change generated is not suitable for a comparison between cities or between time periods unless standardised by averaging on a hectares per year basis.

Before turning to the examination of the quantitative data of land use change in the individual cities, some general comments about patterns of land development in the case study areas can be made based on Figs. 16, 18 and 20 which show which show which land was already built up in 1968, what new land was developed in each of the two subsequent decades, and which land remained unbuilt at the end of the period.

It is worth nothing that a 'built up' plot of land is defined as any plot that has a building on it, plus areas such as parks which, although not actually built on, are in a final urban use. Equally, schools invariably have a large playground, which while evidently not built on, is part of the school plot and therefore considered built up. Parking lots are only considered built up if they are either a multi-storey car park, or are on the same plot as a building, for instance parking attached to a retail store or apartment building. Other parking lots which occupy a whole plot are considered to be a temporary use pending further development and are therefore considered not built up. The main distinction made in the mapping therefore is between 'built up land' on the one hand as described above, and land which is not built up, such as agricultural land, vacant building plots, or parking lots. Therefore, the mapping allows a highly accurate measurement of the rate of build up of land within the case study areas. The area occupied by roads, rivers and railways is in all cases excluded from the total of buildable land in the data analysis below.

Much active agricultural land remains spread rather evenly throughout each of the case study areas. In almost all cases the areas most recently built on were in agricultural use in the previous period, although in some instances they were 
either vacant or parking previously, and in a very few cases were built up in 1968, vacant in 1981, and built up again in 1992. That sort of detail could not be shown on a single map, but is reflected in the quantitative analysis of land use change examined below. Perhaps the most striking feature of patterns of urbanisation in the case study areas is the extraordinary degree of scatteration of new development during the most recent two decades. As will be made clear below, that scatteration is equally prevalent both inside and outside the project areas.

\subsubsection{A brief tour of the case study areas}

In order to allow a better understanding of the urban form of the case study areas, Figs. 17, 19 and 21 show selected windows on the city planning maps from which Figs. 16, 18 and 20 were drawn. The case study areas were simply too large to include this scale for the whole area, but it is hoped that these glimpses of the underlying detail of buildings, agricultural areas and road networks allow a better feel for the urban areas being examined here. Although the base maps are in Japanese, the buildings and roads should be relatively easy to read. Somewhat harder to distinguish is the difference between active agricultural land, which is marked with a symbol in the middle of fields to indicate orchards (an 'o'), vegetables ( $a$ ' $v$ '), rice paddy ( $a^{\text {' } " '), ~ e t c ., ~ a n d ~ v a c a n t ~ l a n d, ~ w h i c h ~ h a s ~ n o ~ i n d i c a t i o n ~}$ of a crop. However, for this discussion the most important features are the buildings and roads. A brief tour of the three case study areas follows.

It is clear from Fig. 16 that the Urawa case study area was primarily rural in 1968. Only a small area in the south west corner was already significantly developed. In the late 1960s, however, the new JR Musashino line was built, and a new East Urawa Station was located in the south west of the case study area (shown in the lower right of detail D, Fig. 17). Soon after, in 1970, a large Local Government LR project was begun to develop the area around the new station as seen in Fig. 13. Like many projects begun in the early 1970s, however, it took a long time to complete, and was finally wound up in 1996.

Fig. 17 shows four details. Block $\mathrm{A}$ is an area which has not been developed with LR and is a good example of an area where development has proceeded along existing rural roads and on short extensions to them. Most of the land is still actively farmed, and the clusters of farm buildings are still clearly evident. The unfinished Omiya Tokyo National Highway is seen cutting across the bottom left corner. The area was designated as Problem Area in 1982, however, most of the tightly packed housing has been built since then. Most of the area was still LR promotion area in 1996. Block B shows a typical area that has been developed with LR. The road layout is a modified grid dominated by two main arterial roads. The right half of the area was an Association project started in 1966 and finished in 1976, while the left half is still being developed with two Association projects started in 1978 and planned to finish in 1997 or 1998. Much active farmland remains throughout the area, though the right half is somewhat more built up than the left. Block $\mathrm{C}$ shows an area partly developed through LR and partly not. The most built up areas are outside the LR projects. It appears that during the 1970s this area was being built up rapidly, and the LR projects were 
begun in the remaining areas which had not yet been developed. The result is that over a decade after the projects were finished, the two arterial roads which should lead from the lower left to upper right are still incomplete, and will require much expensive demolition of housing to finish. Block D shows the area near East

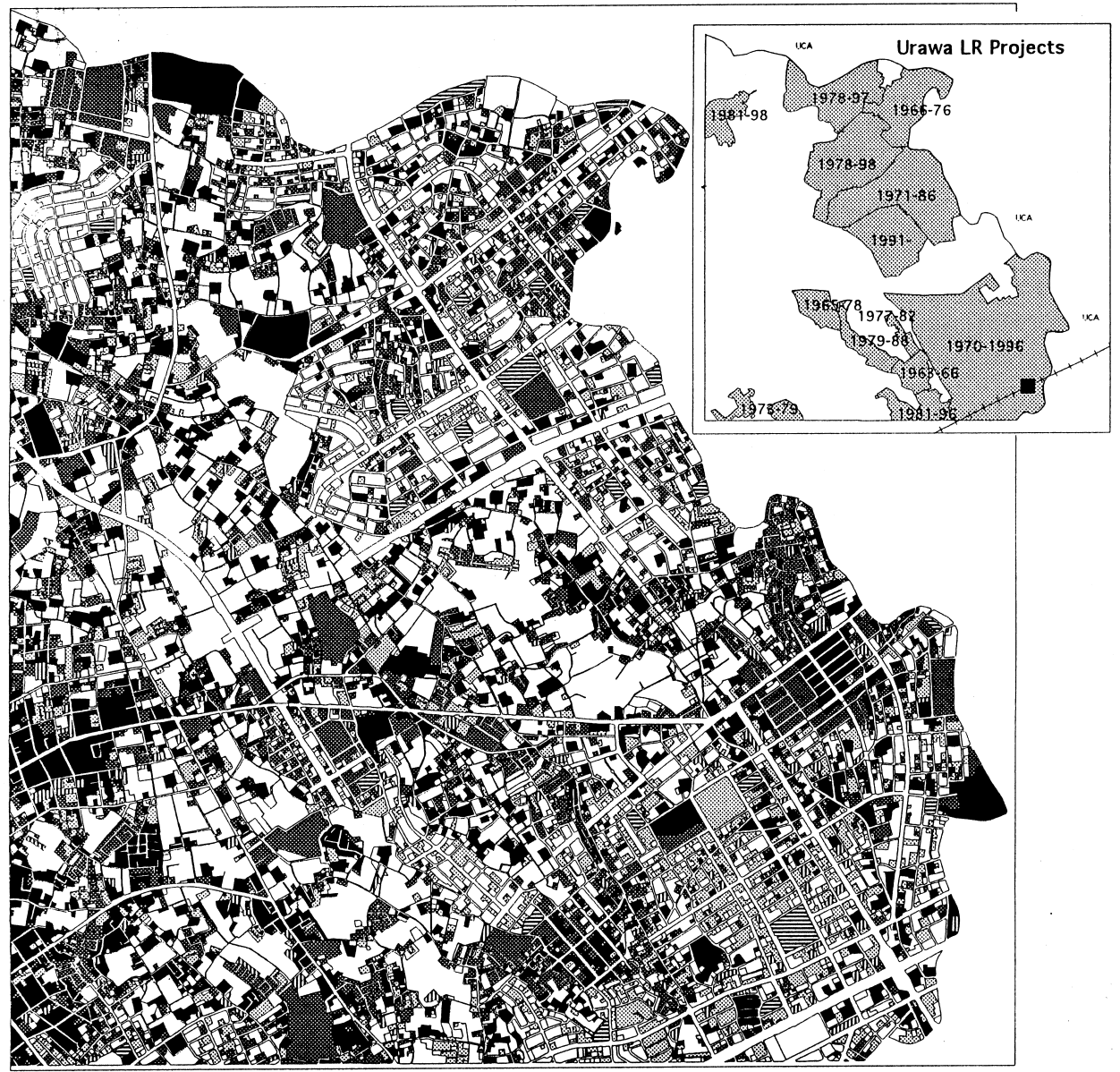

Urawa Land Development $1968-1992$
Built up in 1968
Built up by 1982
Built up by 1992
$\square$ Agricultural and Vacant in 1992
$\square$ Parking in 1992
Parks in 1992

Fig. 16. Urawa land use change. 
Urawa Station. Most of the buildings in this area date from the 1980s when extensive building occurred. The large square area in the middle left is a park which was completed after the original of this map was drawn in 1992.

Fig. 18 shows the Omiya case study area, while Fig. 19 shows five details of its base maps. Unlike the Urawa case study area, in the Omiya area there are several large areas that have been comprehensively developed with roads and public facilities without the use of LR. The main such area is the long narrow strip running from the lower right to the middle left of the case study area. This area was largely swamp in 1968 and was reclaimed and developed by the city in the 1970s and 1980s. Most of this area is now occupied by public facilities such as schools and parks, and a regional public gymnasium. Part of the area was also sold as housing lots. The other notable aspect of the Omiya case study area is the extreme degree of scatteration of development, particularly in the non LR areas. Block A of Fig. 19 shows an area developed by LR in the early 1970s. The dense area of houses in the middle of the block actually dates from the 1960s however, and was built as company housing for Japan National Railways employees. The street grid conforms to the LR project plan because the plan was decided in 1961, almost 10 years before the project was actually begun. The rest of the project shows the familiar pattern of buildings surrounded by actively farmed fields. Block B shows a part of the area that was ZGS downzoned in the late 1980s because of opposition to the Local Government's planned LR project. In the centre of the block is a large multi-storey condominium (manshon) complex built during the 1980s by Development Permit. The two large blocks of flats were designed to be at the intersection of two of the major arterial roads that were planned to cross the area as discussed further in Section 3.4 below, which were indeed partly built as a development permit requirement of the manshon project. They remain incomplete, however, and the area is difficult to access by road. Although the area that was ZGS downzoned was a 'Designated Problem Area' and had been planned for LR development, with the downzoning there appears to be no immediate hope of starting a project there.

Block $\mathrm{C}$ shows an area of LR just to the east of the ZGS area where the roads were still under construction when the map was prepared in 1992. This area is very little developed and remains mostly open farmland, although the LR project here was started in 1971. The project still further east, however, also started in 1971 was finished in 1989 and was considerably built up by 1992, as shown in Fig. 18. Block D, shows an area typical of the unplanned development that is common in the Omiya case study area. An $18 \mathrm{~m}$ wide arterial road is planned to cut through the middle of this housing from lower left to upper right. Although in the southern portion are several broad roads, a park and a large junior high school on extensive grounds, these are part of the swamp reclamation project mentioned above. The majority of the roads in the area are very narrow, with many dead ends and most traffic funnelled to a few through roads. This area was considered too built up to be a 'Designated Problem Area' and so LR projects have not been planned here. Block E shows an area just to the south and west which was almost entirely 'Designated Problem Area' designated in 1982, and which contains the 

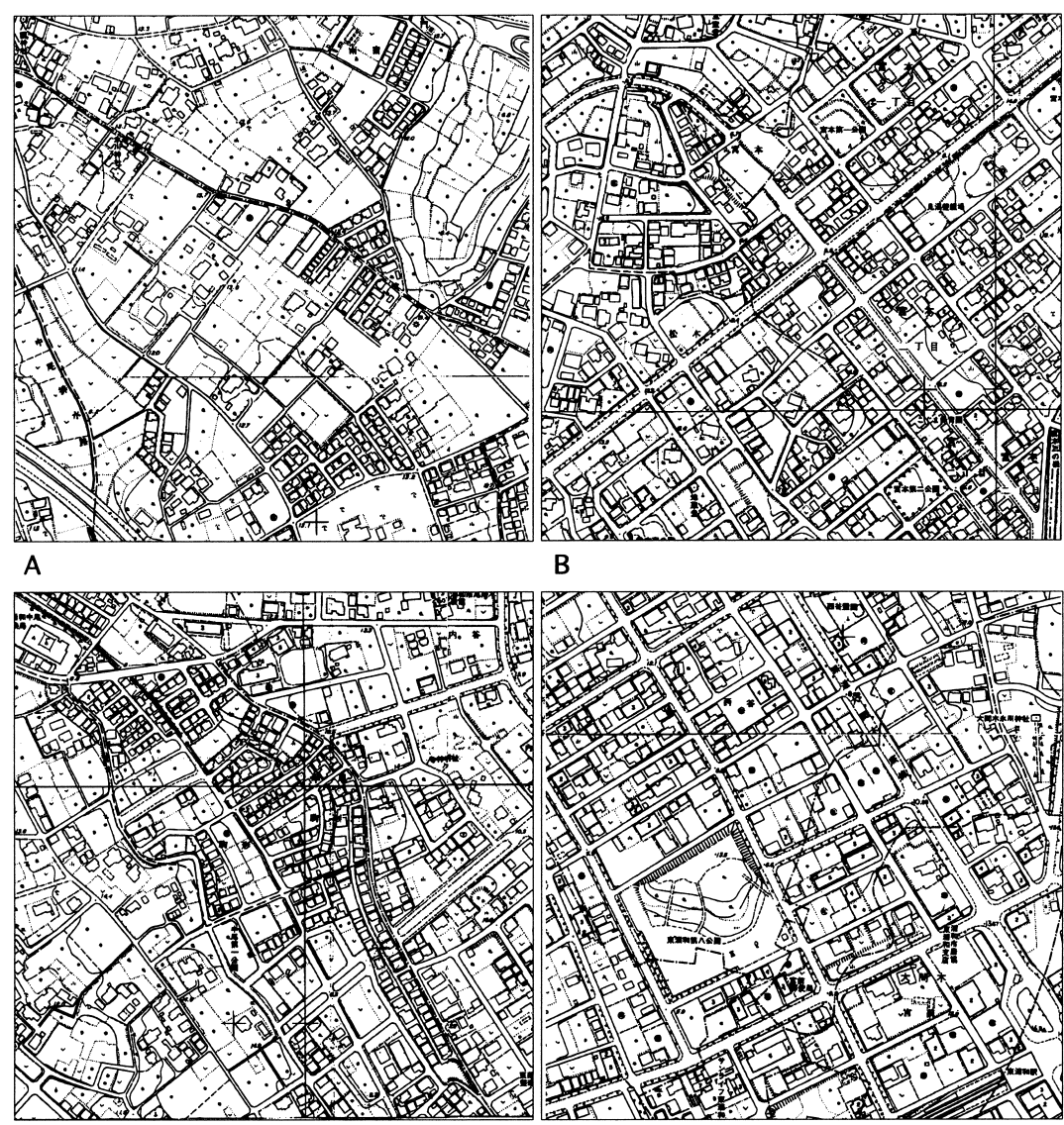

B
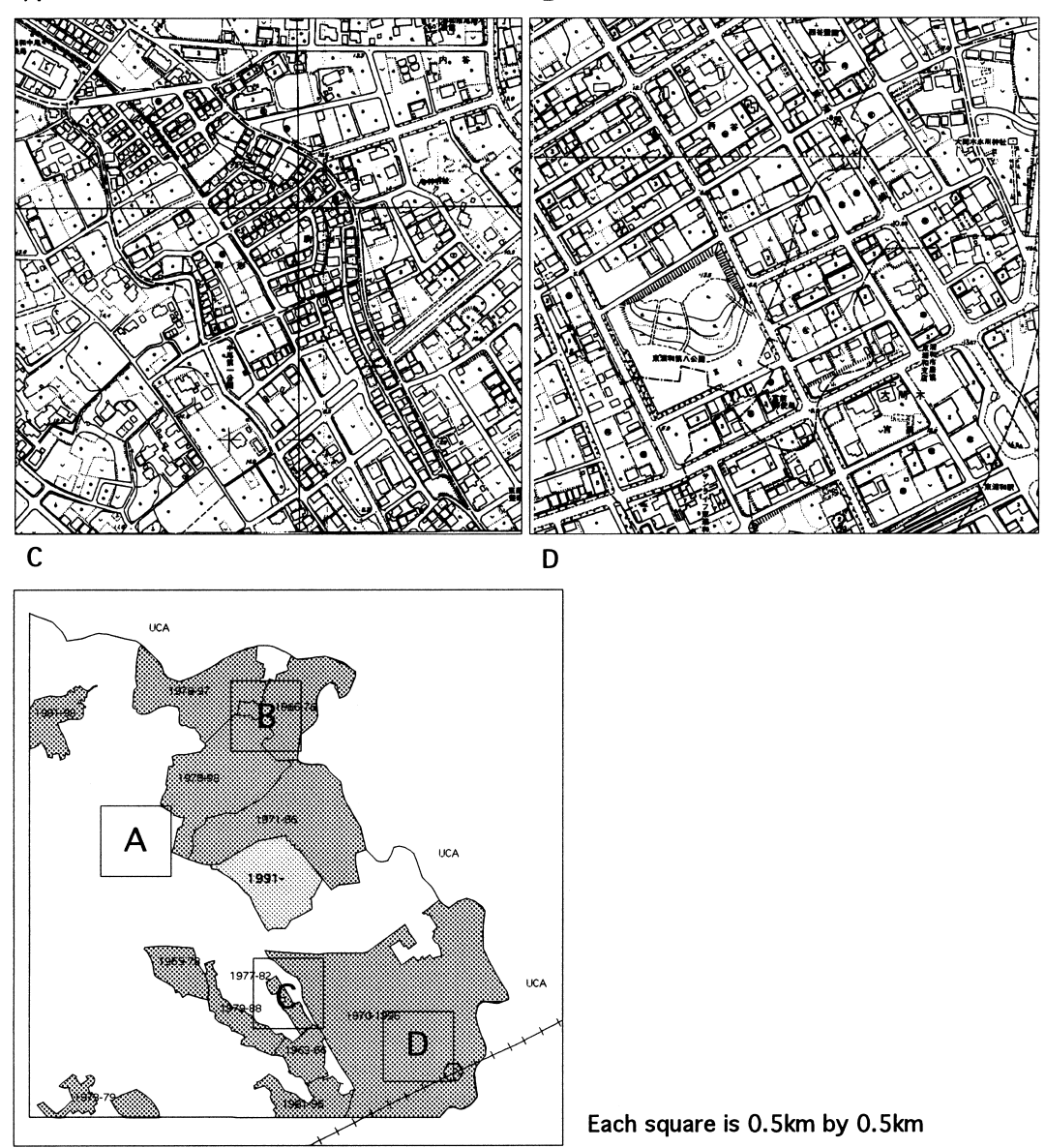

Each square is $0.5 \mathrm{~km}$ by $0.5 \mathrm{~km}$

Fig. 17. City planning map details, Urawa. 


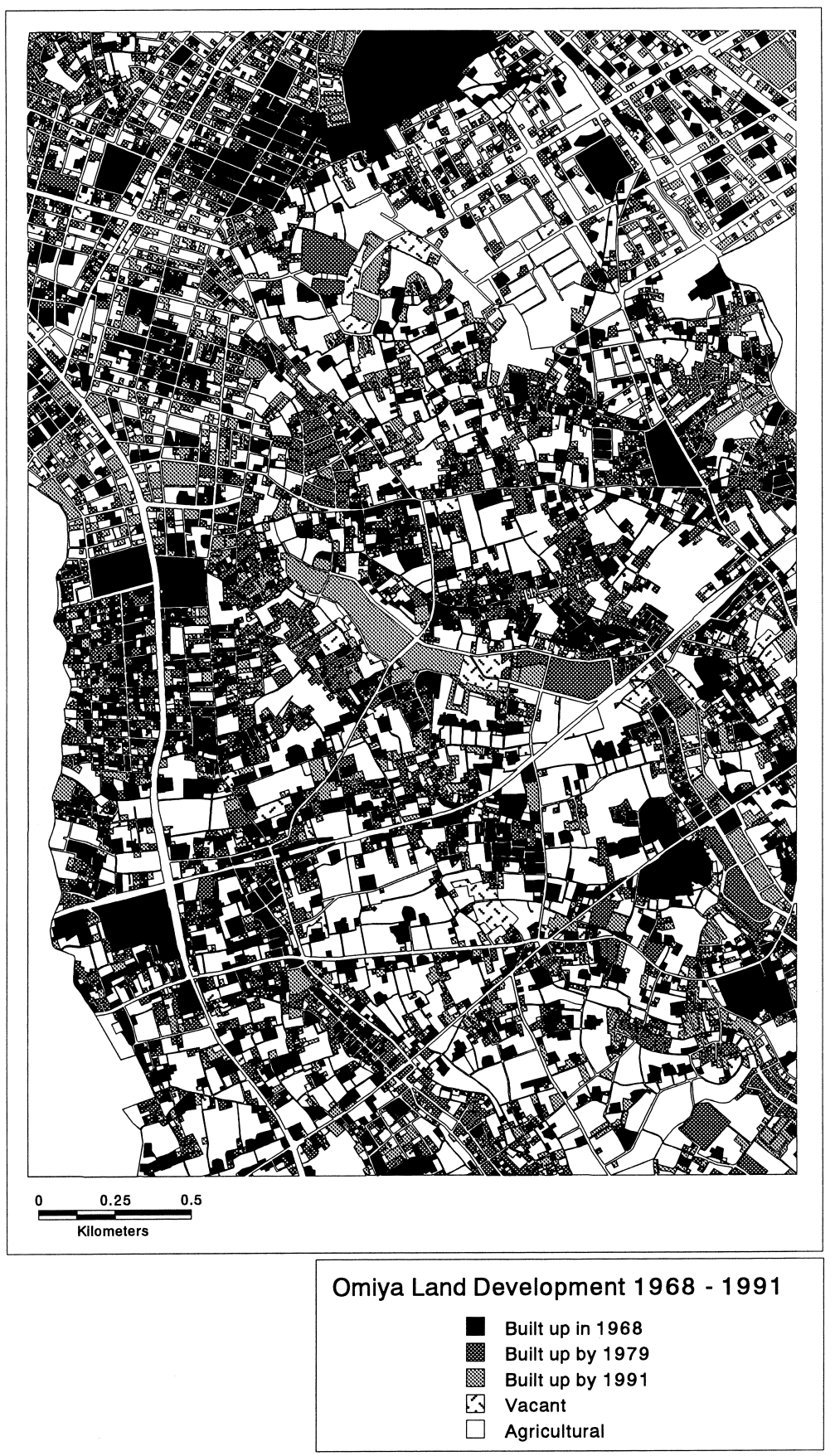

Fig. 18. Omiya land use change. 


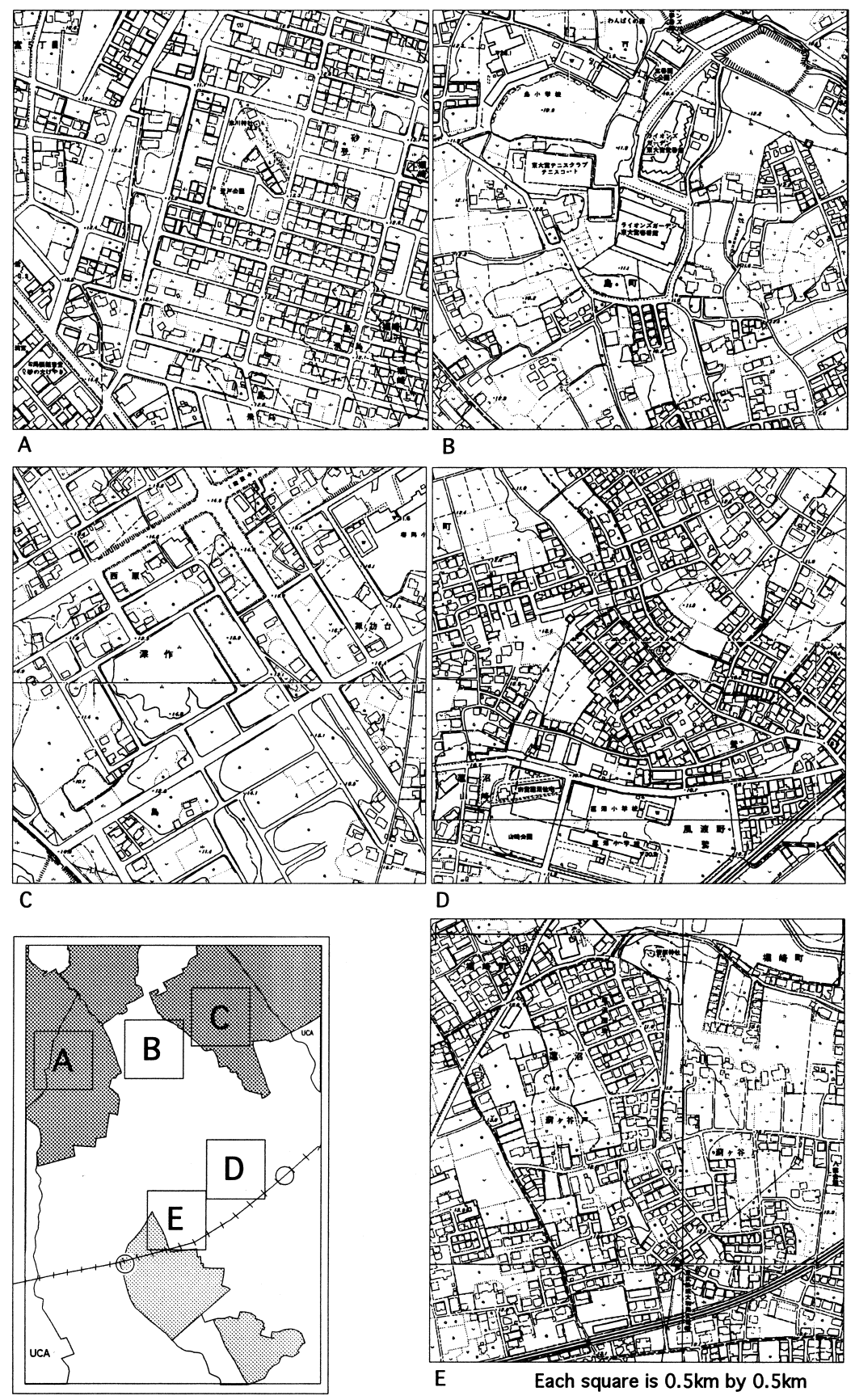

Fig. 19. City planning map details, Omiya. 
corner of a new LR project started in 1995. The balance is still LR promotion area where a project is actively being initiated. A quick reference to Fig. 18 shows, however, what the LR initiators are up against, the area saw extensive new development between 1979 and 1991. The Tobu Noda railway line is visible in the south of the block.

Fig. 20 shows the pattern of build up in the Ageo case study area and Fig. 21 shows details. Ageo has generally seen less building outside the LR areas and planned developments, although some has taken place. New developments, although still scattered, are more heavily concentrated in the LR areas, the planned developments such as the JHC apartment housing and the Mitsui housing estate, and in the area near Ageo station which was already DID in 1970. Block A shows an area of a new LR project started in 1987 as a result of Flexible Senbiki. The new partly built arterial roads are clearly visible, as are the clusters of old farm buildings, tightly packed rows of new housing development and the pre LR rural road network. Block $B$ shows an area of one of the first LR projects in Ageo, begun in 1966 and finished in 1972. Although more built up than Block A, the extent of open fields and orchards is remarkable considering that more than twenty years have passed since the project was completed. Yet this area is typical of LR areas in its mix of large business premises, tightly packed detached housing, expansive farmers homes and cultivated land. Block $\mathrm{C}$ shows part of an area of Mitsui Homes developed in the 1970s and part of the large aree of JHC apartment blocks developed in the 1960s. The tightly packed detached housing of the Mitsui housing is typical of large scale housing development in Japanese suburban areas. Block D shows a part of the area near the Ageo station which was already DID in 1970. This area is typical of the sprawl areas which developed in the 1960s and gradually filled in after. Apart from the fact that the roads are commonly too narrow, and there are no public spaces such as parks, these areas are by no means slums, and are often quite pleasant residential areas. The remnants of tilled fields are also typical of such areas. The large road cutting across the upper left corner was built during the 1980s and necessitated substantial demolition of existing structures. It connects the dense housing of Block $\mathrm{C}$ with the town centre and train station.

In summary, it seems apparent that development has been spread rather evenly throughout each of the three case study areas. The vast majority of new developments are small, usually involving the construction of just one or two houses near an existing building. Slightly larger developments of up to a dozen small houses are also common, but in almost all cases such developments are under the $1000 \mathrm{~m}^{2}$ Development Permit threshold. Most of the larger blocks of land which have been developed are for schools and other public facilities such as public housing, and in a few cases rather larger developments have been built on former industrial sites. Much active agricultural land remains throughout the areas under study, even in the areas which were already partly built up thirty years ago, and within LR project areas. While much development has clearly taken place, it has been very evenly scattered over the whole case study area, and in each study area over half the buildable land remains unbuilt. In particular, it is 


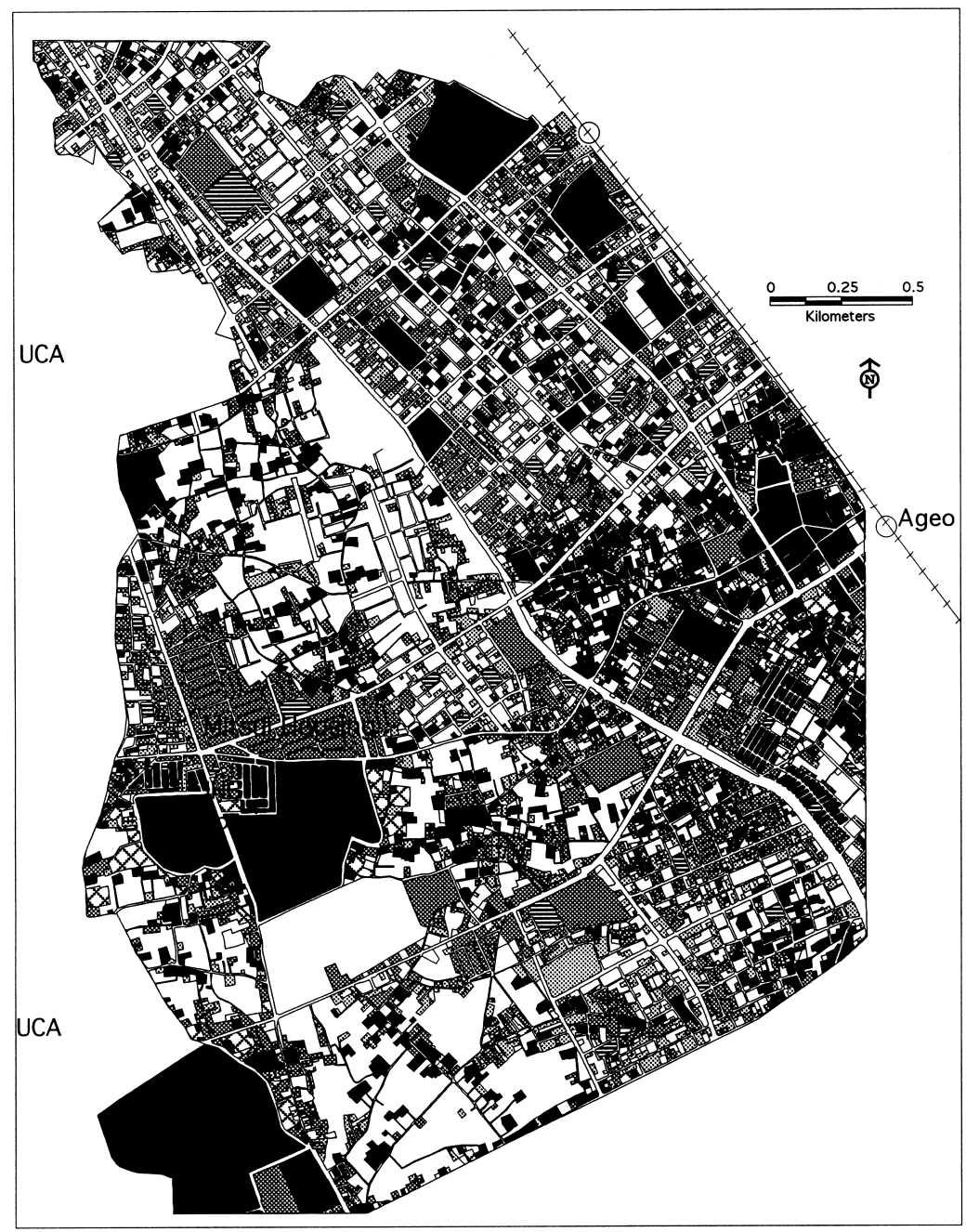

$$
\begin{gathered}
\text { Ageo Land Development 1969-1991 } \\
\text { Built up by } 1968 \\
\text { Built up by } 1982 \\
\text { Built up by } 1992 \\
\text { Agricultural and Vacant } \\
\text { Parking } \\
\text { Parks }
\end{gathered}
$$

Fig. 20. Ageo land use change. 

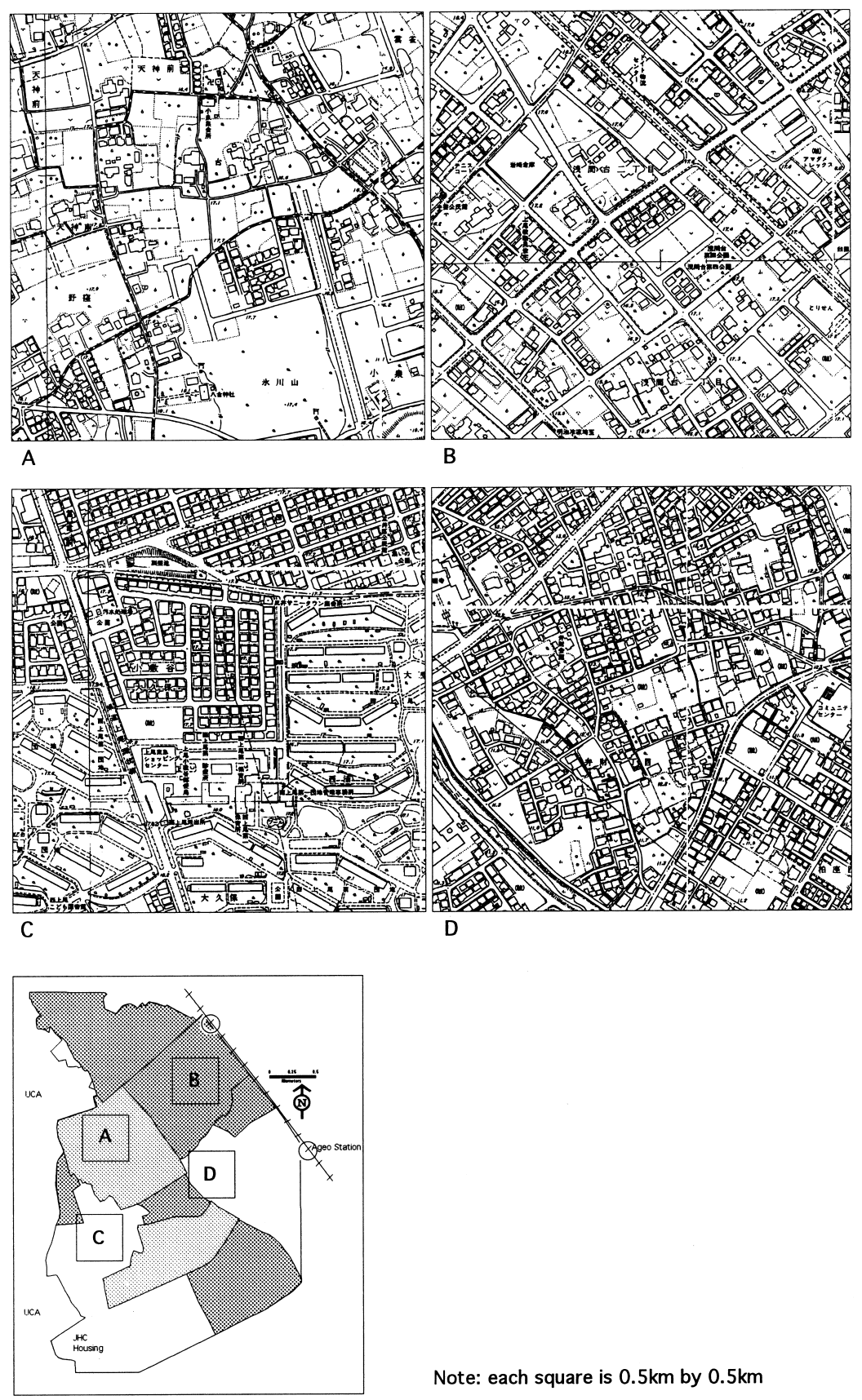

Note: each square is $0.5 \mathrm{~km}$ by $0.5 \mathrm{~km}$

Fig. 21. City planning map details, Ageo. 
notable that most development has taken place rather far away from existing developed areas. Near areas which were significantly built up in 1968 much the same pattern of unbuilt land remains in the 1990s, although now some of that land is classified as vacant or parking rather than agricultural.

Within all LR areas modified grid road networks have been created, and arterial roads built, while in non LR areas most development has taken place along existing rural roads, or as small dead-end extensions to those. The changes in road and sewer infrastructure are examined in more detail in the next section. The rest of this section is devoted to an analysis of the differences in rates of development of LR and non LR areas. The implications of these patterns of development for urban form are discussed at the end of the chapter.

\subsubsection{Comparing land development inside and outside LR projects}

Table 16 shows data on the rate of build-up of all land in the Urawa case study area, within all LR projects including those begun recently, within LR projects which were already completed by 1980 , and of areas outside LR projects. LR projects represent some $43 \%$ of the Urawa case study area. In 1968 only $15 \%$ of the LR areas were built up, compared to $23 \%$ of non LR areas. This is probably due to the fact that it is easier to start LR projects in less built up areas. In the

Table 16

Urawa land development (ha, \% $)^{\mathrm{a}}$

\begin{tabular}{|c|c|c|c|c|}
\hline & Area & Built up by 1968 & Built up by 1982 & Built up by 1992 \\
\hline Whole case study area & 728.3 & 144.6 & 280.3 & 363.7 \\
\hline $\begin{array}{l}\% \text { of whole } \\
\text { case study area built up }\end{array}$ & & $19.8 \%$ & $38.5 \%$ & $49.9 \%$ \\
\hline LR project area & $\begin{array}{l}311.2(42.8 \% \text { of } \\
\text { case study area) }\end{array}$ & 46.9 & 101.2 & 157.2 \\
\hline $\begin{array}{l}\% \text { of LR } \\
\text { project area built up }\end{array}$ & & $15.1 \%$ & $32.5 \%$ & $50.5 \%$ \\
\hline $\begin{array}{l}\text { LR projects completed } \\
\text { by } 1980\end{array}$ & $\begin{array}{l}45.9(6.3 \% \text { of } \\
\text { case study area })\end{array}$ & 5.7 & 24.2 & 29.0 \\
\hline $\begin{array}{l}\% \text { of project } \\
\text { area built up }\end{array}$ & & $12.5 \%$ & $52.7 \%$ & $63.1 \%$ \\
\hline Non LR area & $\begin{array}{l}417.1(57.2 \% \text { of } \\
\text { case study area) }\end{array}$ & 97.7 & 179.1 & 206.5 \\
\hline $\begin{array}{l}\% \text { of Non } \\
\text { LR project area built up }\end{array}$ & & $23.4 \%$ & $42.9 \%$ & $49.5 \%$ \\
\hline
\end{tabular}

\footnotetext{
${ }^{a}$ Source: Calculated from GIS mapping. In all cases land area represents buildable area excluding roads. Parks are considered built up, as they have been converted from an agricultural or vacant use to a final urban use. Totals may not add due to rounding.
} 
most built up areas in the west of the case study area LR projects were not attempted. It appears that in the short run LR projects delay build-up, while in the long run LR projects build-up faster than non LR areas. Within all LR areas taken together the built up area increased from $15 \%$ to $50 \%$, an increase of 35 percentage points, while in non LR areas the built up area increased from $23 \%$ to $49 \%$, an increase of only 26 percentage points. More telling, however, is that in the project areas already finished by 1980 , the built up area increased from $12 \%$ to $63 \%$, an increase of 51 percentage points. This confirms that in Urawa, even if projects slowed development while they were being carried out, they did result in faster development after the project was completed compared to non LR areas. It is noteworthy, however, that in the area as a whole only about half the buildable land has been built up. The area with the highest rate of build-up, the LR projects already completed by 1982 was still only $63 \%$ built up by 1992, and more surprisingly saw on average only $1 \%$ of the area built up during each of the ten years since 1982. This was, however, faster than in the non LR areas which were only built up an additional 6.4 percentage points over ten years.

It is worth explaining this pattern a little here. While projects are actually under construction, the built up area changes little. Until roads are built, and the new plots designated and redistributed to the landowners there are restrictions on new building. Specifically, landowners need not be compensated for the demolition or moving of any building that is built after the project is legally begun. Towards the end of the project, therefore, a significant amount of land is likely to be built up. This will include any building activity delayed during the course of project construction, as well as land developed during the project, such as parks and other community facilities such as community centres, which are considered built up here as they represent land which has a final urban use. Finally, immediately after project completion, the plots sold to cover the costs of the project are almost always built on, as unlike the original farm land owners, buyers of these plots will have high carrying costs for land and will want to recoup their investment as quickly as possible. After these building activities are completed, however, the rate of build-up slows considerably.

As was the case with Urawa, in Omiya the LR areas had a lower overall level of development in 1968 than the non LR areas as shown in Table 17, confirming that LR projects are more often initiated in less developed areas. Again, in areas where the projects were completed by 1980, levels of development were considerably higher than in non LR areas. These areas also had higher rates of built up land at the beginning of the period, but that was because one of the projects was almost complete in 1968 and had already seen considerable building. However, in the case of Omiya the rate of development in LR areas as a whole was slower than in non LR areas, resulting in an even greater disparity at the end of the period than at the beginning. This is in part a result of the fact that more LR projects have been initiated recently in Omiya in largely agricultural areas, and these new areas saw little build up over the study period. It also seems, however, that the three LR projects which were started in the early 1970s were very slow to complete, and also built up rather slowly. Also in the non LR area 
Table 17

Omiya land development (ha, \%) $)^{\mathrm{a}}$

\begin{tabular}{|c|c|c|c|c|}
\hline & Area & Built up by 1968 & Built up by 1979 & Built up by 1991 \\
\hline Whole case study area & 759.3 & 185.0 & 302.6 & 388.5 \\
\hline $\begin{array}{l}\% \text { of whole } \\
\text { case study area built up }\end{array}$ & & $24.4 \%$ & $39.8 \%$ & $51.2 \%$ \\
\hline LR project area & $\begin{array}{l}255.1(33.6 \% \text { of } \\
\text { case study area) }\end{array}$ & 56.1 & 86.9 & 117.8 \\
\hline $\begin{array}{l}\% \text { of LR } \\
\text { project area built up }\end{array}$ & & $21.9 \%$ & $34.0 \%$ & $46.2 \%$ \\
\hline $\begin{array}{l}\text { LR projects completed } \\
\text { by } 1980\end{array}$ & $\begin{array}{l}50.2(6.6 \% \text { of } \\
\text { case study area })\end{array}$ & 16.6 & 28.9 & 34.0 \\
\hline $\begin{array}{l}\% \text { of project } \\
\text { area built up }\end{array}$ & & $33.1 \%$ & $57.6 \%$ & $67.7 \%$ \\
\hline Non LR area & $\begin{array}{l}504.2(65.4 \% \text { of } \\
\text { case study area) }\end{array}$ & 128.9 & 215.7 & 270.6 \\
\hline $\begin{array}{l}\% \text { of Non } \\
\text { LR project area built up }\end{array}$ & & $25.6 \%$ & $42.7 \%$ & $53.7 \%$ \\
\hline
\end{tabular}

${ }^{\text {a }}$ Source: Calculated from GIS mapping. Totals may not add due to rounding.

there was a very large land reclamation project undertaken by the local government. This area, which runs from the lower right towards the middle of the case study area was swamp in 1968 and was drained and serviced with roads, was largely built up by 1991, including several schools, some large parks and playing fields and a public gymnasium as well as some areas of detached housing. That area contributed to the relatively fast rate of build up seen in non LR areas. Apart from this area, most developments in the case study area have been small and scattered.

Of the three case study areas the one in Ageo included the largest area of existing 1970 DID area, as shown in Table 18, in part because as it is the smallest city it was difficult to get a comparably sized study area without including some of the existing built up area. That is reflected in the higher percentage of the non LR area which was built up in 1968. However, as in Urawa, over the whole period the LR areas as a whole, even including some large projects begun in the mid 1980s were built up faster (by 31.5 percentage points) than the non LR areas (22.6 percentage points). The completed LR projects also showed a higher build-up rate than the non LR area. Ageo also saw the least amount of scattered building in areas outside the LR projects. Although the non LR area also saw considerable build-up, a large part of that is accounted for by the large Mitsui Housing estate which was built in the 1970s just north of the Japan Housing Corporation apartment complex. 
Table 18

Ageo land development (ha, \%) ${ }^{\mathrm{a}}$

\begin{tabular}{lllll}
\hline & Area & Built up by 1968 & Built up by 1979 & Built up by 1991 \\
\hline Whole case study area & $711.7(100 \%)$ & 203.5 & 336.0 & 401.4 \\
$\begin{array}{l}\text { \% of whole } \\
\text { case study area built up }\end{array}$ & & $28.6 \%$ & $47.2 \%$ & $56.4 \%$ \\
\hline $\begin{array}{l}\text { LR project area } \\
\% \text { of LR } \\
\text { project area built up }\end{array}$ & $369.7(51.9 \%)$ & 75.94 & 146.0 & 192.4 \\
\hline $\begin{array}{l}\text { LR projects completed } \\
\text { by 1981 }\end{array}$ & $110.6(15.5 \%$ of & 29.9 & $39.5 \%$ & $52.0 \%$ \\
$\begin{array}{l}\text { \% of project } \\
\text { area built up }\end{array}$ & case study area) & & 54.8 & 67.5 \\
\hline $\begin{array}{l}\text { Non LR area } \\
\% \text { of Non }\end{array}$ & $27.0 \%$ & $49.6 \%$ & $61.1 \%$ \\
\begin{tabular}{l} 
LR project area built up \\
\hline
\end{tabular} & $435.9(61.2 \%)$ & 141.3 & & \\
\hline
\end{tabular}

${ }^{\text {a }}$ Source: Calculated from GIS mapping. Totals may not add due to rounding.

It seems that the effects of LR projects on patterns and rates of urban build-up in a given area depend on a range of factors. Perhaps the most important of these is the speed with which the projects are completed. If they cover much of an urban fringe area, and are rather quickly completed, it seems that development rates within LR areas will be higher than outside as they contribute to the available supply of buildable land. However, if projects take very long times to complete, then it seems that to some degree development is delayed within the projects and can be pushed outside LR areas.

From the examination of the three case study cities it can be concluded that although long project development times appear to result in a period of delayed development, rates of build-up in the long run are faster in LR areas than in non LR areas. However, a highly dispersed pattern of development has continued throughout the case study areas, and all the LR project areas retain large stocks of vacant and agricultural land, in some cases many years after completion.

\subsection{LR and the provision of basic urban infrastructure}

One final aspect of the role of LR projects in the planning and development of these suburban fringe areas is examined here, their role in the provision of basic urban infrastructure such as roads and sewerage. As LR projects are primarily designed to provide these public goods, it is expected that provision within LR areas would generally be good. However, the role of LR in relation to areas outside the projects themselves is not clear. 


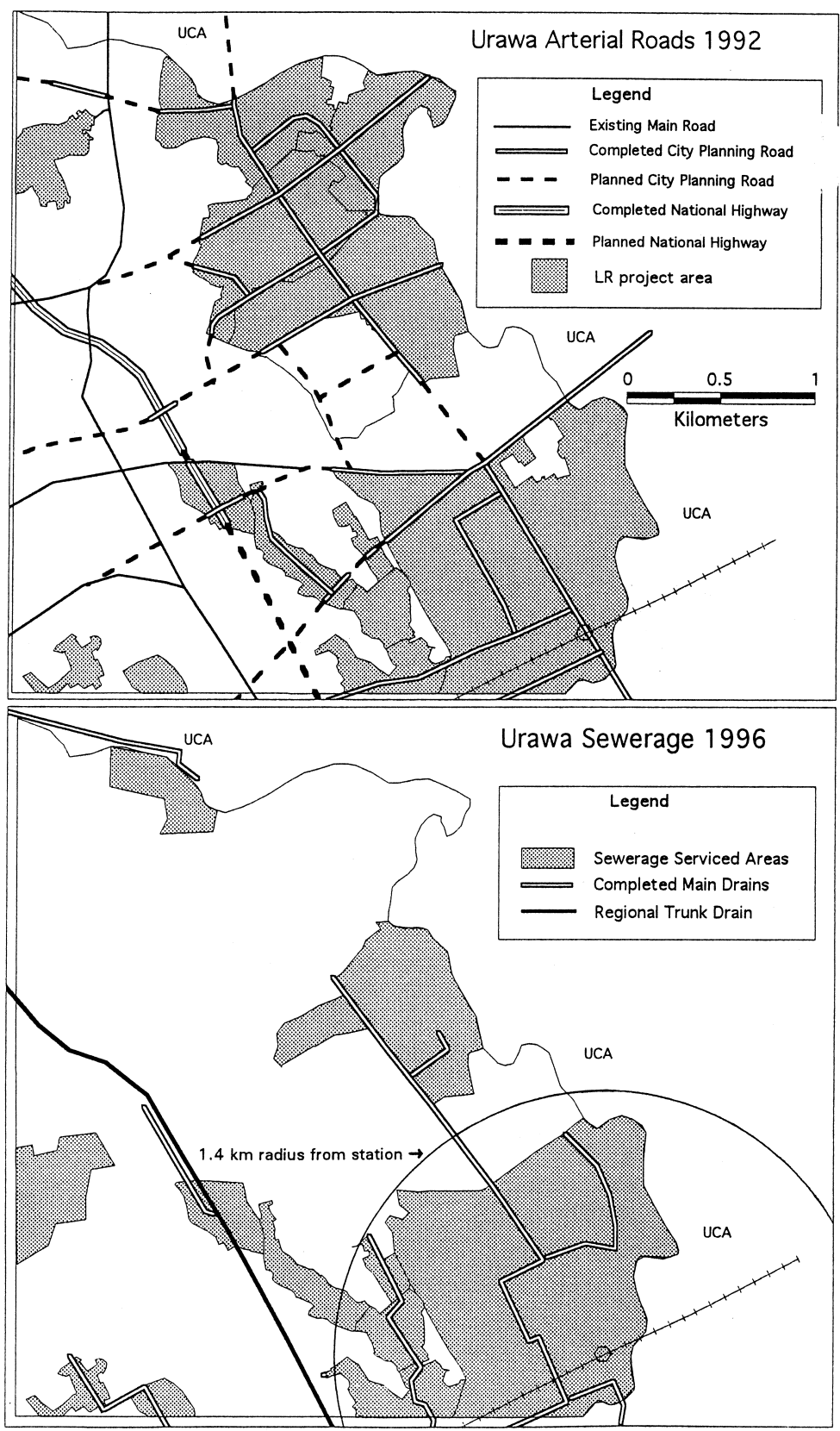

Fig. 22. Urawa arterial roads 1992, and sewerage network 1996. 

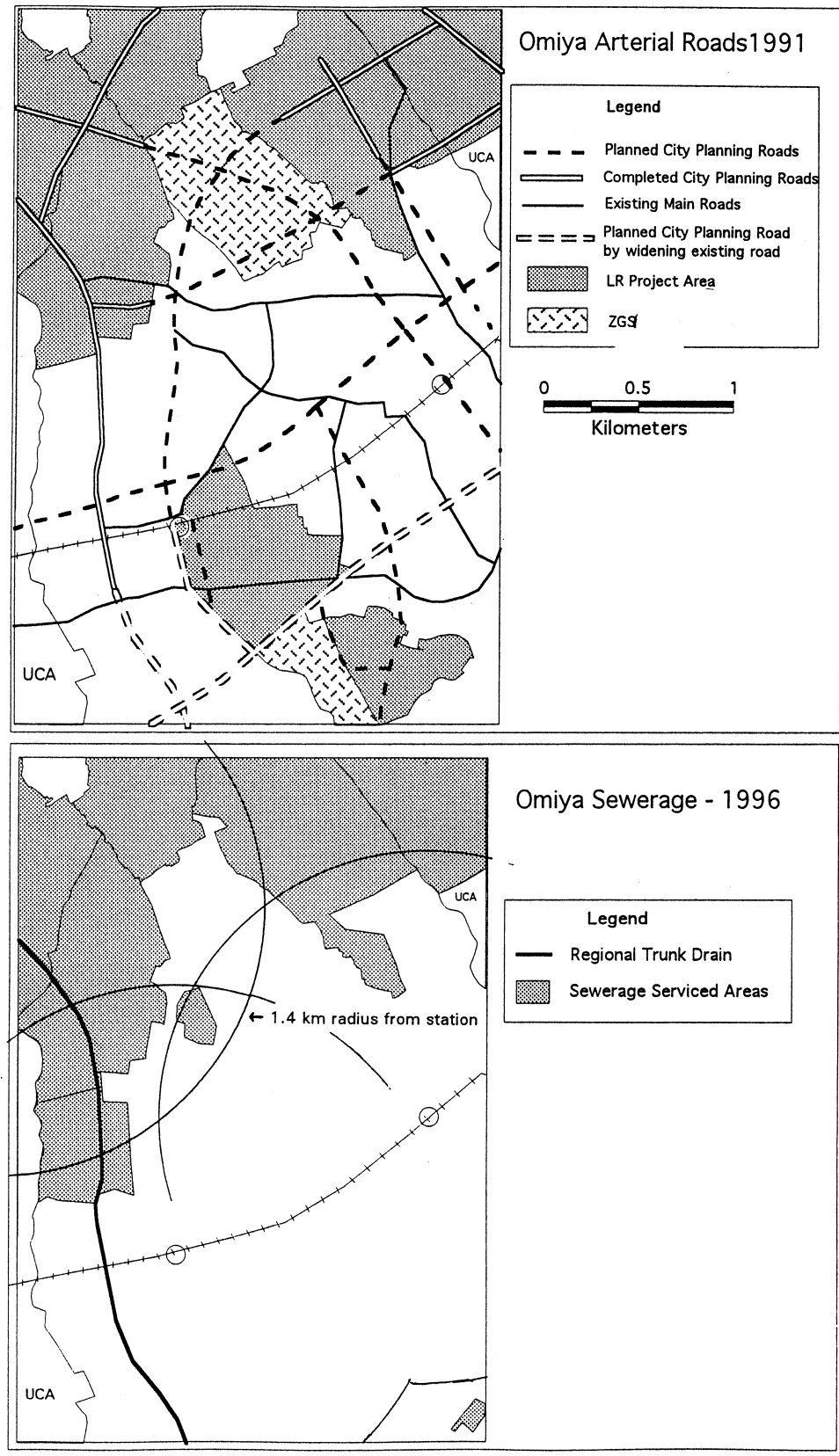

Fig. 23. Omiya arterial roads, 1991 and sewerage network 1996. 


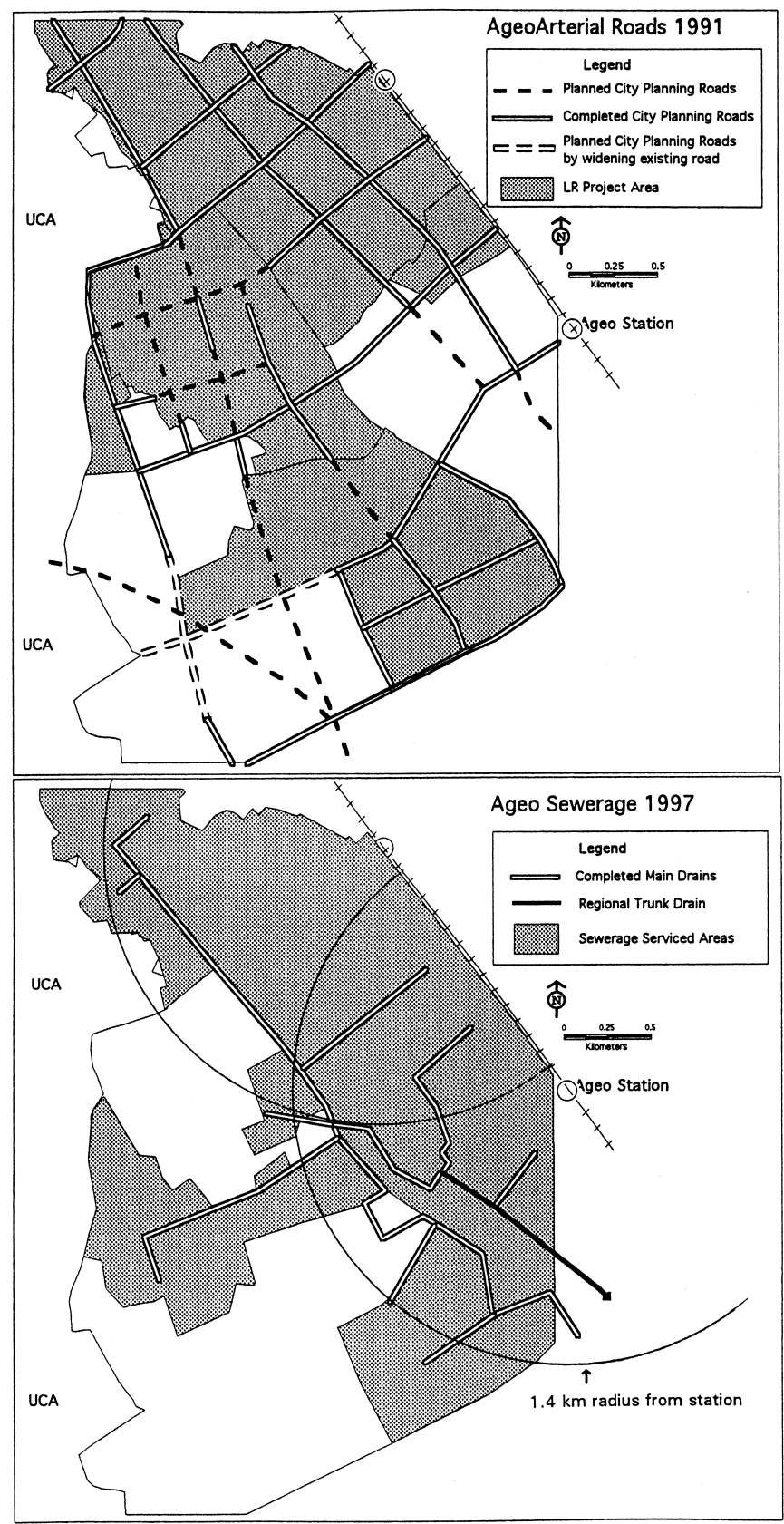

Fig. 24. Ageo arterial roads, 1991 and sewerage network 1997. 
Figs. 22-24 show the arterial road networks of City Planning Roads (Toshi Keikaku Doro) and sewerage serviced areas of the three case study areas. Within the case study areas it is clear that to a large extent such provision has occurred only in the LR project areas. Even though the City Planning Road network was planned in the mid 1960s, in all three cities it remains fragmentary after 30 years, particularly in Urawa and Omiya, where most of the arterial roads remain unbuilt. Sewer provision is also largely confined to LR areas, though not entirely so and even some early LR areas are not connected to main sewers. Non LR areas have seen almost no building of the City Planning Roads. Built up areas have very narrow roads with frequent dead ends while partly built up areas have seen a scatter of building along rural lanes. The few non LR areas which have sewer connections are mostly public housing developments. All other buildings use septic tanks.

There are significant variations between the three cities, however, which should be noted. The arterial road network in Urawa in 1992, shown in Fig. 22 is fragmentary. Apart from the unfinished Omiya-Tokyo Line, a new national highway running from the upper left to lower middle of the case study area, arterial roads have been built only within project areas. Virtually the entire length of this highway was originally planned to run through LR project areas. However, by 1995 only one piece of the highway had been built with LR. That bit, at the very southern end of the completed portion of the highway, is $25 \mathrm{~m}$ wide and 400 $\mathrm{m}$ long and was built over 20 years ago. Most of the road already completed has been built by buying the land along the route instead of by LR. The city is still trying to initiate the two projects including the highway in the most southerly portion of the case study area. The incresed traffic in the area which has resulted from development over the period is still largely being carried by the pre-existing road infrastructure. The resulting traffic chaos is easily imagined. Through roads are highly congested at all times of day, and it is extremely easy to get lost. The logic of the old rural road network has been destroyed, while the big grid of the new system is far from complete. It is not clear how much longer it will take to complete the planned arterial roads.

It seems clear that the strategy pursued by the Urawa LR department of carrying out small scattered LR projects when possible instead of insisting on larger projects which cover the whole area has posed particular problems with regard to the arterial road system. The southern part of the case study area in particular is rather a patchwork of LR and non LR, with many small unconnected bits of completed main road. The bits of arterial road scattered around the case study areas do provide excellent skateboard and bicycle playgrounds for generations of local children, however, as I was able to observe in my tours of the areas.

The lower map in Fig. 22 shows that sewerage provision in the Urawa case study area is virtually entirely restricted to LR areas. However, it is interesting to note that not all the LR areas are serviced with sewerage. This is apparently the result of the fact that when the projects in the north east were built, during the late 1960s and early 1970s, they were too far from main drains and treatment 
plants to be able to connect to them. These areas are now planned for retroactive servicing. Also indicated in the lower part of Fig. 22 is the $1.4 \mathrm{~km}$ radius from Urawa East Station. It shows clearly that the LR projects in the north east are outside an easy walking range of the rail station, as defined in Chapter 2. The five projects in the north of the Urawa case study area are, in fact, all typical cases of 3C type projects, being outside the walkable area, and outside the DID area when they were initiated. The fact that it was not possible to connect them to the sewer system, and the fact that the arterial roads within the projects are not linked to others in the city is a good illustration of the infrastructure problems associated with such locations.

In Omiya, shown in Fig. 23, a rather similar pattern is evident. However, all the LR areas have been serviced with sewerage, except the two new areas in the southern part of the case study area, which were only started in the 1990s and are designated for sewer connection soon. In Omiya also the existing network of main roads was rather better, and several of those have seen improvements outside of LR projects. Also in several areas which were outside both the LR projects and areas where projects are planned shown in Fig. 14 there have been several large scale planned developments, both public housing and by development permit. These have resulted in improved road networks, though generally not as good as in the LR areas. A major problem with the planned arterial road network has resulted from the failure to initiate the LR project in the northern ZGS area. It is unclear how long it will be before the east and west sides of the case study area are joined with through roads. As in Urawa, the two projects in the north east of the case study area were 3C type projects, being more than $1.4 \mathrm{~km}$ from a station as shown in the lower part of Fig. 23, and outside the DID area when they were first started.

In Ageo, shown in Fig. 24, the completion rate of arterial roads within the case study area is highest of the three cities. That appears to have followed fairly directly from the higher proportion of the area covered by completed and in progress LR projects. The same is true of the area serviced by sewers. Almost the whole area of UPA west of the rail line is now serviced, apart from the projects now in process, and the small remaining area, which is also scheduled for LR in the near future.

In the three cities as a whole, a substantial area has sewerage provision, much larger than the LR project area, as shown in Table 13, so it is clearly possible to provide sewerage without LR. However, it is significant that none of the areas where LR projects are planned but not yet started are serviced with sewers. In Urawa for example, which had the highest sewerage provision rate of the three cities, most of the UPA area is serviced, apart from those areas such as the case study area where LR projects are planned. This is certainly logical if projects are expected to start imminently, as that infrastructure is expected to be provided by the projects themselves. Thus the fact that within the case study areas urban infrastructure provision is virtually only found within the LR areas seems to follow directly from the fact that LR projects are planned for the rest of the area. From the point of view of those trying to start new projects, investment in an area 
in advance of a project would be counterproductive, as the city sewer connections provided by LR are one of the main incentives for households to join projects. Also, wherever possible the local government wants to restrain development in LR target areas, and improving roads and sewers would be more likely to promote development. However, in cases such as Urawa and Omiya, where after many years of active trying most of the area is still not LR the result of this strategy has been scattered and patchy roads and main sewer networks.

\subsection{LR projects and urban development at the local scale}

This section summarises the main features of urbanisation in the case study areas, and relates these findings to the main issue addressed by the chapter, how LR projects affect patterns of development at the local scale.

First, it is apparent that development has been spread rather evenly throughout each of the three case study areas. Although LR projects do in the long run build up more quickly than non LR areas, for much of the period rates of build-up were comparable between the two areas. Further, much active agricultural land remains throughout the areas under study, even in the areas which were already partly built up thirty years ago, and within LR project areas.

Second, basic improvements to urban facilities such as roads, sewerage and parks are almost exclusively found in the LR areas. In non LR areas urbanisation has proceeded along existing rural lanes, frequently by building a short dead-end lane from the existing road. This is the typical sprawl style development the 1968 planning system was designed to prevent. Because urban facilities have only been built within the LR areas, larger scale network infrastructure such as the arterial road system remains largely non-functional, especially in Urawa and Omiya.

Third, planners have been unable to prevent continued development within LR promotion areas, even in the routes of arterial roads. In theory local governments can prevent development within LR promotion areas until the project has started. However, it is clear that development has continued, and in many cases houses have been built in the path of arterial roads which were first planned in the 1960s.

Fourth, all the case study areas have seen an extremely slow process of development. While much development has taken place, in each case study area over half the buildable land remains unbuilt. Within the whole of the three case study areas from 1968 to $1991 / 92$ some $28 \%$ of the buildable land was built up, about $1.2 \%$ per year, totalling $52 \%$ by the end of the period. If that rate of buildup continues, it will take another 40 years for the case study areas to be fully built up. In comparative planning terms this is an extremely long time for such relatively small areas of suburban fringe land to be developed. The LR projects themselves also take a long time from first conception to completion.

This is an important point and should be elaborated. The extended period of suburban development certainly has positive aspects. It results in a great diversity of housing styles, because most houses are designed and built individually. This leads in some cases to quite a pleasant and diverse streetscape. The extended period of development will also probably result in a good population age 
structure, with a wide mix of ages. As most people moving to the suburbs are young families and people in Japan tend to move seldom once they have bought a house, in cases where large areas are built at once there is often a tremendous immediate demand for schools and other facilities for young children, which later become empty as the children grow up. An area built up over a period of 50 or more years will be unlikely to experience such problems. Further, the large areas left vacant will allow a range of new developments over time, often at higher densities as the city matures, an urbanisation strategy some consider efficient (see Ewing, 1997).

On the other hand, there will clearly also be negative consequences of this pattern of suburban development. The kind of certainty and stability of residential environment which is highly valued in, for example, the United States (Sies, 1997) is very noticeably absent. The residential areas in the case study areas are undergoing a process of constant, and often radical change. Some change is simply the building of new housing, but often it is more drastic, such as the building of arterial roads and associated commercial uses, often cutting through existing housing areas. It should, however, be noted that there does not appear to be the same kind of concern about this kind of urban change as would certainly arise in most other developed countries although this may be primarily a result of a lack of alternatives, as almost all suburban areas show this pattern of constant change. Waldichuk and Whitney (1997), for example, have recently suggested that urban fringe residents largely welcome further urban development. The question of suburban residential preferences, and available strategies to protect residential environments or property values in Japan deserves further research.

Perhaps most problematic is the poor state of the basic infrastructure. To say that during extended periods the road and sewerage systems have been incomplete would be an understatement, and as the areas have built up congestion has become a serious problem. Because a great deal of development has been allowed to be built in non LR areas without basic services, these areas will require much expensive retrofitting of roads and services, whether or not it is possible to do that with LR projects. It seems almost certain that because of the extended period of build-up and incremental after the fact provision of services, infrastructure provision will ultimately be vastly more expensive than it would have been if the arterial roads and main sewers had simply been built in the early 1970s when land prices were low, and there was little development in the area. Some of these costs are borne directly by individual households which must pay for their own sewage and wastewater disposal (primarily using cesspits). Over the longer term, however, the high costs of retroactive servicing of new urban growth are borne by all taxpayers in the city. Unfortunately it is difficult if not impossible to calculate how great the difference might have been.

The question of the relationship between LR and urban sprawl are addressed in the next chapter. 


\section{CHAPTER 4}

\section{Conclusions}

This chapter draws together the main conclusions of the research. Broadly speaking the chapter moves from the specific conclusions about the relationship between LR and urban sprawl suggested by the case studies, proceeds to a more general summary of some possible implications for our understanding of Land Readjustment as a land development and planning tool, and winds up with a more wide ranging discussion of what the study suggests about Japanese urban planning more generally.

\subsection{Land readjustment and urban sprawl}

The specific question the research set out to address was: what have been the effects of the widespread use of Land Readjustment for land development on the patterns of urban growth of the suburban areas surrounding Tokyo? These effects are reviewed first at the metropolitan scale, and then at the local scale, following the framework of Chapters 2 and 3.

The first hypothesis suggested that for a number of reasons LR projects will be more likely to be started in areas away from existing built up areas and commuter rail stations, and will therefore, contribute to the creation of extensive patterns of urban development, or sprawl. The second hypothesis suggested that by encouraging large scale developments in Urbanisation Control Areas (UCA), YTS LR projects, which are rewarded by the upzoning of the area from UCA to Urbanisation Promotion Area (UPA), will tend to undermine the Senbiki system, and will promote a more extensive, sprawling pattern of urban development. The third hypothesis suggested that if LR projects were not developed comprehensively in urban fringe areas, long project development times and higher land prices within LR areas would tend to delay urbanisation within LR projects and would result in higher rates of development in other nearby, non LR locations. That was deemed likely to encourage haphazard sprawl development in those areas.

However, it seems incorrect, on the evidence for Saitama presented here, to suggest that LR projects necessarily create sprawl at the metropolitan scale. In fact, some $56 \%$ of all projects are in locations that seem either unlikely to promote sprawl or likely to prevent it. A major factor behind this appears to have been the 'Flexible Senbiki' policy described in Chapter 2, which helped local governments aggressively to promote the use of LR projects to develop their UPA areas during the $1980 \mathrm{~s}$. In particular, the ZGS policy of downzoning areas where the local landowners do not agree to start LR projects seems, in terms of the analytic framework of Chapter 2, to have been a powerful force encouraging a better urban form.

It also seems clear, however, that to some degree the first hypothesis was correct. Some 44\% of all projects by area (7300 ha) since 1960 have been in 2C, 3B and $3 \mathrm{C}$ type locations, which according to the framework outlined in Chapter 
2 seem likely to promote an extensive, scattered urban settlement pattern, or sprawl. Some $20 \%$ of the whole project area (2914 ha) was in 3C type locations, the sort of location most likely to promote sprawl. Thus there has been large areas of new development in places where urban development should probably have been prevented, and which would probably have remained less developed without the projects. These projects are important because they will have effects on the location of new residential development for many years to come. This pattern of development seems likely to result in higher long term infrastructure costs, and a greater reliance on private automobiles for daily trips. Patterns of project location also support the reasoning of hypothesis one. As shown in Chapter 2, private projects were consistently in locations more likely to promote sprawl, and as seen in Chapter 3 difficulties in gaining consent for projects close to existing developed areas and stations in Omiya and Urawa resulted in projects being started first in locations farthest from stations and existing development.

The number of projects in sprawl promoting locations was also increased by the factors suggested in hypothesis two. As shown in Chapter 2, YTS projects showed the highest tendency to sprawl locations of any subgroup of projects examined. The YTS policy is, therefore, clearly problematic in its influence on patterns of development at the metropolitan scale. This is particularly of concern as YTS is expected to continue, while the ZGS policy has been wound up. It should be noted that it is clearly not a problem in itself to rezone land from UCA to UPA, and indeed the possibility of such a rezoning is a fundamental premise of the Senbiki system. It even seems reasonable to suggest that the linking of such a rezoning to the implementation of a LR project is precisely how the system should work. It is arguable that many of the problems of haphazard sprawl development seen in the case study areas could have been prevented if such a policy had been in place from the start of Senbiki in 1970. If a fairly small UPA had been designated in the beginning, and any expansion of the UPA had been tied to the start of a Land Readjustment project while at the same time there had been reasonably strong controls over UCA development as suggested by Hanayama (1986, p. 109), it seems likely that a phased and comprehensive development of the new suburban areas might have resulted. That opportunity was missed, however, and rather serious problems of suburban development have been created, as seen in Chapter 3. This is, finally, the most cogent argument in support of the suggestion that the area of UPA was over designated in 1970, that as such large areas were designated UPA at the beginning, the chance for a phased expansion of the UPA linked to development by LR projects or other self-serviced developments was lost.

At the metropolitan scale, continuing to develop new projects in UCA areas far from built up areas (YTS) when there is an urgent need to develop projects in existing partly built up sprawl areas seems likely to have a range of adverse impacts. First, it will clearly increase the amount of development in locations far from existing development and public facilities. Second, such projects draw planning and financial resources away from existing areas such as the case study areas studied here, which would have benefited from a more comprehensive 
development of LR projects, and the faster completion of basic facilities such as the City Planning roads. Third, the initiation of new projects in previously undeveloped areas seems likely to result in further delays in the process of buildout of existing LR areas, as some residential and commercial development is drawn to more distant locations.

Since the failure of the First NCRDP in the 1960s, however, the attempt to control patterns of development at the metropolitan scale appears to have been abandoned by Japanese planners, as is witnessed by the fact that virtually the whole Kanto Plain is now designted either Existing Urban Area, Suburban Development Area or Urban Development Area. More surprising is the fact that the NCRDP do not reflect the strong urban structure shown in the UPA and DID areas. Instead, planners pay much more attention to problems of sprawl at the local level, the basic questions of preventing disorderly unserviced development, of achieving rational road layouts, functional sewer systems, and accessible parks. Thus it appears as no contradiction to allow conversions from UCA to UPA in locations far from existing UPA areas or rail stations (as endorsed by the YTS policy) as long as these new UPA areas are serviced with a minimum of local roads and public facilities as a condition of development. Massive infrastructure deficits focussed attention on the immediate problems of trying to get basic infrastructure in place. Given the heavy costs of remedial measures to improve areas of disorderly sprawl, and the enormous areas that have been so developed in the post-war period, such a concern is understandable. However, in the longer term, and metropolitan scale planning is always primarily directed at the longer term, the cumulative effects of the large land areas developed with land readjustment in locations far from existing built up areas or public transit facilities are likely to be profound.

The effects of LR on urban form at the local level are more complex. It appears that build up in the long run is faster within LR areas, so it was not correct to suppose that higher land prices would substantially delay development within LR projects, as suggested in hypothesis three. However, it does seem that long project development times can result in delayed build up within project areas, and much development occurring outside them. Therefore it seems that, as suggested in hypothesis three, where it has been impossible to develop LR projects in a comprehensive manner, the main problems of sprawl have continued. In this sense it is useful to compare the case of Ageo with that of Omiya and Urawa. For whatever reason, it has been possible to carry out a relatively comprehensive programme of LR in the Ageo case study area. Almost the whole UPA area that was not DID in 1970 is now either LR or other comprehensive development. This has allowed a high level of completion of the arterial roads network, and has meant that most development has been prevented in areas which were not yet LR. This contrasts strongly with the situation in the case study areas of Omiya and Urawa, where LR projects have been scattered throughout the undeveloped part of the UPA, road and sewer infrastructure is fragmentary, and much development has taken place in non LR areas. In both of these areas, it seems likely that local governments face long term difficulties, and enormous costs, to correct these 
problems of haphazard urban growth, whether that is done through LR or otherwise.

Perhaps the most distinctive characteristic of urbanisation in the case study areas is the extreme degree of scatteration, which prevails both in areas developed with LR and those not so developed. Small clusters of buildings stand dispersed rather evenly throughout the areas studied, as do large tracts of undeveloped agricultural land. As scatteration is prevalent both within and outside of LR project areas, it may be that the extreme degree of scatteration seen in Japanese suburban areas is essentially unrelated to LR projects, resulting more from the fragmentation of land ownership and the lack of controls over land subdivision and development described in Chapter 1 . The strong propensity towards scattered plot-by-plot development clearly creates a difficult environment for urban planning, however, and quite possibly has served to increase local government reliance on LR to achieve comprehensive development, as the method can still be used even in areas that have seen some scattered build up. It is tempting to speculate that the sense of urgency about preventing such scattered unserviced development that is common among planners in the West may be tempered in Japan by the fact that LR holds out the possibility of later redevelopment of such sprawl areas, but further evidence would be needed for that to be more than mere speculation.

LR projects clearly can promote leapfrog development patterns. In both Urawa and Omiya, because of difficulties in initiating projects in locations close to existing built up areas, many projects were initiated in areas far from existing development, jumping over large areas of undeveloped farm land. These are typical 3C type developments within the framework of Chapter 2, far from existing rail stations or developed areas. Because LR projects do in the long run result in faster rates of build-up, the result has been that some development has been located in areas farther from existing development, and in generally less accessible locations than would otherwise have been the case. Because in neither Omiya nor Urawa have the arterial roads within these projects been connected to the rest of the network, accessibility is very poor to local rail stations. However, the projects do have good road connections to the nearby Tohoku Expressway shown in Fig. 2, which has an interchange just to the west of each of the Urawa and Omiya case study areas. This seems likely to lead to increased car use. In these two cities, the development of the LR projects in 3C type locations also probably had the effect of promoting more haphazard development in the intervening areas than if the projects had been located adjacent to the existing built up area. In Ageo, on the other hand, because projects were initiated first close to the existing built up area and the rail stations, the problem of leapfrog development of LR projects was avoided.

It seems clear that within LR projects the serious problem of haphazard unserviced growth along existing rural roads is prevented. By reorganising land holdings into regular plots and by providing roads, sewers and public space, LR projects provide the infrastructural framework within which urbanisation can proceed in an orderly and structured manner. This is clearly more efficient and 
less expensive than constructing these basic urban services after fringe areas are already built up. However, basic urban facilities such as roads, sewerage and parks are found almost exclusively in the LR areas. Because LR project areas cover only a small portion of the planned area, and urban facilities have only been built within the LR areas, larger scale network infrastructure such as the arterial road system remains largely non-functional, especially in Urawa and Omiya.

The experience of Omiya and Urawa suggest that it is difficult to develop LR projects in a comprehensive manner, particularly in places where urbanisation pressure is strong. That underlines a serious problem with LR as an urban planning instrument. It is very hard to get projects started, and they are easy to oppose, even in Japan where there has been a long tradition of LR, and many experienced professionals are available. It is quite common to end up with a scattering of LR projects surrounded by a general sea of sprawl. Thus, while it is clear that within LR areas the problems of haphazard sprawl are decisively avoided, it is the fact that LR projects themselves have been rather haphazardly scattered throughout the newly urbanising areas of UPA, as seen in the Omiya and Urawa case study areas, that has been most problematic. This observation is supported by the pattern of the Ageo case study area, where a comprehensive programme of LR has been achieved, and the serious problems seen in Omiya and Urawa have been largely avoided.

One troubling consequence of the scattered development of LR projects in these urban fringe areas is the poor state of the arterial road system. The disconnected bits of arterial road have done little to improve accessibility to existing built up areas or to rail stations. Congestion is heavy on the few through roads, and is likely only to increase with the increasing population of the areas. Until the planned arterial road system is completed, therefore, accessibility can be expected to steadily worsen. The problem is that it is impossible to predict how long it will take to complete the basic grid of arterials, given the limited progress seen during the 24 years of the case study period.

One of the most distinctive features of Japanese urbanisation is the extended periods for Japanese suburban areas to build up. It seems important that all the case study areas have seen an extremely slow process of development. While much development has taken place, in each case study area over half the buildable land remains unbuilt. Within the three case study areas from 1968 to 1991/92 some $28 \%$ of the buildable land was built up, about $1.2 \%$ per year, totalling $52 \%$ by the end of the period. If that rate of build-up continues, it will take another 40 years for the case study areas to be fully built up. In comparative planning terms this is an extremely long time for such relatively small areas of suburban fringe land to be developed. As discussed in Chapter 3, these long development periods seem likely to produce a range of effects, both negative and positive. The uncertainty that this is likely to produce in residential areas is perhaps the greatest contrast with suburban residential areas in other developed countries. In the context of the present study it was not possible to examine the interesting questions surrounding Japanese people's attitudes towards these sorts of 
constantly changing suburban environments. It is well known that in most other developed countries stability in residential areas is highly valued, in order to protect investment values, to protect the local environment, and to protect valued amenities. This attitude is manifested in the widespread phenomenon of activism to preserve valued environmental amenities in residential areas. It would be useful to compare the attitudes of residents in Japanese suburban areas such as those examined in the case study areas towards their local environment with those in other developed countries.

An important consequence of the pattern of suburban growth seen in the case study areas is that because of the highly scattered nature of most suburban development, large areas of suburban land have been left undeveloped. These enormous reserves of undeveloped land on which development can not legally be denied mean that Tokyo's physical and population growth are essentially unstoppable and are to a great extent unplannable under the current planning regime. Thus whatever planning policies are adopted in future, Japanese suburbs seem likely to continue to grow in haphazard and inefficient ways, local governments will continue to spend most of their infrastructure budgets on expensive remedial measures, and residents will continue to suffer from poor public services.

The effects of the widespread use of LR for land development are therefore complex, and difficult to neatly summarise. At the metropolitan scale, it appears that there has been a significant tendency to develop LR projects in locations which will be likely to promote metropolitan sprawl. To some degree the predicted tendency for LR projects to be in locations that increase metropolitan scale sprawl was mitigated by the ZGS policy of using the threat of downzoning of undeveloped areas within the UPA to encourage more LR projects close to existing built up areas, but that policy has been abandoned. That suggests that in future a more pronounced trend towards sprawl promoting projects is likely. The impacts of these developments could be very great over the long run. At the local scale it has been difficult to develop LR projects comprehensively, and so local governments could not prevent continued sprawl within the UPA areas where LR was intended to play the main development role. As a result extensive new areas of scattered, unserviced sprawl development have been created in areas where LR projects were planned but have not been carried out. LR projects thus clearly prevent unserviced sprawl within the project area, but have been inadequate to prevent sprawl at the larger scale of the city or region.

\subsection{Implications for the understanding of land readjustment}

In several aspects the picture of Land Readjustment that emerged from the case studies is not consistent with the interpretation found in the English language literature on LR. First, it seems that very few LR projects are started autonomously by local landowners. In fact, Local Governments invest a great deal of time and energy into organising projects. The scale of personnel resources required to launch LR projects is indeed such that it would be surprising if private 
land owners would be able to start projects themselves, except in exceptional cases. The vast energy required to start LR projects is little discussed in the international literature. However, the heavy commitment of time and energy required to launch projects should be better understood by those countries considering adopting the system. Developing a successful LR programme is not simply a matter of establishing the necessary laws and incentives. An activist local government, with sufficient staff and resources to be able to sustain an active organising programme over many years is clearly required.

The emphasis in the LR literature on LR as based on 'consensus' among landowners is perhaps unfortunate. In English the concept of consensus normally includes some notion of a process of decision making which is designed to arrive at a mutually agreeable outcome. The possibility of the process of decision making affecting the eventual decisions taken is an important part of the concept. The organising of LR projects seen in the case study areas does not fit this idea of consensus. It would be more accurate to describe the process as one in which local government organisers design a project, then work intensively for 5-10 years to organise consent to that project, making use of a wide range of persuasive techniques. While the achievements of the organisers are often impressive, it is incorrect to call this a consensus based process.

It appears that the primary influence of landowners on LR project locations is in the form of a veto. In the Japanese case that has been quite a powerful veto it seems, as in the case study areas only $46 \%$ of the 'problem areas' that escaped downzoning by promising to start a LR project had become LR 11 years later. This veto power is closely related to the difficulties experienced in trying to use LR as a comprehensive development method in suburban areas. It is perhaps not an overstatement to suggest that in other countries where landowners have similarly strong rights and incentives to oppose LR projects, it would be unwise to rely on LR as an important part of a suburban development strategy. However, if other urban programmes were responsible for the key suburban planning measures and development control, then any gains in infrastructure contributed by LR might simply be counted a good thing.

The question of whether or not Japanese-style LR is suitable for developing countries has not been directly examined in this study, but it may be worthwhile to point out some problems suggested by this examination of the practice of LR in Japan. First, due to the complexity of the process, and the typically long times involved in project planning and implementation, LR does not appear to be an easy or quick solution to the serious planning problems of developing country cities. Second, it should certainly not be considered a substitute for an effective planning regime. Rather any positive results from LR will depend on LR being carried out in the context of an effective planning system at both the metropolitan and local scales. Further, the heavy demands of LR on planning resources, in particular the time of skilled personnel seems to be a major shortcoming of the method. Even in Japan the demands of project initiation and management have been a severe constraint on the ability of local government planning departments to carry out needed projects. 
It is worth noting, however, that the fact that it does seem that land owners are more willing to accept LR projects in areas farther from existing development suggests a possible strategy for developing countries. If LR projects are planned and begun far enough in advance of urban development pressure they may be more easily and quickly implemented. For example, the experience of Ageo city does seem to suggest that where large areas of LR projects are started well in advance of significant development pressure, comprehensive development using LR may be more easily achieved than in areas which are already significantly developed before LR projects are implemented on a large scale. Such a use of LR would require a solid long range metropolitan structure plan and co-ordinated infrastructure investment, however, both of which are difficult to achieve in rapidly urbanising developing countries.

\subsection{City planning in Japan}

The study was also revealing more generally of important differences between Japanese suburban development and that in other developed countries. The serious difficulties of achieving basic public goods in new suburban areas appears to have focussed energies at that level and left little time for considerations of larger patterns of growth at the metropolitan scale. It appears that in their use of the term 'urban sprawl' Japanese planners are primarily concerned with local sprawl, not sprawl at the metropolitan scale. Repeated queries about the role of LR in shaping overall patterns of urban development in the larger Kanto region appeared incomprehensible to the planners interviewed. It is of course understandable that LR projects are not seen as a method of planning metropolitan scale growth, as they are fundamentally small scale land development projects. However, as suggested in Chapter 2, it seems highly likely that they do have impacts on larger patterns of growth, and that it might be valuable to understand what those effects are. It appears that the problems of sprawl at the local level are so severe, and memories of the resounding defeat of the first NCRDP are so recent, that planners are reluctant to tackle issues of growth management at the metropolitan scale. However, it must be said that the abandonment of attempts to shape metropolitan scale patterns of growth certainly seems more tenable in a land rich country such as the US than in Japan which shares many of the constraints of space seen in European countries, where the need to attempt to shape metropolitan growth patterns is widely accepted. And even in the US issues of metropolitan growth management appear to be solidly back on the public agenda again. In the Japanese case it seems highly likely that current patterns of urban growth will lead to heavy present and future costs to be paid primarily in reduced quality of life and poorer urban and suburban living environments.

The present study thus supports Hebbert's (1994) conclusion that there would probably be significant social costs of unregulated urbanisation in Japan arising from incompatible neighbours, high travel costs, land prices which are raised by speculative pressures in an unregulated land market, and traditional planning 
arguments that the most cost-effective way of providing urban infrastructure is in compact, physically contiguous developments built comprehensively. From the longer perspective therefore, the creation of vast new areas of unserviced urban development during the period since the passage of the new city planning law of 1968 seems likely to be remembered as one of the great failures of post-war public policy in Japan. An understandable concern of policy makers with ensuring an ever-growing supply of housing was allied with the political debts of the ruling LDP to farm land owners and land developers to encourage a relatively laissezfaire approach to land development regulation. At the same time, LR was explicitly seen as an urban planning method that enabled the state to devolve responsibility for investment in local public goods to the local people who would use them. The state spent little on social overhead capital, instead devoting all available resources to enabling rapid industrial growth. Nagamine has argued that because Japan needed all its economic resources for catch-up industrialisation, the country could not afford city planning and the associated social overhead investment. As he put it "one of the major factors in accounting for the prosperity of the Japanese economy is that her people have opted to tolerate, rightly or wrongly, a meagre resource allocation for their living conditions, thereby leaving the maximum amount of resources for industrial development." Therefore, "Japan has been able to afford only such a living environment as LR could offer. Indeed LR has been the most vital tool for Japan to muddle through, coping with heavy demands for urban land and resource constraints, particularly during the high economic growth period" (Nagamine, 1986, p. 52).

The focus on industrial growth, and the reluctance to impose obligations on developers for fear of slowing economic growth or driving up housing prices was widely seen as a necessary corollary to the pursuit of economic expansion, and higher standards of housing and public goods would have to be financed later, after economic security was achieved. At the same time the deliberate strategy of encouraging the growth of land asset values to create an ever growing capital base for industrial investment and expansion had the effect of fuelling the inflation of land prices. As is well known land prices in Japanese urban areas were far higher than those in other developed country cities well before the speculative trading of the bubble economy drove up land prices after 1985, and have remained so even with their steady decline since the collapse of the bubble in 1992. These high land prices worked primarily to the benefit of a small number of net sellers of land, at the expense of net land purchasers such as new suburban residents and the suburban local governments that have to acquire public space for their growing populations.

Unfortunately the frenzied land trading and speculation of the bubble and the massive overhang of bad debt that its collapse produced effectively wiped out much of the capital base of the Japanese banking system. Japanese banks which boasted the world's largest asset bases during the 1980s found themselves with a negative net worth in the mid 1990s and had to be bailed out with tens of trillions of yen in capital infusions from the Japanese central government in 1998 and 1999. The huge asset base which provided part of the justification for hands-off 
urban development policies has been transformed into a mountain of public debt used to refinance the banking system.

The Japanese urban dweller is thus left with the worst of all worlds. Urban development policies which encouraged the minimum of public spending, and the maximum profitability and asset growth for land owners and land developers as a part of the rapid economic growth formula have saddled suburban residents and governments with huge backlogs of unbuilt infrastructure that will take generations and vast retroactive investment to remedy. Even then, however, standards will almost inevitably be much lower than could have been the case if the public goods had been built in advance of urbanisation either directly by local governments or as an obligation on land developers. While there is no doubt therefore that Japan is a much richer country for its post-war experience of rapid economic growth, the long travel times, incomplete and congested road systems, lack of public services and of public space, cash strapped and expensive local governments and non-existent urban design seems to have greatly undermined the possibility that such wealth will be translated into a higher quality of life for most Japanese urban residents.

The Japanese case is interesting in part because in most other developed countries land development controls of one sort or another have largely prevented such haphazard unserviced suburban development in the post-war period. Because such basic problems have been all but eliminated, it has become fashionable to argue for the scrapping of urban planning systems in favour of a greater freedom for private market forces. The Japanese experience of largely uncontrolled suburban growth, however, appears to support the basic assumption that land development control is necessary to ensure the public interest, as has long been argued by urban planners. Countries experiencing rapid urban growth would benefit from understanding the pitfalls inherent in the Japanese strategy of focussing exclusively on economic growth in the hope of remedying the inevitable urban problems thus created at a later time. Even though it may be very difficult to secure basic minimum standards of public space and urban amenities while rapid economic and urban growth is occurring, it will be more difficult later.

\section{Acknowledgments}

The author gratefully acknowleges the help and advice of Professor Michael Hebbert, Dr. Mark Kleinman, Dr. Minoru Takamizawa, Professor Junichiro Okata, Hitoshi Nakamura, the many officers in local government planning departments and the local landowners and residents in the case study cities, all of whom contributed greatly to the completeion of the Ph.D. thesis of which this paper is a product. The research was supported financially by the Canadian Social Sciences and Humanities Research Council, the Japanese Ministry of Education and the Japanese Society for the Promotion of Science. As always, the author alone is responsible for any errors. 


\section{References}

Alden, J.D., 1986. Some strengths and weaknesses of Japanese urban planning. Town Planning Review 57 (2), 127-134.

Apter, D.E., Sawa, N., 1984. Against the State. Harvard University Press, Cambridge, MA.

Archer, R.W., 1997. The potential of the urban land pooling/readjustment technique to provide land for low-cost housing in developing countries. Human Settlements Development Program HSD Working Paper (No. 61).

Arisue, T., Aoki, E., 1970. The development of railway network in the Tokyo region from the point of view of the metropolitan growth. In: Association of Japanese Geographers, (Ed.), Japanese Cities: A Geographical Approach. Tokyo Association of Japanese Geographers, pp. 191-200.

Barlow Report, 1940. Report of the Royal Commission on the Distribution of the Industrial Population, London, HMSO.

Barret, B., Therivel, R., 1991. Environmental Policy and Impact Assessment in Japan. Routledge, London.

Blowers, A. (Ed.), 1993. Planning for a Sustainable Environment. Earthscan, London.

Blumenfeld, H., 1967. The Modern Metropolis. MIT Press, Boston, MA.

Breheny, M.J. 1992. The contradictions of the compact city: a review. In: Breheny, M.J. (Ed.), Sustainable Development and Urban Form. Pion, London, pp. 138-159.

Breheny, M.J., Rookwood, R. 1993. Planning the sustainable city region. In: Blowers, A. (Ed.), Planning for a Sustainable Environment. Earthscan, London, pp. 150-189.

Broadbent, J., 1998. Environmental Politics in Japan. Cambridge University Press, Cambridge, UK.

Calder, K.E., 1988. Crisis and Compensation: Public Policy and Political Stability in Japan, 1949-1986. Princeton University Press, Princeton.

Capital Region Comprehensive Planning Institute, 1987. Senbiki. Capital Region Comprehensive Planning Institute, Tokyo.

Cervero, R., 1989. America's Suburban Centers: The Land Use-Transportation Link. Unwin Hyman, Boston.

Cherry, G.E., 1988. Cities and Plans. Edward Arnold, London.

City Planning Association, 1995. City Planning Handbook Toshi Keikaku Handobuku. Ministry of Construction Kensetsusho, Tokyo.

Commission of the European Communities CEC, 1990. Green Paper on the urban environment. Commission of the European Communities, Brussels.

Cullingworth, J.B., Nadin, V., 1994. Town and Country Planning in Britain. Routledge, London.

Doebele, W. (Ed.), 1982. Land Readjustment: A Different Approach to Financing Urbanization. Lexington Books, Lexington, Massachusetts.

Doi, K., 1986. Report on the master plan for the Saitama urban area Saitama Ken no Kokoromi 'Saitamaken Toshi Kihon Keikaku' no Sakutei. City Planning Review Toshi Keikaku 139, 71-76.

Echenique, M.H., 1994. 'Let's Build in Lines' Revisited. Environment and Planning B: Planning and Design 21, s95-s105.

Elkin, T., McLaren, D., et al., 1991. Reviving the City: Towards Sustainable Urban Development. Friends of the Earth, London.

Ewing, R., 1997. Is Los Angeles style sprawl desirable? Journal of the American Planning Association 63 (1), 107-126.

Garreau, J., 1991. Edge City: Life on the New Frontier. Doubleday, New York.

Ginsberg, N. 1991. Extended metropolitan regions in Asia: a new spatial paradigm. In: Ginsberg, N., Koppel, B., McGee, T.G. (Eds.), The Extended Metropolis: Settlement Transition in Asia. University of Hawaii Press, Honolulu, pp. 27-46.

Golany, G., Hanaki, K., et al. 1998. In: Japanese Urban Environment. Elsevier Science, Oxford.

Gordon, P., Richardson, H.W., 1990. Gasoline consumption and cities: a reply. Journal of the American Planning Association 55, 342-345.

Gordon, P., Richardson, H.W. 1995. Sustainable Congestion. In: Brotchie, J., Batty, M., Blakely, E., 
Hall, P., Newton, P. (Eds.), Cities in Competition: Productive and Sustainable Cities for the 21st Century Melbourne. Longman, Melbourne, pp. 348-358.

Haley, J.O., Yamamura, K., 1992. Land Issues in Japan: A Policy Failure. Society for Japanese Studies, Seattle, Washington.

Hall, P., 1988. Cities of Tomorrow. Blackwell, Oxford.

Hall, P., Gracey, H., et al., 1973. The Containment of Urban England. Allen and Unwin, London.

Hanayama, Y., 1986. Land Markets and Land Policy in a Metropolitan Area: A Case Study of Tokyo. Oelgeschlager, Gunn Hain, Boston.

Hayashi, K. 1982. Land readjustment in Nagoya. In: Doebele, W. (Ed.), Land Readjustment: A Different Approach to Financing Urbanization. Lexington Books, Lexington, MA, pp. 107-126.

Hebbert, M., 1986. Urban sprawl and urban planning in Japan. Town Planning Review 57 (2), 141158

Hebbert, M. 1989. Rural land use planning in japan. In: Cloke, P.J. (Ed.), Rural Land Use Planning in Developed Nations. Unwin Hyman, London, pp. 130-151.

Hebbert, M. 1994. Sen-biki amidst Desakota: Urban Sprawl and Urban Planning in Japan. In: Philip Shapira, I.M., Edgington, David W. (Eds.), Planning for Cities and Regions in Japan. Liverpool University Press, Liverpool, pp. 70-91.

Hebbert, M., Nakai, N., 1988a. Deregulation of Japanese planning Town Planning Review 59 (4), 383 395 .

Hebbert, M., Nakai, N., 1988b. How Tokyo Grows. STICERD, London.

Higasa, T., 1993. Land readjustment works from the point of view of urban planning system Toshi Keikaku Seido Ron kara mita Tochi Kukaku Seiri Jigyo. City Planning Review Toshi Keikaku 42 (1), 6-9.

Honjo, M., Inoue, T. 1984. Summary and acknowledgements. In: Honjo, M., Inoue, T. (Eds.), Urban Development Policies and Land Management: Japan and Asia. City of Nagoya, Nagoya, pp. 1-14.

Huddle, N., Reich, M., 1975. Island of Dreams. Autumn Press, Tokyo.

Hwang, M.-C. 1986. Republic of Korea urban land development: a case study of Seoul. In: Nagamine, H. (Ed.), Urban Development Policies and Programmes: Focus on Land Management. United Nations Centre for Regional Development, Nagoya, Japan:, pp. 244-314.

Inoue, T. 1984. An overview and future prospects of urban development in Japan focused on the land readjustment method. In: Honjo, H., Inoue, T. (Eds.), Urban Development Policies and Land Management: Japan and Asia. City of Nagoya, Nagoya, pp. 36-53.

Inoue, T., 1985. Applicability of Kukaku Seiri to Urban Development. In: MOC (Ed.), International Seminar on Kukaku Seiri 1985, Ministry of Construction, Tokyo, pp. 7-25.

Ishida, Y., 1986a. A short history of Japanese land readjustment 1870-1980 Nihon ni Okeru Tochi Kukaku Seiri Seidoshi Gaisetsu 1870-1980. Comprehensive Urban Studies No. 28, Tokyo Metropolitan University Center for Urban Studies, Tokyo, pp. 45-88.

Ishida, Y. 1986b. The district planning system and land readjustment. In: Minerbi, L., Nakamura, P., Nitz, K., Yanai, J. (Eds.), Land Readjustment: The Japanese System. Oelgeschlager, Gunn and Hain, Boston, pp. 163-169.

Ishida, Y., 1987. The Last 100 Years of Japanese Urban Planning Nihon Kindai Toshikeikaku no Hyakunen. Jichitai Kenkyusha, Tokyo.

Ishida, Y., Hatano, H., et al., 1987. Influences of Lex Adickes upon Legislations of Japanese Land Readjustment System Nihon Ni Okeru Tochi Kukaku Seiri Seido no Seiritsu to Adickes Ho. Collected Papers of the Japanese City Planning Association Nihon Toshi Keikaku Gakkai Ronbun Shu 22, 121-126.

Japan National Land Agency, 1987. The Fourth Comprehensive National Development Plan. National Land Agency Kokudocho, Tokyo.

Japan Statistics Bureau, 1996. Japan Statistical Yearbook, vol. 45. Management and Coordination Agency Government of Japan. Tokyo.

Johnson, C., 1982. MITI and the Japanese Miracle: The Growth of Industrial Policy, 1925-1975. Standford University Press, Stanford.

Katsumata, W., 1993. Possibilities of environmental improvement considering the conditions of the inhabitants in small-scale residential developments in the Suburb of Tokyo metropolitan area 
Shutoken Kogai Minikaihatsu Jutakuchi ni Okeru KyoJu Jissai to Jukankyo Seibi no Hoko. Nihon Toshi Keikaku Gakkai Ronbun Shu 28, 823-828.

Kishii, T., 1993. On the history of Kukaku Seiri Tochi Kukaku Seiri Jigyo no Hensen ni Kansuru Kosatsu. City Planning Review Toshi Keikaku 42 (1), 10-16.

Kotoh, H., 1991. A study of the urbanisation curve in land readjustment areas Kukaku Seiri Jigyo no Shikaika Kyokusen ni Kansuru Kenkyu. Collected Papers of the Japanese City Planning Association Nihon Toshi Keikaku Gakkai Ronbun Shu 26, 541-546.

Krauss, E., Simcock, B. 1980. Citizens' movements: The growth and impact of environmental protest in Japan. In: Steiner, K., Kraus, E., Flanagan, S. (Eds.), Political Opposition and Local Politics in Japan. Princeton University Press, Princeton, pp. 187-227.

Kurosawa, T., Teraoku, J., et al., 1996. The influence of the national capital region development plan in Saitama prefecture Saitama Ken ni okeru Shutoken Seibi Keikaku no Eikyo ni kansuru Kenkyu. Collected Papers of the Japanese City Planning Association Nihon Toshi Keikaku Gakkai Ronbun Shu 31, 1-6.

Larsson, G., 1993. Land Readjustment: A Modern Approach To Urbanisation. Avebury, Aldershot

Latz, G., 1989. Agricultural Development in Japan. University of Chicago Press, Chicago.

Lynch, K., 1981. A Theory of Good City Form. MIT Press, Cambridge, MA.

MacDougall, T.E. 1980. Political opposition and big city elections in Japan, 1947-1975. In: Steiner, F. Krauss, E., Flanagan, S. (Eds.), Political Opposition and Local Politics in Japan. Princeton University Press, Princeton, pp. 55-94.

March, L., 1967. Homes beyond the fringe. Royal Institute of British Architects Journal, Aug. 334337.

Matsubara, H., 1982. A study of large-scale residential development by private railway enterprises, the case of Tama Den-en Toshi Tokyu Tama Den-en Toshi ni okeru Jutakuchi Keisei. Geographical Review of Japan Chirigaku Hyoron 55 (3), 165-183.

McKean, M., 1981. Environmental Protest and Citizen Politics in Japan. University of California Press, Berkeley.

Minerbi, L., Nakamura, P., et al. (Eds.), 1981. Land Readjustment: The Japanese System. Oelgeschlager, Gunn and Hain, Boston.

Misra, B., 1984. Japanese experience in physical development and land management transferability of development experience. Regional Development Dialogue (Special Issue).

Miyazawa, M. 1982. Land readjustment in Japan. In: Doebele, W. (Ed.), Land Readjustment: A Different Approach to Financing Urbanization. Lexington Books, Lexington, MA, pp. 91-106.

MOC, 1991a. City planning in Japan. Japan Ministry of Construction and Japan International Cooperation Agency, Tokyo.

MOC, 1991b. Executive Manual for Land Readjustment. Tokyo Japan Ministry of Construction and Japan International Engineering Construction Association.

Mori, H., 1998. Land conversion at the urban fringe: a comparative study of Japan. Britain and the Netherlands Urban Studies 35 (9), 1541-1558.

Morimura, M., 1994. Change in the Japanese urban planning priorities and the response of urban planners 1960-90. In: U.O.T. Dept. of Urban Engineering (Ed.), Contemporary Studies in Urban Environmental Management in Japan. Tokyo Kajima Institute Publishing, pp. 8-24

Mumford, L., 1940. The Culture of Cities. Secker and Warburg, London.

Munemoto, J., Hakagawa, H., et al., 1994. A Study on the Urbanisation of Fukuoka City and Land Readjustment Projects. In: Proceedings of International Symposium on City Planning Fukuoka and Kitakyushu, 323-332.

Murahashi, M., 1993. The land readjustment project and the formation of the urban area Tochi Kukaku Seiri Jigyo to Shigaichi Keisei. City Planning Review Toshi Keikaku 42 (1), 40-46.

Nagamine, H., 1986. The land readjustment techniques of Japan. Habitat International 10 (1,2), 51-58.

Nakai, N., 1988. Urbanization promotion and control in metropolitan Japan. Planning Perspectives 3, $197-216$.

Nakano, M., 1993. International contribution through Land Readjustment Works Tochi Kukaku Seiri Jigyo ni yoru Kokusai Koken. City Planning Review Toshi Keikaku 42 (1), 52-61.

Narai, T., Doi, K., et al., 1991. A study on the flexible operation of the city plans of UPA and UCA in 
Saitama prefecture Kuikikubu Seido no Unyo ni okeru 'Saitama Hoshiki' no Jisseki to Koka. Collected Papers of the City Planning Association Nihon Toshi Keikaku Gakkai Ronbun Shu 26, 697-702.

Newman, P., Kenworthy, J., 1989. Cities and Automobile Dependence: A Sourcebook. Aldershot/ Brookfield VT Gower.

Newman, P., Kenworthy, J., 1992. Is there a role for physical planners? Journal of the America Planning Association 58, 353-362.

Nishi, K., 1993. Changes in social and economic situation affecting land readjustment works and current issues Tochi Kukaku Seiri Jigyo o Torimaku Shakaikeizai Josei no Henka to Konnichiteki Kadai. City Planning Review Toshi Keikaku 42 (1), 26-39.

Nishiyama, Y. 1986. Western influence on urban planning administration in Japan: focus on land management. In: Nagamine, H. (Ed.), Urban Development Policies and Programmes, Focus on Land Management. Japan United Nations Centre for Regional Development, Nagoya, Japan, pp. 315355

Nishiyama, Y., 1988. Transfer of Japanese land readjustment technique - achievements and problems. City Planning Review Toshi Keikaku 155, 39-43.

Nishiyama, Y., 1995. Land readjustment projects in a Japanese social context. Paper delivered at 8th International Seminar on Land Readjustment and Urban Development, Nov. 1995.

Noguchi, Y., 1990. Land problem in Japan. Hitotsubashi Journal of Economics 31, 73-86.

Noguchi, Y. 1992. Land problems and policies in Japan structural aspects. In: Haley, J.O., Yamamura, K. (Eds.), Land Issues in Japan: A Policy Failure? Society for Japanese Studies, Seattle, pp. 11-32.

Noguchi, Y. 1994. Land prices and house prices in Japan. In: Noguchi, Y., Poterba, J.M. (Eds.), Housing Markets in the United States and Japan. University of Chicago Press, Chicago and London, pp. 11-28

OECD, 1986. Urban Policies in Japan. Organization for Economic Cooperation and Development, Paris.

Ohta, K., 1994. Transport problems and policies of the Tokyo metropolitan region. In: U.O.T. Dept. of Urban Engineering (Ed.), Contemporary Studies in Urban Environmental Management in Japan. Kajima Institute Publishing, Tokyo, pp. 106-127.

Owens, S.E., 1986. Energy, Planning and Urban Form. Pion, London.

Owens, S.E., 1991. Energy Conscious Planning. Council for the Protection of Rural England, London.

Pressman, N. 1985. Forces for spatial change. In: Brotchie, J., Newton, P., Hall, P., Nijkamp, P. (Eds.), The Future of Urban Form. Croom Helm, London, pp. 349-361.

Reade, E.J., 1987. British Town and Country Planning. Open University Press, Milton Keynes.

Reich, M.R., 1983. Environmental policy and Japanese Society. Part I: Successes and failures. International Journal of Environmental Studies 20, 191-198.

Rickaby, P.A., 1987. Six settlement patterns compared. Environment and Planning B: Planning and Design 14, 193-223.

Saarinen, E., 1943. The City: Its Growth, its Decay, its Future. MIT Press, Boston, MA.

Saitama Prefecture, 1987. Saitama prefecture city planning basic survey Saitama Ken Toshi Keikaku Kisochosa. Urawa, Japan, Saitama Prefecture Housing and Urban Affairs Department, City Planning Office, Saitama Ken Jutaku Toshi Bu Toshi Keikaku Ka.

Saitama Prefecture, 1992. Saitama Prefecture city planning basic survey Saitama Ken Toshi Keikaku Kisochosa. Urawa, Japan, Saitama Prefecture Housing and Urban Affairs Department, City Planning Office, Saitama Ken Jutaku Toshi Bu Toshi Keikaku Ka.

Saitama Prefecture, 1995. Saitama Prefecture land readjustment projects data and maps. Urawa, Japan: Saitama Ken Tochi Kukaku Seiri Jigyo Sokatsuhyo Saitama Prefecture Housing and Urban Affairs Department Urban Facilities Office, Saitama Ken Jutaku Toshi Bu Toshi Seibi Ka.

Saitama Prefecture, 1997. Reference materials: collected reference materials on Senbiki in Saitama Prefecture. Saitama Prefecture Government, Urawa, Japan.

Samuels, R.J., 1983. The Politics of Regional Policy in Japan: Localities Incorporated. Princeton University Press, Princeton, NJ.

Shapira, P., Masser, I., et al. (Eds.), 1994. Planning for Cities and Regions in Japan. Livepool University Press, Liverpool. 
Sherlock, H., 1991. Cities are Good for Us. Paladin, London.

Shimoda, Y., 1993. The land readjustment program for urban development Machizukuri no Dodai toshite no Tochi Kukaku Seiri Jigyo. City Planning Review Toshi Keikaku 42 (1), 36-39.

Sies, M.C., 1997. Paradise retained: an analysis of persistence in planned, exclusive suburbs, 1880-1980. Planning Perspectives 12, 165-191.

Sorensen, A., 1998. Land readjustment, urban planning and urban sprawl in the Tokyo metropolitan area. Ph.D. Thesis. Planning Studies, Geography. University of London, London.

Sorensen, A., 2000. Conflict, consensus or consent: implications of Japanese land readjustment practice for developing countries. Habitat International 24, 51-73.

Steiner, K. 1980. Toward a framework for the study of local opposition. In: Steiner, K., Kraus, E., Flanagan, S. (Eds.), Political Opposition and Local Politics in Japan. Princeton University Press, Princeton, pp. 3-34.

Stone, P.A., 1970. Urban Development in Britain: Standards, Costs and Resources, 1964-2004. Cambridge University Press, Cambridge.

Stone, P.A., 1988. Development and Planning Economy: Environmental and Research Issues. E. and F.N. Spon, London.

Sugiyama, J., Nakagawa, Y., 1988. A feasibility study on Land readjustment projects in case study of Tokyo metropolitan area Tokyo Shuhenkubu ni Okeru Tochi Kukaku Seiri Jigyo Jitsugensei Hyoka Kento ni kansuru Kenkyu. Collected Papers of the Japanese City Planning Association Nihon Toshi Keikaku Gakkai Ronbun Shu 23, 343-348.

Tachibanaki, T. 1992. Higher land prices as a cause of increasing inequality: changes in wealth distribution and socio-economic effects. In: Haley, J.O., Yamamura, K. (Eds.), Land Issues in Japan: A Policy Failure? Society for Japanese Studies, Seattle, pp. 175-194.

Taniguchi, M.D., Nakagawa, et al. 1995. The changing urban hierarchy in Japan: the impact of the high speed rail. In: Brotchie, J., Batty, M., Blakely, E., Hall, P., Newton, P. (Eds.), Cities in Competition: Productive and Sustainable Cities for the 21st Century. Longman, Melbourne, pp. 191-199.

Toronto, 1996. Report of the GTA Task Force, January 1996. Queen's Printer, Toronto.

Ukai, I., 1993. Land readjustment projects and citizen participation Tochi Kukaku Seiri Jigyo to Jumin no Goi Keisei. City Planning Review Toshi Keikaku 42 (1), 30-35.

Unwin, R., 1994. Town Planning in Practice: An Introduction to the Art of Designing Cities and Suburbs. Princeton Architectural Press, New York.

Urawa City Land Readjustment Association, 1992. The Urawa City land readjustment association 20th Anniversary Review Urawa Shi Tochi Kukaku Seiri Kyôkai 20nen no Ayumi. Urawa, Land Readjustment Association of Urawa City 40.

Waldichuk, T., Whitney, H., 1997. 'Inhabitants' attitudes toward agricultural activities and urban development in an urbanizing Konjuka area in the rural-urban fringe of Tokyo. Geographical Review of Japan 70 ((Ser.B) 1), 32-40.

Wegener, M. 1994. Tokyo's land market and its impact on housing and urban life. In: Shapira, P., Masser, I., Edgington, David W. (Eds.), Planning for Cities and Regions in Japan. Liverpool University Press, Liverpool, pp. 92-112.

Witherick, M.E. 1981. Tokyo. In: Pacione, M. (Ed.), Urban Problems and Planning in the Developed World London. Croom Helm, London, pp. 120-156.

Yamaga, S. 1970. Urbanization in the northern suburbs of Tokyo. In: Association of Japanese Geographers (Ed.), Japanese Cities: A Geographical Approach. Association of Japanese Geographers, Tokyo, pp. 73-78.

Yamamura, K. 1992. LDP dominance and high land price in Japan: a study in positive political economy. In: Haley, J.O., Yamamura, K. (Eds.), Land Issues in Japan: A Policy Failure? Society for Japanese Studies, Seattle, pp. 33-76. 